\title{
Characterization of diversity of fungi forming arbuscular endomycorrhizae in selected plant communities
}

\author{
Sidney Luiz Sturmer \\ West Virginia University
}

Follow this and additional works at: https://researchrepository.wvu.edu/etd

\section{Recommended Citation}

Sturmer, Sidney Luiz, "Characterization of diversity of fungi forming arbuscular endomycorrhizae in selected plant communities" (1998). Graduate Theses, Dissertations, and Problem Reports. 3151. https://researchrepository.wvu.edu/etd/3151

This Dissertation is protected by copyright and/or related rights. It has been brought to you by the The Research Repository @ WVU with permission from the rights-holder(s). You are free to use this Dissertation in any way that is permitted by the copyright and related rights legislation that applies to your use. For other uses you must obtain permission from the rights-holder(s) directly, unless additional rights are indicated by a Creative Commons license in the record and/ or on the work itself. This Dissertation has been accepted for inclusion in WVU Graduate Theses, Dissertations, and Problem Reports collection by an authorized administrator of The Research Repository @ WVU. For more information, please contact researchrepository@mail.wvu.edu. 


\title{
CHARACTERIZATION OF DIVERSITY OF FUNGI FORMING ARBUSCULAR ENDOMYCORRHIZAE IN SELECTED PLANT COMMUNITIES
}

\author{
Sidney L. Stürmer \\ Dissertation submitted to the College of Agriculture, Forestry and Consumer \\ Sciences of West Virginia University in partial fulfillment of the \\ requirements for the degree of \\ Doctor in Philosophy \\ in \\ Developmental Biology \\ Joseph Morton, Chair \\ Jonathan Cumming \\ Keith Garbutt \\ Daniel Panaccione \\ Alan Sexstone \\ December 11, 1998 \\ Morgantown, West Virginia
}

Keywords: Arbuscular Mycorrhizal Fungi, Systematics, Taxonomy, Ecology 


\title{
CHARACTERIZATION OF DIVERSITY OF FUNGI FORMING ARBUSCULAR ENDOMYCORRHIZAE IN SELECTED PLANT COMMUNITIES
}

\author{
Sidney L. Stürmer
}

(ABSTRACT)

Knowledge of taxonomic and functional diversity of arbuscular mycorrhizal fungi (Glomales, Zygomycetes) is important in understanding the biology and ecology of such a widespread mycorrhizal symbiosis. More definitive criteria for grouping and ranking taxa were established by reinterpreting morphological characters in selected species of Glomus (Glomaceae) and Acaulospora and Entrophospora (Acaulosporaceae) based on spore ontogenesis. Members of both families shared some patterns, such as discrete stages of spore growth and differentiation in three phases, resulting in the formation of three possible character complexes: a spore wall, flexible inner walls, and a pregermination structure. Families differed in presence or absence of one or more of these complexes. Genera diverged in subcellular organization of these complexes, and species diverged solely with changes in structure and phenotypic differences in the spore wall. With improved criteria for species delimitation, studies then were conducted to assess taxonomic structure in fungal communities. This process required methods to induce or stimulate sporulation by cryptic fungal species, such as successive propagation cycles of trap pot cultures. Trap cultures varied widely in their efficiency to detect non-sporulating species (15-100\%), possibly because of differences in the environment, especially temperature, between the native habitat and greenhouse conditions. Glomus species dominated all baited communities, both in number and amount of sporulation. Infectivity of total fungal propagules was predicted by spore numbers, but infectivity was not correlated with species richness. Inocula of single isolates from three fungal communities were established from trap cultures to examine the proportion of effective and non-effective fungi present in each community. Effectiveness assays using soybean and red clover as hosts revealed that at least one fungal isolate from each community was effective in increasing plant growth and phosphorus foliar content. Fungal isolates that were highly effective or non-effective produced similar responses in both hosts, suggesting that effectiveness has a heritable component. A mix of all members of each fungal community performed as well or better than the most effective isolate in each community. These results suggest that management of indigenous fungal communities may be a preferred strategy to introduction of commercial inocula in natural or managed ecosystems. 


\section{ACKNOWLEDGEMENTS}

I would like to thank my advisor Dr. Joe Morton for all his guidance, support, friendship and criticisms that helped me to be a better researcher and person.

I thank all faculty members of the Plant Pathology and Environmental Microbiology, and Dr. Daniel Panaccione, Dr. Alan Sexstone, Dr. Jonathan Cumming and Dr. Keith Garbutt for their guidance as members of my committee. Also, thanks to Dr. Edwin Townsend for his help and advice on the statistical analyses.

I thank West Virginia University and CNPq-Brazil for financial support.

Also, a warm thank to Dr. Steve Bentivenga who helped me in many ways while at WVU and Marlise Franke-Snyder for being genuine friends.

My thanks to Bill Wheeler and Beth Thomas for helping me with my experiments and to Kris Nichols, Kelly Heldreth and Nancy Arnold for being such nice friends all the time.

I also would like to thanks my former advisor, Dr. Margarida de Mendonça, for all encouragement and support she gave me during my initial steps on my career, and also everybody in the mycorrhizal laboratory in Florianópolis, SC.

My very special thanks to all my Brazilian friends I made here: Edson, Marcia, Alexandre, Karina, Luciana, and Neto who made my days here more pleasant, and especially Mara (mãezona) for her happiness, support and good cooking.

To my family, especially my parents Noir and Maria Stürmer, and my brothers Pablo and Diego Stürmer, for their love and support for all these years and throughout my life (obrigado de coração!!).

And, to Carla Ferreira, my soul-mate and better-half for her immense support on the last steps of this journey, thank you for your wonderful and unconditional love. 


\section{TABLE OF CONTENTS}

\section{Page}

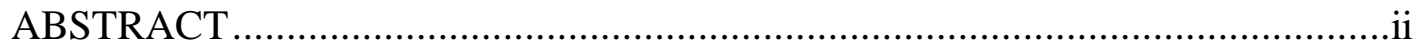

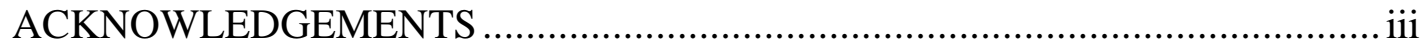

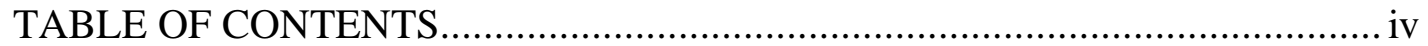

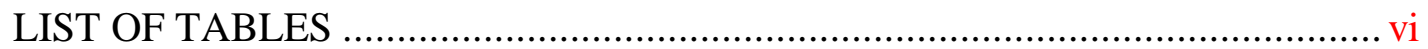

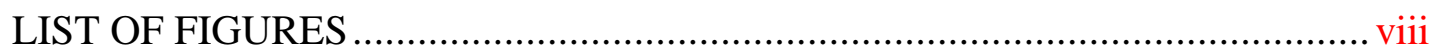

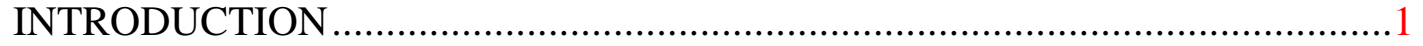

Chapter 1 - Developmental patterns defining morphological characters

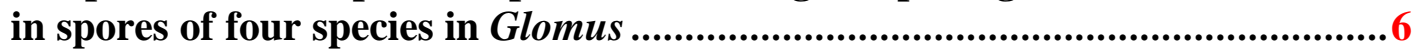

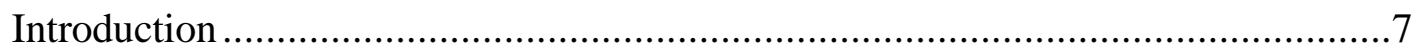

Material and Methods ......................................................................... 7

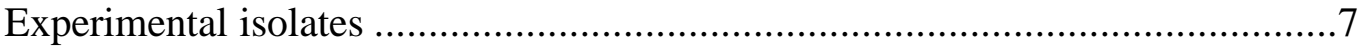

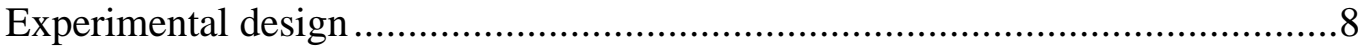

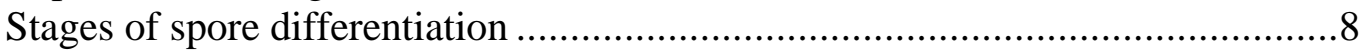

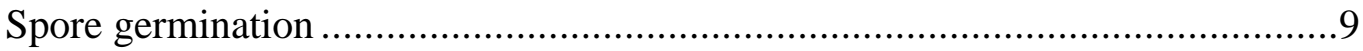

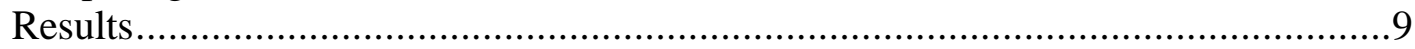

Differentiation of Glomus etunicatum spores ........................................... 9

Differentiation of Glomus clarum spores .................................................. 10

Differentiation of Glomus intraradices spores ............................................. 10

Differentiation of Glomus claroideum spores ..............................................11

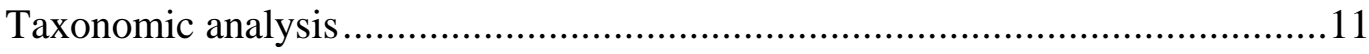

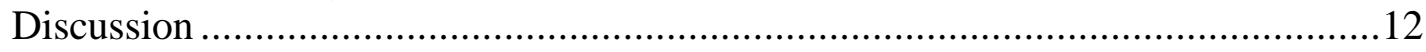

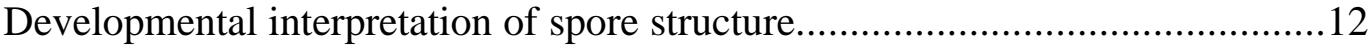

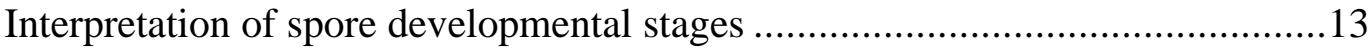

Phylogenetic interpretation of developmental sequences............................... 13

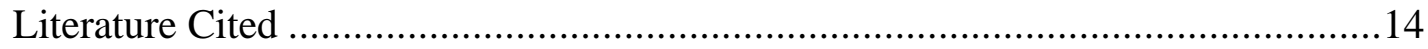

Chapter 2 - Taxonomic reinterpretation of morphological characters in Acaulosporaceae based on developmental patterns in two Acaulospora and one Entrophospora species.......................................................21

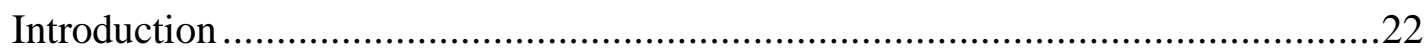

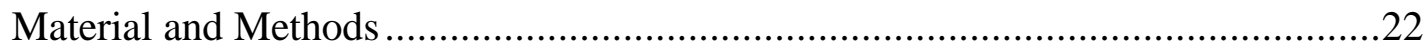

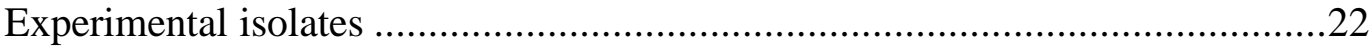

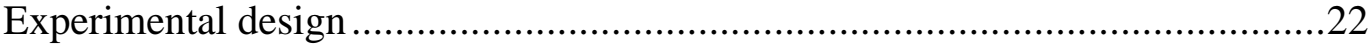

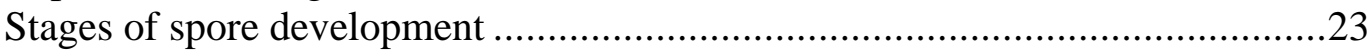

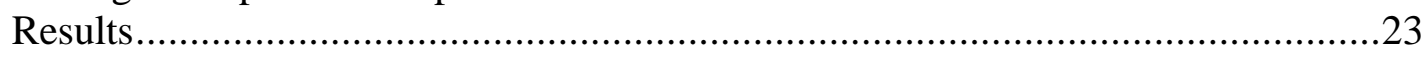

Differentiation of Acaulospora laevis spores ............................................24

Differentiation of Acaulospora spinosa spores............................................24

Differentiation of Entrophospora colombiana spores .................................25

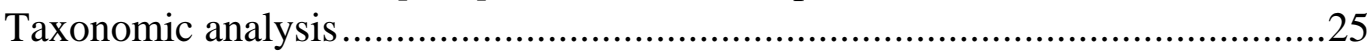

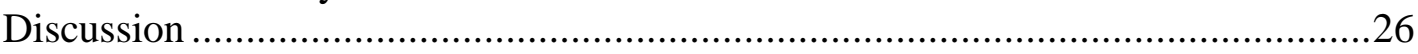

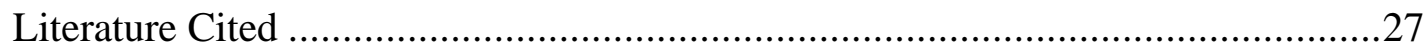


Chapter 3 - Diversity of arbuscular mycorrhizal fungi in selected habitats using trap cultures methodology .....................................................................34

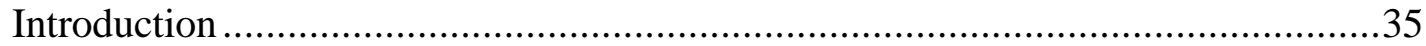

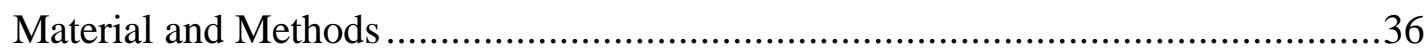

AMF in Five Soils ............................................................................. 36

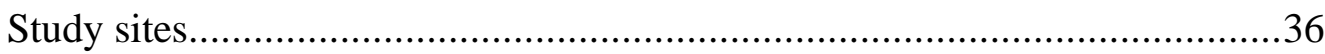

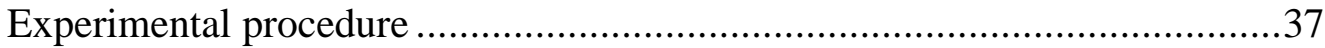

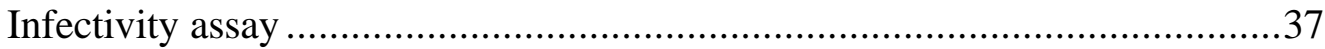

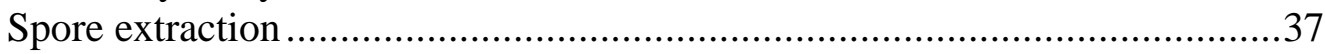

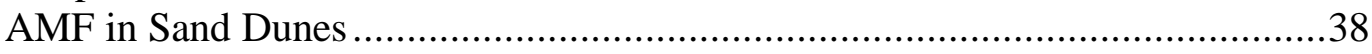

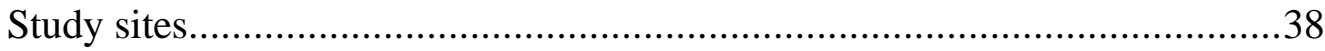

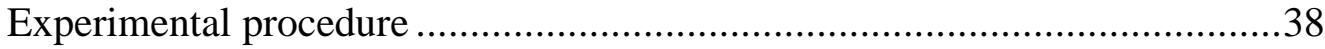

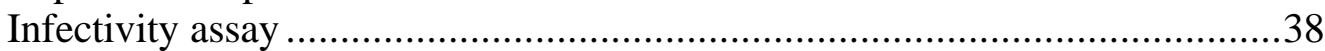

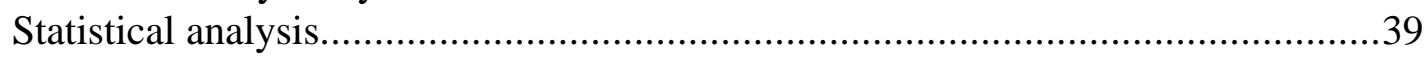

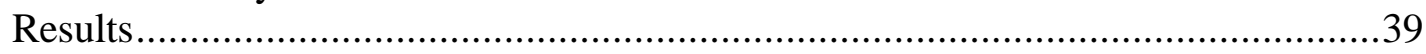

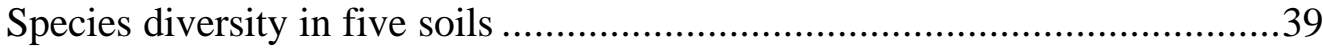

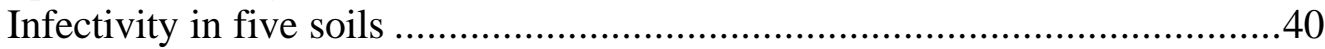

Species diversity in sand dunes .......................................................40

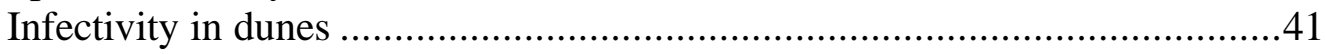

Regression models of fungal diversity in dunes .................................4 41

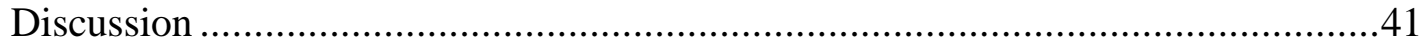

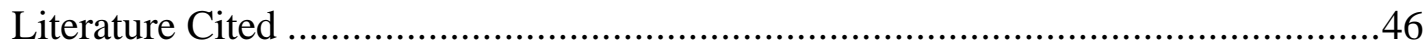

Chapter 4 - Effect of different fungal isolates from the same mycorrhizal community on plant growth and phosphorus uptake in soybean and red clover ........................................................................................................73

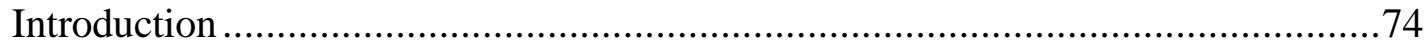

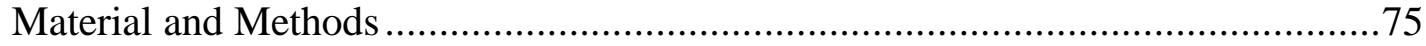

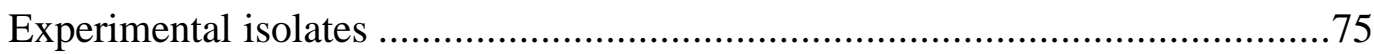

Growth medium ................................................................................ 75

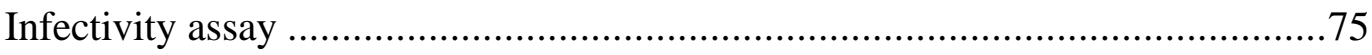

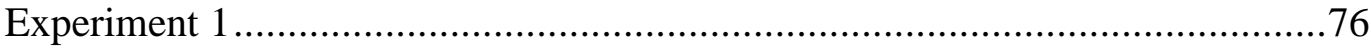

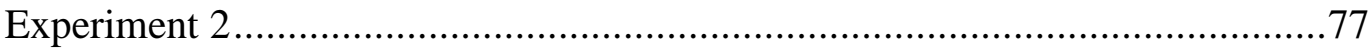

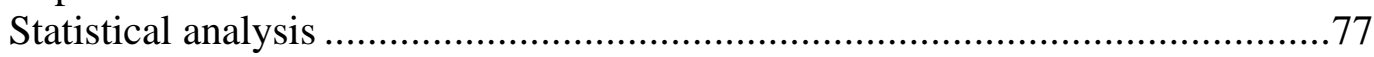

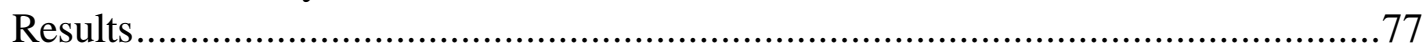

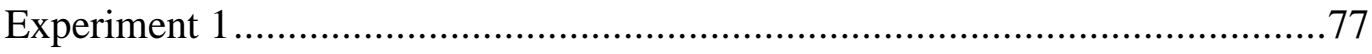

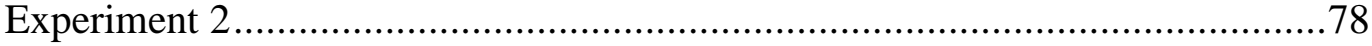

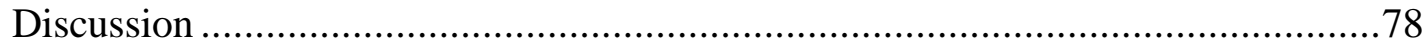

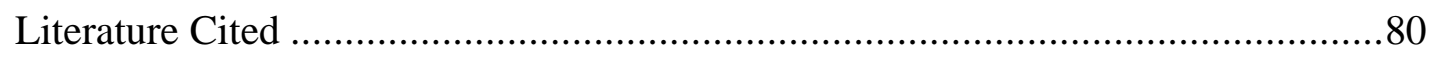

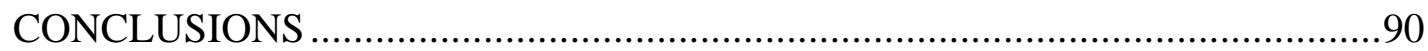

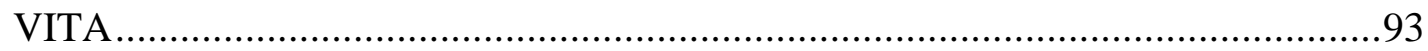




\section{LIST OF TABLES}

\section{Chapter 3}

1 Environmental and soil chemical properties of the 5 selected habitats within the U.S.A.

2 Environmental and soil chemical properties of the sand dunes habitats studied.

3 Spore abundance of AMF species present in a revegetated site in California (CA-R), as detected from field soil and over two cycles of trap cultures.

4 Spore abundance of AMF species present in a prairie site in Kansas (KS), as detected from field soil and over two cycles of trap cultures.

5 Spore abundance of AMF species present in a corn field in Minnesota (MN), as detected from field soil and over two cycles of trap cultures.

6 Spore abundance of AMF species present in a abandoned mine site in West Virginia (WV), as detected from field soil and over two cycles of trap cultures.

7 Similarity coefficients for AMF from five habitats within the U.S.A 55

8 Spore abundance of AMF fungal species present in a sand dune site in Brazil, extracted from field soil and two cycles of trap cultures.

9 Spore abundance of AMF fungal species present in a sand dune site in U.S.A., extracted from field soil and two cycles of trap cultures

10 Spore abundance of AMF fungal species present in a sand dune site in Japan, extracted from field soil and two cycles of trap cultures.

11 Spore abundance of AMF fungal species present in a sand dune site in Netherlands, extracted from field soil and two cycles of trap cultures.

12 Similarity coefficients for AMF from four sand dune habitats.

13 Summary of simple and multiple linear regressions of spore number of the most abundant species in each soil considered singly or in combination to predict levels of colonization in infectivity assays.

14 Summary of stepwise regression of soil and environmental characteristics to predict number of AMF species in all nine habitats studied.

15 Summary of stepwise regression considering two factors together influencing number of AMF species in all nine soils studied.

\section{Chapter 4}

1 Fungal species recovered from bait cultures of rhizosphere soil

from three plant communities. 
2 Mycorrhizal root length of 7 weeks old soybean plants. ................................ 84

3 Mycorrhizal root length of 8 weeks old red clover plants............................. 85 


\section{LIST OF FIGURES}

Introduction $\quad$ Page

1 Classification of arbuscular mycorrhizal fungi in Glomales..............................5

\section{Chapter 1}

1 Murographic representation of the linear sequence in differentiation of layers in the maturing spore wall of Glomus etunicatum, G. clarum, G. intraradices and G. claroideum......................................................... 16

2-7 Glomus etunicatum UT315 - stages in the differentiation of spore wall layers in spores mounted in PVLG + Melzer's reagent $(1: 1, \mathrm{v} / \mathrm{v})$.

8-13 Glomus clarum FL979A - stages in the differentiation of spore wall layers in spores mounted in PVLG + Melzer's reagent $(1: 1, \mathrm{v} / \mathrm{v})$

14-19 Glomus intraradices KS906 - stages in the differentiation of spore wall layers in spores mounted in PVLG + Melzer's reagent $(1: 1, \mathrm{v} / \mathrm{v})$.

20-25 Glomus claroideum BR147A - stages in the differentiation of spore wall layers in spores mounted in PVLG + Melzer's reagent $(1: 1, \mathrm{v} / \mathrm{v})$.

\section{Chapter 2}

1 Murographic representation of the sequence of development of layers in spores of (A) Acaulospora laevis and A. spinosa, and (B)

Entrophospora colombiana.

2-7 Acaulospora laevis AU211 - stages in the differentiation of spore wall and inner walls layers in spores mounted in PVLG + Melzer's reagent $(1: 1, \mathrm{v} / \mathrm{v})$.

8-13 Acaulospora spinosa WV861A - stages in the differentiation of spore wall and inner wall layers in spores mounted in PVLG + Melzer's reagent $(1: 1, \mathrm{v} / \mathrm{v})$.....

14-19 Entrophospora colombiana CL356 - stages in the differentiation of spore wall and inner wall layers in spores mounted in PVLG + Melzer's reagent $(1: 1, \mathrm{v} / \mathrm{v})$.

\section{Chapter 3}

1 Number of AMF species recovered from the field and after successive propagation cycles of trap cultures from 5 habitats in the U.S.A....

2 Species rank-log abundance curves for AMF community recovered in the field and after two cycles of trap cultures for the five habitats in the U.S.A.

3 Arbuscular mycorrhizal colonizaton after 21-day infectivity assays for field soil, first and second trap cycles from 5 habitats in the U.S.A. 
4 Cluster analysis resulting from the average method of soil chemical and environmental properties by the four sand dune habitats studied.

5 Number of AMF species recovered from the field and after successive cycles of trap cultures from sand dunes habitats in four countries.

6 Species rank-log abundance curves for AMF community recovered in the field and after two cycles of trap cultures for all sand dunes habitats.

$7 \quad$ Mycorrhizal colonization after 21-day infectivity assays for field soil, first and second trap cycles from four sand dunes habitats.

8 The relationship between the number of AMF species and the percentage of colonization of 21-day infectivity assays within the same propagation cycle for sand dune habitats studied $\left(\mathrm{r}^{2}<0.01, \mathrm{P}=0.93\right)$.

9 The relationship between the percentage colonization of 21-day infectivity assays and number of spores detected within the same propagation cycle for sand dunes habitats studied $\left(\mathrm{r}^{2}<0.52, \mathrm{P}<0.01\right)$

\section{Chapter 4}

1 Shoot dry weight of soybean plants inoculated with AMF isolates from three different communities. 86

2 Phosphorus content of soybean shoots inoculated with AMF isolates from three different communities.

3 Shoot dry weight of red clover plants inoculated with AMF isolates alone or in combination.

4 Phosphorus content of red clover shoots inoculated with AMF isolates alone or in combination. 


\section{INTRODUCTION}

Mycorrhizae are global associations between roots of terrestrial plants and cosmopolitan soil-borne fungi (Smith and Read, 1997). Among seven different types of mycorrhizal associations, the one formed by arbuscular mycorrhizal fungi in the order Glomales, Zygomycetes (Fig. 1) is the most common and widespread in nature (Brundrett, 1991).

Arbuscular mycorrhizal fungi (AMF) are hypothesized to have played a crucial role in the evolution of land plants (Pirozynski and Malloch, 1975), as evidenced by mycorrhiza-like fossils in tissues of Rynia and Asteroxylon from the Devonian (Pirozynski, 1981). Structures discovered in root fossils from the Triassic also resemble vesicles and intraradical spores of extant AMF (Stubblefield et al., 1987), and arbuscules-like structure were observed in plant fossils dating from the Devonian (Taylor et al., 1995). Using the small-subunit rRNA as a molecular clock, the origin of AM-like fungi has been estimated at 353-462 Myr ago, coincident with emergence of land plants (Simon et al., 1993). Morton (1990) hypothesized that the arbuscular mycorrhizal association coevolved with plants since that time, explaining the widespread presence of AMF in most angiosperms and pteridophytes. AMF are absent in roots of genera of some plant families (Trappe and Luoma, 1992; Peat and Fitter, 1993), a pattern suggestive of an association that was shared by all ancestral plants groups and then lost sporadically by some taxa in more recent times (Trappe, 1987). The broad distribution range of AMF in tropical and temperate forests, deserts, sand dunes, grasslands and agroecosystems (Brundrett, 1991; Hayman, 1982) appears to be a consequence of the extended time scale for dispersal and general lack of host specificity (Morton and Bentivenga, 1994).

Organisms of AMF have a bimodal pattern of differentiation (Morton, 1990). The vegetative thallus consists of arbuscules, intraradical vesicles (shared only by species in the suborder Glomineae), extraradical auxiliary cells (shared only by species in the suborder Gigasporineae), and intraradical and extraradical hyphae (Smith and Read, 1997; Morton and Benny, 1990). Arbuscules are finely branched structures in close contact with the cell plasma membrane, functioning in exchange of nutrients between host and fungal cells (Smith and Read, 1997). Hyphae are important in nutrient acquisition and as propagules to initiate new root colonization (Graham et al., 1982; Friese and Allen, 1991). Vesicles are globose structures arising from swelling of the hyphae and filled with glycogen granules and lipids and are considered to be storage structures (Bonfante-Fasolo, 1984; Brundrett, 1991). AMF reproduce asexually by means of spores formed in the soil or sometimes within roots (Morton, 1990). Spores function in dissemination and short-term survival of the organism and they also contain most of the morphological diversity for classification of species and higher taxa (Morton, 1988; Morton, 1990).

Types and organization of subcellular structures of asexual spores have been the basis for taxonomy of glomalean fungi. Since the first Linnean classification by Gerdemann and Trappe (1974), progress involved standardization of definitions of discrete subcellular structures (e.g., types of "spore walls") in a wide range of taxa (Morton, 1988; Walker, 1983) followed by ontogenetic studies to provide more dynamic interpretations of characters and their states and to define their levels of taxonomic resolution (Morton and Bentivenga, 1994).

The focus on developmental processes is a well-established means to define characters based on their origin, transformational states during differentiation and sequence in which they are formed (Gould, 1977). Comparative developmental studies in different taxa also provide 
the basis to distinguish between phylogenetically informative homologous traits versus noninformative analogous traits (Patterson, 1982). Franke and Morton (1994) were the first to carry out rigorous comparative ontogenetic analysis between isolates of Scutellospora pellucida and $S$. heterogama and determine origin and individuality of subcellular spore characters. Their results were extended to species of the two genera in the family Gigasporaceae, Scutellospora (Morton, 1995) and Gigaspora (Bentivenga and Morton, 1995). From these ontogenetic studies, a developmental model was proposed (Morton et al., 1995), which identified specific character complexes resolving species and higher taxa. However, further testing of the universality of this model is required by incorporating data from other families of Glomales, Glomaceae and Acaulosporaceae.

The definition of grouping and ranking criteria among morphological characters is important in assessing taxonomic structure of AMF communities present in almost all plant communities worldwide. AMF are found in all habitats, and are absent only in highly disturbed, eroded, or fumigated soils (Brundrett, 1991; Smith and Read, 1997). Species richness even in soils limiting diversity of plant communities can be high, with 6-8 species coexisting in the same root system in many different habitats (Abbott and Robson, 1991; Brundrett, 1991; Morton et al., 1995). Johnson et al. (1991), examining AMF communities resulting from old field succession, found 25 species of AMF in 15 sites and Bever et al. (1996) found 23 species in $75 \mathrm{~m}^{2}$ area of an old-field community near Durham, North Carolina. At a regional level, Koske (1987) detected 23 AMF species associate with dune plants along the Atlantic coast, with an average species richness of 4.9 and richness increasing along an increasing temperature gradient southward.

Measurement of AMF species richness and abundance in natural habitats has been limited by methodology. Most surveys of AMF in the field are based on samples of fieldcollected spores, which often are present in such low numbers or so parasitized that accurate identification is difficult. These data, at best, are informative in assessing species distribution and dispersal patterns. They do not provide an accurate measure of local fungal community structure, because nonsporulating species may be present and they are not detected in samples. Trap culture methodologies of field soil samples are only beginning to be used to induce sporulation by these cryptic species, and results thus far (Bever et al., 1996; Stutz and Morton, 1996) suggest that greater than $50 \%$ of the fungi present in a root system are not detected by direct field sampling protocols.

Once taxonomic structure of a fungal community is determined, there remains a question as to the functional contribution of each member to the mycorrhizal symbiosis in a host plant. AMF can markedly influence plant growth and yield by enhancing uptake of mineral nutrients, particularly phosphorus, in nutrient-poor soils (Azcon-Aguilar et al., 1982; Smith and Read, 1997). Shoot biomass and phosphorus uptake have been the main traits analyzed when investigating mycorrhizal benefits to plants.

Most studies conducted to date have interpreted results on the basis of plant hosts of interest and any fungal isolate that can be obtained, regardless of its origin or properties. For an understanding of community dynamics, all of the fungi in each community should be isolated and studied individually and together. Procedures involve growing the fungi on plant hosts in pot culture, since these fungal symbionts are obligate biotrophs (Morton et al., 1995). 
My research seeks to accomplish the following objectives to integrate form and function: (i) reinterpret subcellular morphological characters in spores of species in Glomus (Glomaceae) and Acaulospora and Entrophospora (Acaulosporaceae) by assessing origin and boundary conditions during ontogenesis (Chapters 1 and 2); (ii) characterize taxonomic structure of AMF communities in nine habitats by isolating and identifying AMF species induced to sporulate as a result of successive propagation cycles of trap pot cultures (Chapter 3); and, (iii) assess functional diversity of AMF isolated from three different communities by measuring relative mycorrhizal effectiveness on two mycotrophic assay hosts (Chapter 4).

\section{LITERATURE CITED}

Abbott, L.K., and A.D. Robson. 1991. Factors influencing the occurrence of vesiculararbuscular mycorrhizas. Agriculture, Ecosystem and Environment 35:121-150.

Azcon-Aguilar, C., J.M. Barea, R. Azcon, and J. Olivares. 1982. Effectiveness of Rhizobium and VA mycorrhiza in the introduction of Hedysarum coronarium in a new habitat. Agriculture, Ecosystem and Environment, 7:199-206.

Bentivenga, S. P., and J. B. Morton. 1995. A monograph of the genus Gigaspora incorporating developmental patterns of morphological characters. Mycologia 87:720732.

Bever, J.D., J. Morton, J. Antonovics, and P.A. Schultz. 1996. Host-dependent sporulation and species diversity of arbuscular mycorrhizal fungi in a mown grassland. Journal of Ecology 84:71-82.

Bonfante-Fasolo, P. 1984. Anatomy and morphology of VA mycorrhizae. Pp. 5-33. In: VA Mycorrhiza. C.Ll. Powell and D.J. Bagyaraj (Eds.). CRC Press, Boca Raton, Florida.

Brundrett, M.C. 1991. Mycorrhizas in natural ecosystems. Advances in Ecological Research 21:171-213.

Franke, M., and J. Morton. 1994. Ontogenetic comparisons of arbuscular mycorrhizal fungi Scutellospora heterogama and Scutellospora pellucida: revision of taxonomic character concepts, species descriptions, and phylogenetic hypotheses. Canadian Journal of Botany 72:122-134.

Friese, C.F., and M.F. Allen. 1991. The spread of VA mycorrhizal fungal hyphae in the soil: inoculum types and external hyphae architecture. Mycological Research 92:317-321.

Gerdemann, J.W., and J.M. Trappe. 1974. Endogonaceae in the Pacific Northwest. Mycologia Memoir 5:1-76.

Gould, S.J. 1977. Ontogeny and Phylogeny. Harvard University Press, Massachusetts. 501 pp.

Graham, J.H., R.G. Linderman, and J.A. Menge. 1982. Development of external hyphae by different isolates of mycorrhizal Glomus spp. in relation to root colonization and growth of troyer citrange. New Phytologist 91:183-189.

Hayman, D.S. 1982. Influence of soils and fertility on activity and survival of vesiculararbuscular mycorrhizal fungi. Phytopathology 72:1119-1125.

Johnson, N.C., D.R. Zak, D. Tilman, and F.L. Pfleger. 1991. Dynamics of vesiculararbuscular mycorrhizae during old field succession. Oecologia 86:349-358.

Koske, R.E. 1987. Distribution of VA mycorrhizal fungi along a latitudinal temperature gradient. Mycologia 79:55-68.

Morton, J.B. 1988. Taxonomy of VA mycorrhizal fungi: classification, nomenclature, and identification. Mycotaxon 32:267-324. 
Morton, J. B. 1990. Evolutionary relationships among arbuscular mycorrhizal fungi in the Endogonaceae. Mycologia 82:192-207.

Morton, J.B. 1995. Taxonomic and phylogenetic divergence among five Scutellospora species based on comparative developmental sequence. Mycologia 87:127-137.

Morton, J.B., and G. L. Benny. 1990. Revised classification of arbuscular mycorrhizal fungi (Zygomycetes): a new order, Glomales, two new suborders, Glomineae and Gigasporineae, and two new families, Acaulosporaceae and Gigasporaceae, with an emendation of Glomaceae. Mycotaxon 37:471-491.

Morton, J.B., and S.P. Bentivenga. 1994. Levels of diversity in endomycorrhizal fungi (Glomales, Zygomycetes) and their role in defining taxonomic and non-taxonomic groups. Plant and Soil 159:47-59.

Morton, J.B., S. P. Bentivenga, and J. D. Bever. 1995. Discovery, measurement, and interpretation of diversity in symbiotic endomycorrhizal fungi (Glomales, Zygomycetes). Canadian Journal of Botany 73(suppl. 1):S25-S32.

Patterson, C. 1982. Morphological characters and homology. pp. 21-74. In: Problems of Phylogenetic reconstruction. Eds., K. A. Joysey and A. E. Friday. Academic Press, London.

Peat, H.J., and A.H. Fitter. 1993. The distribution of arbuscular mycorrhizas in the British flora. New Phytologist 125:845-854.

Pirozynski, K.A. 1981. Interactions between fungi and plants through the ages. Canadian Journal of Botany 59:1824-1827.

Pirozynski, K.A., and D.W. Malloch. 1975. The origin of land plants: a matter of mycotrophism. BioSystems 6:153-164.

Simon, L., J. Bousquet, R. C. Lévesque, and M. Lalonde. 1993. Origin and diversification of endomycorrhizal fungi and coincidence with vascular land plants. Nature 363:67-69.

Smith, S.E., and D.J. Read. 1997. Mycorrhizal Symbiosis. Academic Press, London. 605 pp.

Stubblefield, S.P., T.N. Taylor, and J.M. Trappe. 1987. Fossil mycorrhizae: a case for symbiosis. Science 237:59-60.

Stutz, J.C., and J.B. Morton. 1996. Successive pot cultures reveal high species richness of arbuscular endomycorrhizal fungi in arid ecosystems. Canadian Journal of Botany 74:1883-1889.

Taylor, T.N., W. Remy, H. Hass, and H. Kerp. 1995. Fossil arbuscular mycorrhizae from the Early Devonian. Mycologia 87:560-573.

Trappe, J.M. 1987. Phylogenetic and ecological aspects of mycotrophy in the angiosperms from an evolutionary standpoint. Pp. 5-25. In: Ecophysiology of VA Mycorrhizal Plants. G. Safir (Ed.) CRC Press, Boca Raton, Florida.

Trappe, J.M., and D.L. Luoma. 1992. The ties that bind: fungi in ecosystems. Pp. 17-27. In: The Fungal Community - Its Organization and Role in the Ecosystem. G.C. Carroll and D.T. Wicklow (Eds.) Marcel Dekker, Inc., New York.

Walker, C. 1983. Taxonomic concepts in the Endogonaceae: spore wall characteristics in species descriptions. Mycotaxon 18:443-455. 


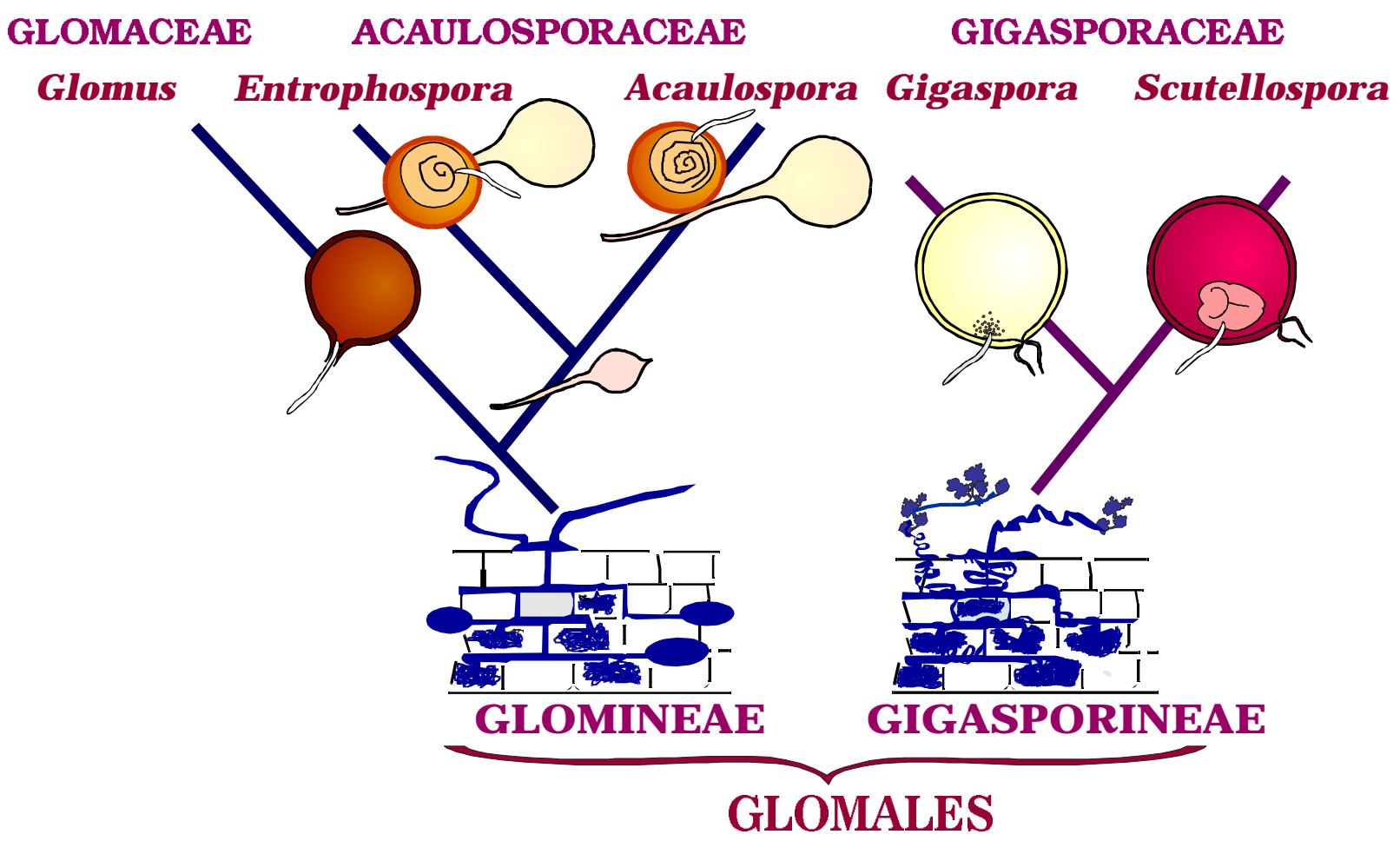

Fig. 1 Classification of arbuscular mycorrhizal fungi in Glomales 


\section{CHAPTER ONE}

\section{DEVELOPMENTAL PATTERNS DEFINING MORPHOLOGICAL CHARACTERS IN SPORES OF FOUR SPECIES IN GLOMUS}

(Reprinted with permission from Mycologia, vol. 89, no. 1, copyright 1997, The New York Botanical Garden.) 


\section{INTRODUCTION}

Among arbuscular endomycorrhizal fungi in the order Glomales, $56 \%$ of the described species are in the genus Glomus (Morton and Benny, 1990), including species formerly in the genus Sclerocystis (Almeida and Schenck, 1990). Nucleotide sequence comparisons (Simon et al., 1993; Simon, 1996) suggest considerable genetic divergence within Glomus, whereas morphological divergence appears to be much smaller (Morton, 1990). The disparity may reside in interpretations of morphological characters based only on arbitrary differences in appearance rather than on empirical data.

Species in Glomus and other genera of Glomales are separated by morphological characters residing mostly in a variety of subcellular structures in spores that have been variously defined as "layers" (Berch, 1987), "walls" (Walker, 1983) or "zones" (Maia et al., 1993). Simplicity in design of these structures in Glomus confines the range of potential phenotypic variation and thus increases the difficulty in determining whether similarities are putative homologs (arising from a common ancestor) or analogs (arising from different ancestors) (Morton, 1990). Ontogenetic comparisons provide a means to assess positional and temporal relationships among subcellular structures and thereby delimit character origins and transformational states important in defining homologies (Patterson, 1982). Studies to date have focused only on one family in Glomales, Gigasporaceae (Bentivenga and Morton, 1995; Franke and Morton, 1994; Morton, 1995).

Most ontogenetic studies of species in the family Glomaceae (Giovannetti et al., 1991; Meier and Charvat, 1992; Wu and Sylvia, 1993) have focused on the mode of spore formation rather than patterns of differentiation of subcellular spore structures important in resolving species. Morton (1996) first detailed spore differentiation of Glomus caledonium (Nicol. \& Gerd.) Trappe \& Gerd. from a reference culture and reinterpreted subcellular structures developmentally.

In this study, I compare spore differentiation sequences of four additional species in Glomus to determine shared and divergent patterns within the genus and with taxa in the family Gigasporaceae. These data are incorporated into a developmental model accommodating all taxa in Glomales (Morton et al., 1995). The four Glomus species also are redescribed based on developmental reinterpretation of taxonomically relevant characters.

\section{MATERIAL AND METHODS}

\section{Experimental isolates}

All isolates were obtained from accessions in the International Culture Collection of Arbuscular and Vesicular-arbuscular Mycorrhizal Fungi (INVAM) at West Virginia University. Accessions of G. etunicatum included BR218 (from S. Stürmer, Santa Catarina, Brazil), CL519 (from E. Sieverding, Valle, Colombia), FL670 (from A. E. Dudeck, Florida, U.S.A.), KS884 (from B. D. Hetrick, Kansas, U.S.A.), PA137 (from D. Douds, Pennsylvania, U.S.A.), UT135 (from T. Wood, Native Plants, Inc., Salt Lake City, Utah, U.S.A.). Accessions of G. clarum consisted of BR147B (from M-.T. Lin, São Paulo, Brazil), FL979A (from N. C. Schenck, Florida, U.S.A.). Accessions of G. intraradices included FL208 (from S. Nemec, Florida, U.S.A.), KS906 (cultured by B. D. Hetrick, Kansas, U.S.A.), UT126 (from T. Wood, Native Plants, Inc., Salt Lake City, Utah, U.S.A.). Glomus claroideum was represented by BR147A 
(from M-.T. Lin, São Paulo, Brazil) and SC186 (from H. Skipper, Clemson, South Carolina, U.S.A.).

Bulk inoculum of each isolate was produced according to standardized protocols discussed by Morton et al. (1993). Briefly, whole inoculum of an INVAM accession (a mix of potting medium, chopped roots, spores, hyphal fragments) was mixed 1:10 (v/v) with the same potting medium previously steamed twice at $100^{\circ} \mathrm{C}$. The potting medium consisted of a sandy loam soil (Lily series) premixed 1:2 (v/v) with quartzite sand (average grain size $=0.9 \mathrm{~mm}$ ) and limed after steaming to $\mathrm{pH}$ 6.2. The inoculated mixture was placed in $15-\mathrm{cm}$ diameter plastic pots and seeded heavily (100-120 seeds) with sudangrass [Sorghum sudanense (Piper) Staph]. Plants were grown for 4 months in a growth room under fluorescent lights with a photon flux density of $245 \mu \mathrm{mol} \mathrm{m} \mathrm{m}^{-2} \mathrm{~s}^{-1}$ at pot level and a 14-hour photoperiod; room temperature ranged from 19 to $30^{\circ} \mathrm{C}$ during the culture period. At harvest, plants were dried in situ for $2-3$ weeks at $22-24^{\circ} \mathrm{C}$, and the pot contents stored in plastic zip-loc bags at $4^{\circ} \mathrm{C}$ until sampled.

\section{Experimental design}

Whole inoculum of each isolate was mixed 1:5 (v/v) with the same growth medium described above and placed in six $4 \times 21 \mathrm{~cm}^{\text {cone-tainers }}{ }^{\mathrm{TM}}$ (Stuewe and Sons, Inc., Corvallis, Oregon). Five to seven surface sterilized sudangrass seeds were placed in each cone-tainer and plants were grown under growth room conditions described above. Spores of each isolate were extracted from one cone-tainer per week from the third to seventh weeks after seedling emergence.

Another pot technique also was used to sequentially sample spores in all developmental stages from the same culture. A cone-tainer containing inoculum of each isolate was seeded with sudangrass and grown for 10 weeks. The contents of a cone-tainer then were transferred to a nylon mesh sleeve with 100- $\mu$ m openings. The sleeve was transplanted into the center of a 15$\mathrm{cm}$ diameter pot. Sterile growth medium (described above) was placed around the sleeve and seeded with sudangrass. A soil core was removed from the newly seeded regions of each pot at weekly intervals between four and eight wk after plant emergence.

Spores were extracted by agitating pot samples $(30 \mathrm{ml})$ in a blender with water for 5-10 seconds and forcing the contents through two nested sieves with 500- and 38- $\mu$ m openings using a water spray. Material retained on the $38-\mu \mathrm{m}$ sieve was transferred to $50-\mathrm{cm}^{3}$ tubes containing $20 \%$ and $60 \%$ sucrose layers and centrifuged at $900 \times g$ for 2 minutes. The supernatant containing suspended spores was decanted into a 38- $\mu \mathrm{m}$ sieve, washed with tap water for 1-2 minutes, and then transferred to a Petri dish. Individual spores were collected using a Pasteur pipette extruded to a fine tip.

\section{Stages of spore differentiation}

Under a stereomicroscope, spores were separated into discrete classes based on color and opacity of spores that corresponded to progressively more mature states. Color was quantified by comparing spores and a printed color chart (INVAM color chart) illuminated simultaneously with a two-branch fiber optic illuminator at $3400 \mathrm{~K}$. Color values consisted of percentage cyan, magenta, yellow, and black (C-M-Y-K). Maturity class I (most juvenile) spores were distinguished as white with opaque contents. Maturity class II spores (intermediate) were recognized by color or opacity of spore contents: G. etunicatum spores were tan (0-10-20-0 to 010-60-0) with contents opaque; G. clarum spores were white with a reflective spore wall layer 
surrounded by a "halo", with contents translucent; and, G. claroideum spores were pale cream (0-5-20-0 to 0-10-20-0) with opaque contents. Maturity class III (fully differentiated spores) was evident by a distinct shift in spore color. No distinction between maturity classes II and III could be determined for spores of $G$. intraradices.

Spores in each maturity class were mounted permanently in PVLG (polyvinyl alcohol, lactic acid, glycerin; Koske and Tessier, 1983) and PVLG mixed 1:1 (v/v) with Melzer's reagent. Slides of whole and broken spores were incubated in a convection oven at $65^{\circ} \mathrm{C}$ for $24-48 \mathrm{~h}$ and then stored as permanent vouchers in INVAM. Spore subcellular structures were examined under a Nikon Optiphot microscope. Selected images were captured in a Sony CCD video camera attached to the microscope, viewed on a Sony Trinitron color monitor and printed with a Sony Mavigraph video image printer (B \& B Microscope Co., Pittsburgh, PA).

Sequential stages in spore subcellular differentiation were defined by the appearance of a new structure in spores of each maturity class or by other morphological changes in spore structure or appearance. Examination of spores from sequential harvests of cone-tainers revealed that differentiation of the spore wall and subtending hyphal wall occurred simultaneously, so that changes in hyphal morphology also were examined in sequential sampling of spores from pots.

\section{Spore germination}

Spores of one isolate of each of the four Glomus species used in this study were germinated using the procedure of Brundrett (1994). Briefly, $50 \mathrm{~g}$ of the pot culture growth medium described above were placed in a plastic Petri dish, watered with 10-15 mL of distilled water, and overlaid with presterilized nylon mesh (50 $\mu \mathrm{m}$ pore size). Between 25 and 30 extracted and washed spores were placed on two halves of a $0.45 \mu \mathrm{m}$ membrane filter topping the nylon mesh. Each Petri dish was incubated in the dark at $28^{\circ} \mathrm{C}$ for $3-4$ weeks, after which spores were stained with $0.05 \%$ Trypan blue in lacto-glycerol. Spores with germ tubes were collected and mounted in PVLG on glass slides and examined with a compound microscope.

\section{RESULTS}

The origin of subcellular characters in spores was discrete enough to recognize discontinuous stages of differentiation for all taxa studied (Fig. 1). Each stage was stable enough to establish correspondence among isolates and group them in a species and also among species sharing common developmental pathways. All layers formed in the spores of the Glomus species in this study are considered part of the spore wall because they were synthesized concurrently and contiguously in the wall of the subtending hypha. Spore ontogenetic sequences differed in each species, so that each is discussed separately.

\section{Differentiation of Glomus etunicatum spores}

Two distinct stages of spore differentiation were resolved (Fig. 1). In stage 1, walls of spores and their subtending hyphae consist of a single hyaline mucilaginous layer (L1), 0.6 to 2.5 $\mu \mathrm{m}$ thick (Fig. 2), reacting in Melzer's reagent to become dark pinkish red (0-60-30-10) to reddish-purple (20-80-60-0).

Stage 2 begins with synthesis of a laminate layer (LAM) from cytoplasmic contents in spore and subtending hypha. It was arbitrarily separated into three substages based on thickening of LAM with addition of sublayers and concomitant changes in spore color. Stage 2A occurs only in spores of maturity class I. Spores are white to pale yellow and consist of L1 and a 
laminate layer that is 0.3 to $1.8 \mu \mathrm{m}$ (mean $=0.9 \mu \mathrm{m})$ (Fig. 3). In stage 2B (maturity class II), spores become tan (0-20-60-0) as existing sublayers thicken and new sublayers are added (Fig. 4). The laminate layer then ranges from 1.2 to $3.1 \mu \mathrm{m}($ mean $=2.0 \mu \mathrm{m})$ in thickness. The outer mucilaginous layer begins to slough or degrade, varying from 0.3 to $1.8 \mu \mathrm{m}$ thick on individual spores. In stage 2C, LAM terminates differentiation, at which time it is orange-brown (0-10-800 to $0-40-100-0)$ in color and 4.8 to $6.4 \mu \mathrm{m}$ (mean $=5.4 \mu \mathrm{m})$ thick. In most spores, the mucilaginous layer has completely sloughed (Fig. 5) at this point. Mature spores range from (60-)80-100(-140) $\mu \mathrm{m}$ in diameter. The innermost sublayer of LAM occasionally separates slightly from the spore wall (Fig. 6) and resembles a thin flexible layer observed in spores of $G$. claroideum, but it is rare and not considered stable enough to be taxonomically informative. Germination occurs when a germ tube emerges from the lumen of subtending hypha (Fig. 7). Origin of the germ tube was not observed.

\section{Differentiation of Glomus clarum spores}

Three discrete stages were identified in spore differentiation (Fig. 1). In stage 1, the spore wall consists only of a highly plastic and hyaline mucilaginous layer (L1) (Fig. 8) that produces folds up to $15.8 \mu \mathrm{m}$ in height (midrange of 1.2 to $4.7 \mu \mathrm{m}$ ) and stains pinkish-purple (20-80-20-0) in Melzer's reagent.

Stage 2 is distinguished by synthesis of a rigid hyaline laminate layer (LAM = L2) with a granular consistency when broken (Fig. 9). This stage was partitioned into two substages based on changes in color of whole spores. Spores in stage $2 \mathrm{~A}$ are white with opaque contents and (40-)140-180(-280) $\mu \mathrm{m}$ in diameter. L2 increases in thickness from 0.5-0.6 $\mu \mathrm{m}$ at the outset (Fig. 9) to 1.1-5.6 $\mu \mathrm{m}$ (mean $=2.8 \mu \mathrm{m})$ at the end of this stage. In stage 2B, spore contents become translucent and whole spores acquire a distinct "halo" in reflected light. L2 continues differentiation, ranging from 2.5-7.5 $\mu \mathrm{m}$ (mean $=4.8 \mu \mathrm{m})$ thick (Fig. 10). L1 sloughs to varying degrees and appears patchy.

Stage 3 begins with synthesis of a second laminate layer (LAM = L3) that becomes pale yellow (0-0-20-0) to yellow (0-0-60-0) at maturity. This stage also was subdivided in arbitrary substages based on visible changes in spore wall components. Stage 3A begins with synthesis of a pale yellow sublayer of L3 (Fig. 11), ranging from 0.3-0.6 $\mu \mathrm{m}$ (mean $=0.4 \mu \mathrm{m}$ ) thick. Whole spores remain white under reflected light. In stage 3B, both L2 and L3 thicken (Fig. 12) and then terminate differentiation. L2 is 8.1-15.6 $\mu \mathrm{m}$ (mean $=11.2 \mu \mathrm{m})$ thick and L3 is $0.9-3.1 \mu \mathrm{m}$ $($ mean $=1.8 \mu \mathrm{m})$ thick at maturity. L1 completely sloughs in most spores in this stage. Mature spores are (120-)180-200(-280) $\mu \mathrm{m}$ in diameter, and range in color from hyaline/white to dark yellow (0-0-80-0). Upon germination, the germ tube appears to arise from the innermost sublayer of the subtending hypha near the spore or at break points where branching of the subtending hypha occurs (Fig. 13).

\section{Differentiation of Glomus intraradices spores}

Two discrete stages in spore differentiation were recognized (Fig. 1). In stage 1, the spore wall consists of two phenotypically distinct layers: an outer mucilaginous layer (L1) and an inner semi-flexible hyaline layer (L2) (Fig. 14). L1 initially is very thin (0.3 to $0.6 \mu \mathrm{m})$, but grows in thickness to a maximum of $3.1 \mu \mathrm{m}$ and stains pinkish red (0-60-30-10) to pale purple (20-60-20-0) in Melzer's reagent. L2 thickens from less than 0.5 $\mu \mathrm{m}$ to 1.2-1.8 $\mu \mathrm{m}$ (Fig. 15).

Stage 2 begins with synthesis and thickening of a contiguous pale yellow laminate layer (LAM) in the wall of the spore and its subtending hypha. Substages also were defined arbitrarily 
based on transformational changes in L1, L2 and LAM of the spore wall. In stage 2A, only a single rigid LAM sublayer, 0.2 to $0.6 \mu \mathrm{m}$ (mean $=0.4 \mu \mathrm{m})$ thick, is present (Fig. 16). Spores are still in maturity class I and vary from (40-)80-100(-120) $\mu \mathrm{m}$ in diameter. Additional pale yellow sublayers of LAM are added in stage 2B (Fig. 17), increasing thickness of the layer to $2 \mu \mathrm{m}$ $($ mean $=1.2 \mu \mathrm{m})$. L2 also increases slightly in thickness, from 1.5 to $3.7 \mu \mathrm{m}$ (mean $=2.5 \mu \mathrm{m})$. L1 varies in degree of sloughing and thickness $(0.3-3.1 \mu \mathrm{m})$ on the same spore. The reaction in Melzer's reagent of L1 fades to a pale pink (0-30-20-0) color. In stage 2C, both L1 and L2 are in advanced stages of sloughing, so that only LAM remains as the spore wall of many spores (Fig. 18). At maturity, spores are hyaline to greenish yellow (0-0-5-0 to 0-5-80-0) and (60-)80-120(160) $\mu \mathrm{m}$ in diameter. The germ tube appears to arise from the innermost sublayer of the subtending hypha near the spore or at breaks in branch hyphae (Fig. 19).

\section{Differentiation of Glomus claroideum spores}

Two distinct stages of spore differentiation were resolved (Fig. 1). In stage 1, the spore wall consists of two thin layers: a mucilaginous layer (L1) 0.6-1.8 $\mu \mathrm{m}$ thick that encloses a semiflexible hyaline layer (L2) 0.6-2.2 $\mu \mathrm{m}$ thick (Fig. 20). L1 stains pink (0-30-20-0) in Melzer's reagent. Spores are white and (60-)100-120(-140) $\mu \mathrm{m}$ in diameter with opaque contents.

Stage 2 consists of a continuum separated arbitrarily into three substages of synthesis of a laminate layer $(\mathrm{LAM}=\mathrm{L} 3)$. In stage $2 \mathrm{~A}$, a pale cream (0-5-20-0) sublayer of LAM is synthesized which ranges from 0.3 to $0.9 \mu \mathrm{m}$ (mean $=0.5 \mu \mathrm{m}$ ) thick (Fig. 21). Additional sublayers are formed in stage $2 \mathrm{~B}$, so the laminate layer is $0.6-3.1 \mu \mathrm{m}$ (mean $=1.8 \mu \mathrm{m}$ ) thick (Fig. 22). L1 and L2 slough partially or totally in some spores in this stage, although the latter generally is more persistent than the former. Spores in this stage are pale cream (0-5-20-0 to 010-20-0) in color and of the same size range as those in stages 1 and $2 \mathrm{~A}$. Stage $2 \mathrm{C}$ is recognized by the complete growth of the laminate layer (L3), thickening to 3.2-6.2 $\mu \mathrm{m}$ (mean $=4.3 \mu \mathrm{m})$ (Fig. 23). L1 and L2 slough completely from most spores and only L3 remains. Spores are a dark cream color (0-10-60-0) and vary from (100-)120-140(-180) $\mu \mathrm{m}$ in diameter. In stage $2 \mathrm{C}$, a thin $(0.3-0.6 \mu \mathrm{m})$ flexible layer separates with high frequency in broken spores and thus is considered a discrete structure (L4). It often detaches from the spore wall in the region of the subtending hypha (Fig. 24). The subtending hyphal wall usually thins a short distance from the spore and detaches. Germ tubes, when present, emerge from the lumen of the subtending hypha (Fig. 25). Origin of the germ tube could not be visibly linked to any structural component of the spore or hyphal wall.

\section{Taxonomic analysis}

Spore size and color of all G. etunicatum isolates are within the range of that described by Becker and Gerdemann (1977). Subcellular organization of spores also conformed to details of the protologue, except that the red to reddish-purple reaction in Melzer's reagent of the outer layer is not reported. The "hyaline outer wall" is reinterpreted developmentally as a mucilaginous layer (L1) of the spore wall.

Spores of G. clarum isolates examined here have a slightly narrower size range than those measured by Nicolson and Schenck (1979). Subcellular organization of spores is revised as phenotypically distinct components of the spore wall. The "hyaline outer mucilaginous coating" is reinterpreted as a distinct layer (L1) differentially reactive in Melzer's reagent, the "outer wall" is a colorless laminate layer (L2), and the "inner wall" is a separate and yellow 
laminate layer (L3). Not included in the protologue is the pinkish-purple (20-80-20-0) reaction of L1 in Melzer's reagent.

Spores of $G$. intraradices isolates examined in this study have a narrower size range than that of isolates measured by Schenck and Smith (1982). These authors describe an "ephemeral outer wall", which in this study is reinterpreted as an outer mucilaginous layer (L1) and the semiflexible hyaline layer (L2) of the spore wall. L1 differentially stains in Melzer's reagent and also can differentially slough with spore age. Schenck and Smith (1982) also describe "1-4 laminate walls" because of the ease with which they separate in broken spores, but developmental evidence indicates they are sublayers of one layer (LAM) of the spore wall. The number of sublayers and their degree of separation are highly variable, differing considerably among spores of one isolate and among different isolates of the species.

Mature spores of $G$. claroideum isolates in this study had a slightly narrower size range than that reported by Schenck and Smith (1982). The subcellular structure in the spore wall differs appreciably from the protologue in description and interpretation. The outer two layers of the spore wall (L1 and L2) were not reported, possibly because only mature spores were studied in which these layers had sloughed (sometimes creating the appearance of adherent debris). L3 and L4 correspond to a "laminated" and a "membranous" wall sensu Walker (1983) respectively, but they are not of independent origin as the original definitions would suggest. The latter is a component layer of the spore wall that, upon separation, is only analogous by appearance with flexible inner walls found in spores of species in other genera.

\section{DISCUSSION}

\section{Developmental interpretation of spore structure}

Developmental patterns elucidated in this study of four Glomus species provide the empirical evidence to reinterpret spore subcellular characters according to their spatial and temporal origins during differentiation. Berch (1987) was the first to hypothesize that these structures were "layers" of a "spore wall" rather than separate "walls" as proposed by Walker (1983). Similarly, Maia et al. (1993) concluded from ultrastructural studies that the spore wall is a single structure subdivided in "zones". Results of this study and those of Morton (1996) confirm that all of the subcellular structures within spores of the Glomus species studied thus far are component parts of one spore wall. Although each component arises de novo in a linear sequence and possesses a distinctive phenotype, all originate as parts of a hyphal wall and a spore wall that codifferentiate and mature at the same rate.

The term "evanescent wall" (Walker, 1983) has been applied to any sloughing structures on the surface of spores (Morton and Benny, 1990). Comparative evidence in this study indicates the term encompasses phenotypically distinct layers of the spore wall that have different developmental (and thus phylogenetic) histories. For example, the most juvenile spores of $G$. etunicatum have only one outer layer that sloughs with age, whereas those of $G$. intraradices have two distinct outer layers that together slough with age.

Similarly, the term "membranous wall" (Walker, 1983) defines a structure of similar appearance in species of different genera but which has a different developmental history in each genus. In Glomus, as exemplified by $G$. claroideum, this structure is reinterpreted as a flexible layer of the spore wall because its attachment in the region of the subtending hypha (unless forcibly detached with applied pressure) indicates common origin as part of the hyphal wall. In 
Scutellospora species, this structure is a separate flexible inner wall consisting of two layers that have no physical connection to spore or hyphal walls (Franke and Morton, 1994; Morton, 1995).

The term "laminated" wall (Walker, 1983) is reinterpreted developmentally as a component layer of the spore wall, consisting of sublayers that are adherent or separate to varying degrees upon breakage and vary in thickness and number. The laminate layer(s) is absent in the hyphal and wall of juvenile spores of species examined in this study, but often it is the only layer(s) present in the wall of mature spores.

\section{Interpretation of spore developmental stages}

The various stages in spore differentiation among fungi propagated from geographically and ecologically disparate sites are as stable in Glomus as are those observed in Scutellospora (Franke and Morton, 1994; Morton, 1995) and Gigaspora (Bentivenga and Morton, 1995). The application of ontogenetic criteria of temporal origin, position, and structural properties of subcellular structures in each stage provide the operational criteria to determine homology (Patterson, 1982) and to group members of a species by common genealogy (Morton et al., 1992).

Comparison of each stage among Glomus species also pinpointed divergence in developmental pathways. For example, the most juvenile spores in stage 1 defined two divergent groups of two species each: (1) G. etunicatum and G. clarum with only one layer in the spore and subtending hyphal wall; and, (2) G. intraradices and G. claroideum with two layers in spore and hyphal wall. In the first group, G. clarum differed from $G$. etunicatum in stage 2 in color of the first laminate layer and diverged further with synthesis of a second yellow laminate layer. In the second group, $G$. claroideum diverged from $G$. intraradices in stage 2 in color of the laminate layer and degree of adherence of sublayers.

\section{Phylogenetic interpretations of developmental sequences}

All taxa incorporated into a developmental model of Glomales consistently express species-level differences solely in component layers of the spore wall. This pattern of variation is most evident in species of Gigaspora and Glomus, in which all stages of development involve differentiation of a spore wall. Gigaspora has only five species, with variation confined to spore size and pigmentation or other properties of the laminate layer (Bentivenga and Morton, 1995). Variation in number of layers and the phenotypic properties of each layer in the spore wall is considerably greater in Glomus and many of these phenotypes are unique to the genus (Morton and Benny, 1990; Morton et al., 1995). Of all taxa studied to date, only in Glomus are these layers formed contiguously in spores and their subtending hyphae. The diversity of these component layers appears to account for the extensive species-level variation in the genus.

Germination events also appear to provide a constraining influence on variation in layers of the spore wall in species of Gigaspora and not in those of Glomus. In Gigaspora, germ tube formation is linked directly with an electron-dense sublayer on the inner surface of the laminate layer of the spore wall (Maia et al., 1993). In contrast, germ tubes in Glomus spores arise mostly from the structure occluding spore contents positioned in the subtending hypha rather than directly from the spore wall.

The presence of one or two layers in the most juvenile spore wall (stage 1) indicates ancestral phenotypes of two possibly distinct groups of species with divergent lineages (Fig. 1). Later unique stages also may have similar grouping and ranking criteria if they are shared by two 
or more species, such as the flexible sublayer of the laminate layer found in G. claroideum and a number of other Glomus species. Walker (1992) has suggested that this sublayer is evidence of polyphyly in Glomus, but its weight in defining distinct lineages has not yet been clearly established.

The morphological evidence for monophyly in Glomales is weak and resides in only one character, arbuscule formation in root cortical cells (Morton, 1990). Molecular evidence also is weak (Simon et al., 1993) in the preponderance of derived taxa sampled and choice of outgroup in the cladistic analysis. Stages of spore development by species in Glomaceae discovered in this paper and in Gigasporaceae (Bentivenga and Morton, 1995; Franke and Morton, 1994; Morton, 1995) show little evidence of homology based on the criteria of correspondence in origin of structures or the composition and position of component parts. These patterns, together with distribution of $\beta$ (1-3) glucans in spore and hyphal cell walls (Gianinazzi-Pearson et al., 1994), strongly support the separation of the two families into two suborders (Morton and Benny, 1990) and suggest Glomales may be polyphyletic. More molecular data sets encompassing a greater number of taxa are needed to further resolve this issue.

\section{LITERATURE CITED}

Almeida, R. T., and N. C. Schenck. 1990. A revision of the genus Sclerocystis (Glomaceae, Glomales). Mycologia 82:703-714.

Becker, W. N., and J. W. Gerdemann. 1977. Glomus etunicatus sp. nov. Mycotaxon 6:29-32.

Bentivenga, S. P., and J. B. Morton. 1995. A monograph of the genus Gigaspora incorporating developmental patterns of morphological characters. Mycologia 87:720-732.

Berch, S. M. 1987. Endogonaceae: Taxonomy, specificity, fossil record, phylogeny. Frontiers in Applied Microbioogy 2:161-188.

Brundrett, M. 1994. Spores of Glomalean fungi. Pp. 35-41. In: Practical Methods in mycorrhiza research. Eds., M. Brundrett, L. Melville, and L. Peterson. Mycologue Publications, Guelph.

Franke, M., and J. B. Morton. 1994. Ontogenetic comparisons of arbuscular mycorrhizal fungi Scutellospora heterogama and Scutellospora pellucida: revision of taxonomic character concepts, species descriptions, and phylogenetic hypotheses. Canadian Journal of Botany 72:122-134.

Gianinazzi-Pearson, V., M.-C. Lemoine, C. Arnold, A. Gollotte, and J. B. Morton. 1994. Localization of $\beta$ (1-3) glucans in spore and hyphal walls of fungi in the Glomales. Mycologia 86:478-485.

Giovannetti, M., L. Avio, and L. Salutini. 1991. Morphological, cytochemical, and ontogenetic characteristics of a new species of vesicular-arbuscular mycorrhizal fungi. Canadian Journal of Botany 69:161-167.

Koske, R. E., and B. Tessier. 1983. A convenient, permanent slide mounting medium. Mycological Society of America News Letter 34:59.

Maia, L. C., J. W. Kimbrough, and G. Benny. 1993. Ultrastructural studies of the spore wall of Gigaspora albida (Glomales). Mycologia 85:883-889.

Meier, R., and I. Charvat. 1992. Peridial development in Glomus mosseae (Glomaceae). American Journal of Botany 79:928-936.

Morton, J. B. 1990. Evolutionary relationships among arbuscular mycorrhizal fungi in the Endogonaceae. Mycologia 82:192-207. 
Morton, J.B. 1995. Taxonomic and phylogenetic divergence among five Scutellospora species based on comparative developmental sequence. Mycologia 87:127-137.

Morton, J.B. 1996. Redescription of Glomus caledonium based on correspondence of spore morphological characters in type specimens and a living reference culture. Mycorrhiza 6:161-166.

Morton, J.B., and G. L. Benny. 1990. Revised classification of arbuscular mycorrhizal fungi (Zygomycetes): a new order, Glomales, two new suborders, Glomineae and Gigasporineae, and two new families, Acaulosporaceae and Gigasporaceae, with an emendation of Glomaceae. Mycotaxon 37:471-491.

Morton, J.B., S. P. Bentivenga, and J. D. Bever. 1995. Discovery, measurement, and interpretation of diversity in symbiotic endomycorrhizal fungi (Glomales, Zygomycetes). Canadian Journal of Botany 73(suppl. 1):S25-S32.

Morton, J.B., S.P. Bentivenga, and W.W. Wheeler. 1993. Germ plasm in the International Collection of Arbuscular and Vesicular-arbuscular Mycorrhizal Fungi (INVAM) and procedures for culture development, documentation and storage. Mycotaxon 48:491-528.

Morton, J.B., M. Franke, and G. Cloud. 1992. The nature of fungal species in Glomales and their role in endomycorrhizal associations. Pp. 65-73. In: Mycorrhizas in ecosystems. Eds., D.J. Read, D. H. Lewis, A. H. Fitter and I. J. Alexander. CAB International, University Press, Cambridge.

Nicolson, T. H., and N. C. Schenck. 1979. Endogonaceous mycorrhizal endophytes in Florida. Mycologia 71:178-198.

Patterson, C. 1982. Morphological characters and homology. pp. 21-74. In: Problems of Phylogenetic reconstruction. Eds., K. A. Joysey and A. E. Friday. Academic Press, London.

Schenck, N. C., and G. S. Smith. 1982. Additional new and unreported species of mycorrhizal fungi (Endogonaceae) from Florida. Mycologia 74:77-92.

Simon, L. 1996. Phylogeny of the Glomales: deciphering the past to understand the present. New Phytologist 133:95-101.

Simon, L., J. Bousquet, R. C. Lévesque, and M. Lalonde. 1993. Origin and diversification of endomycorrhizal fungi and coincidence with vascular land plants. Nature 363:67-69.

Walker, C. 1983. Taxonomic concepts in the Endogonaceae: spore wall concepts in species descriptions. Mycotaxon 18:443-455.

Walker, C. 1992. Systematics and taxonomy of the arbuscular endomycorrhizal fungi (Glomales) - a possible way forward. Agronomie 12:887-897.

Wu, C. -G., and D. M. Sylvia. 1993. Spore ontogeny of Glomus globiferum. Mycologia 85:317-322. 

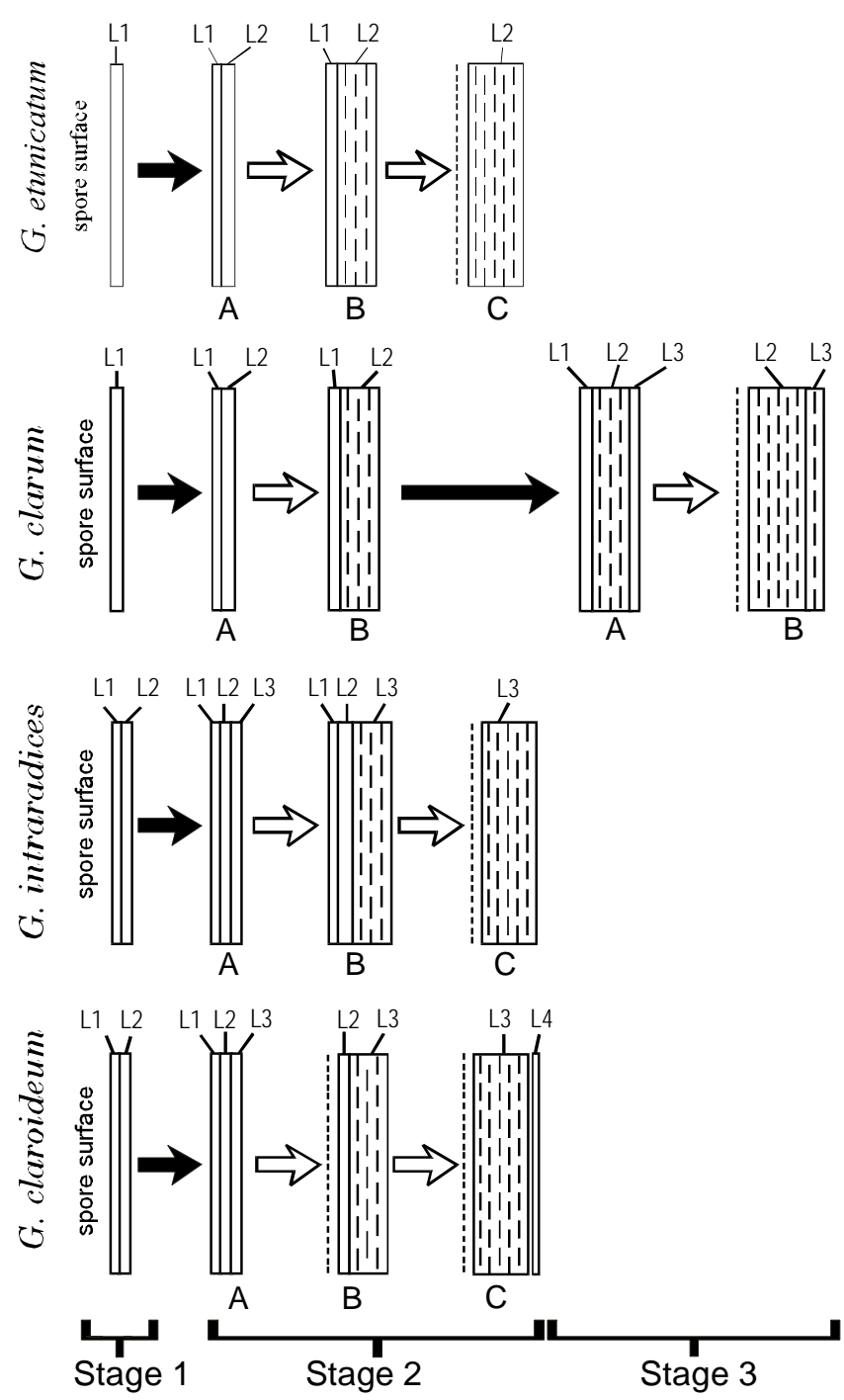

Fig. 1 Murographic representation of the linear sequence in differentiation of layers in the maturing spore wall of Glomus etunicatum, G. clarum, G. intraradices and G. claroideum. L1 through L4 represent phenotypically discrete layers designated numerically in the order they were synthesized. Dashed vertical line alone indicates a layer that has sloughed; dashed vertical lines filling rectangles represent sublayers of a laminate layer (LAM in Figs. 2-25). Filled arrows indicate transitions between discrete and stable stages in spore differentiation; hollow arrows indicate transitions between more arbitrarily defined substages (designated A-C) within a stage. 


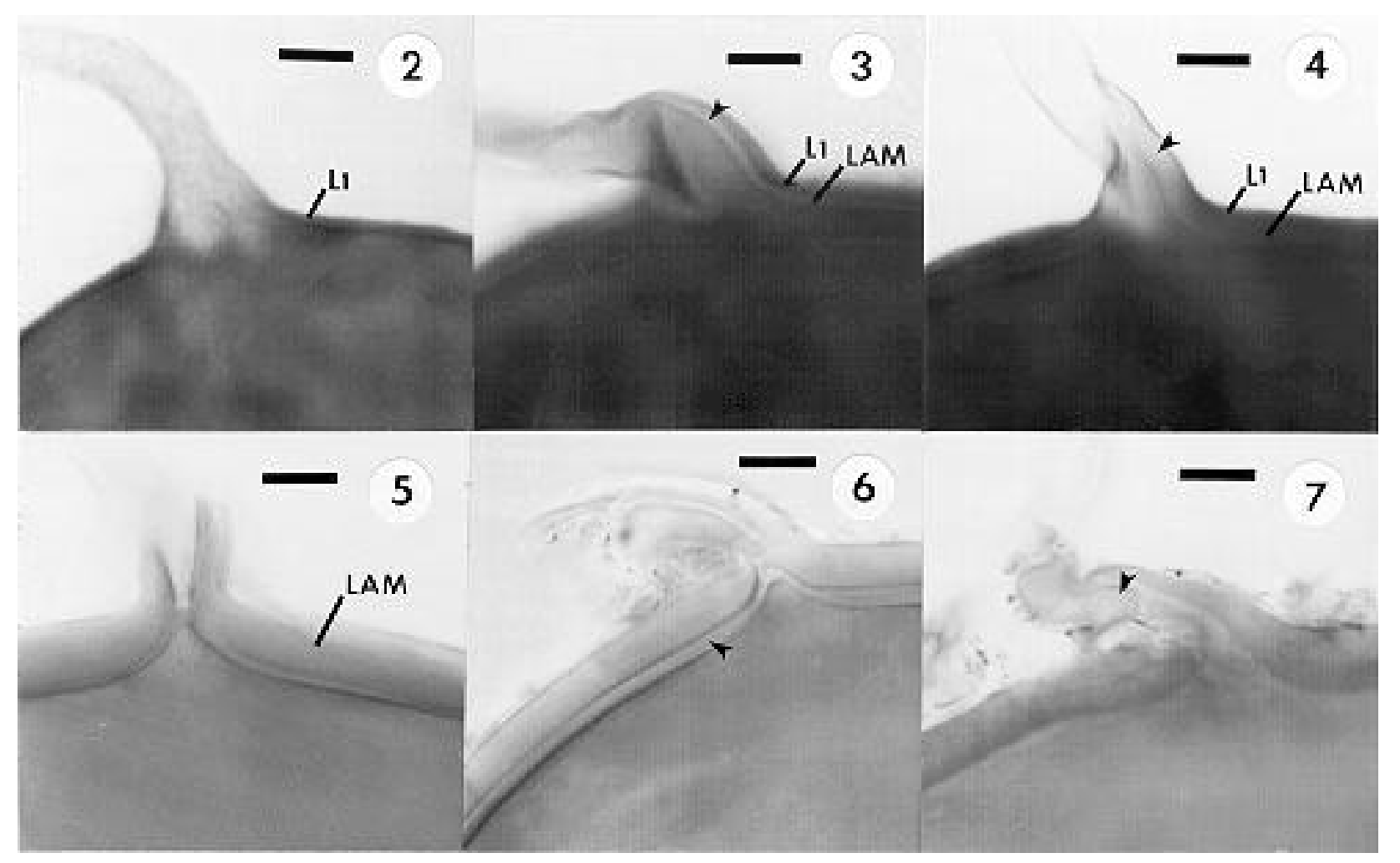

Figs. 2-7 Glomus etunicatum UT315 - stages in the differentiation of spore wall layers in spores mounted in PVLG + Melzer's reagent $(1: 1, \mathrm{v} / \mathrm{v})$. Numbers in brackets refer to voucher slides deposited at INVAM. 2. Most juvenile spore (stage 1), with one mucilaginous layers (L1) present [S2108]. 3. Juvenile spore (stage 2A) with mucilaginous layer (L1) and first sublayer of an orangebrown laminate layer (LAM) arising concurrently in the subtending hyphal wall (arrow) [S2110]. 4. Juvenile spore (stage 2B) with added sublayers in the laminate layer and in the subtending hypha (arrow) [S2917]. 5. Mature spore (stage 2C) with L1 completely sloughed and only LAM remaining [S2918]. 6. Mature spore (stage 2C) with a rare thin sublayer (arrow) separating slightly from LAM [S2113]. 7. Germ tube (arrow) growing through the lumen of the subtending hypha [S2919]. Scale bars $=5 \mu \mathrm{m}$. 


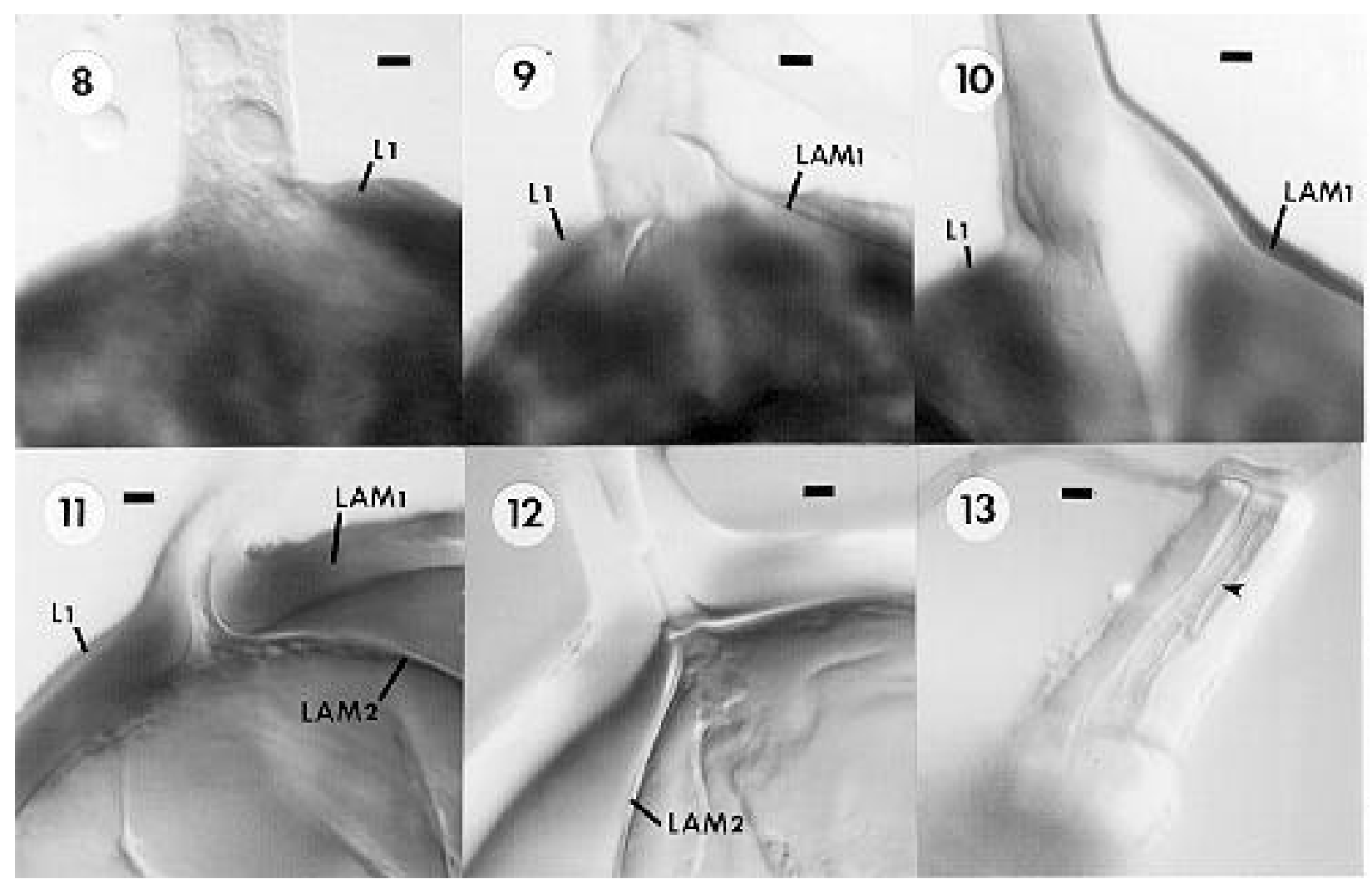

Figs. 8-13 Glomus clarum FL979A - stages in the differentiation of spore wall layers in spores mounted in PVLG + Melzer's reagent (1:1, v/v). Numbers in brackets refer to voucher slides deposited at INVAM. 8. Most juvenile spore (stage 1) with only one mucilaginous layer (L1) present [S2827]. 9. Juvenile spore (stage 2A) with L1 and the first sublayer of a hyaline laminate layer (LAM=L2) originating concurrently in the subtending hyphal wall [S2731]. 10. Juvenile spore (stage 2B) with additional sublayers in L2 [S2731]. 11. Juvenile spore (stage 3A) with L1, a fully differentiated L2, and the first yellow sublayer of a second laminate layer (LAM=L3) arising concurrently in the subtending hyphal wall [S2831]. 12. Mature spore (stage 3B) with L1 sloughed and only the laminate layers L2 and L3 remaining [S2831]. 13. Germ tube (arrow) growing in the lumen of the subtending hypha of a fully differentiated spore [S2832]. Scale bars $=5 \mu \mathrm{m}$. 


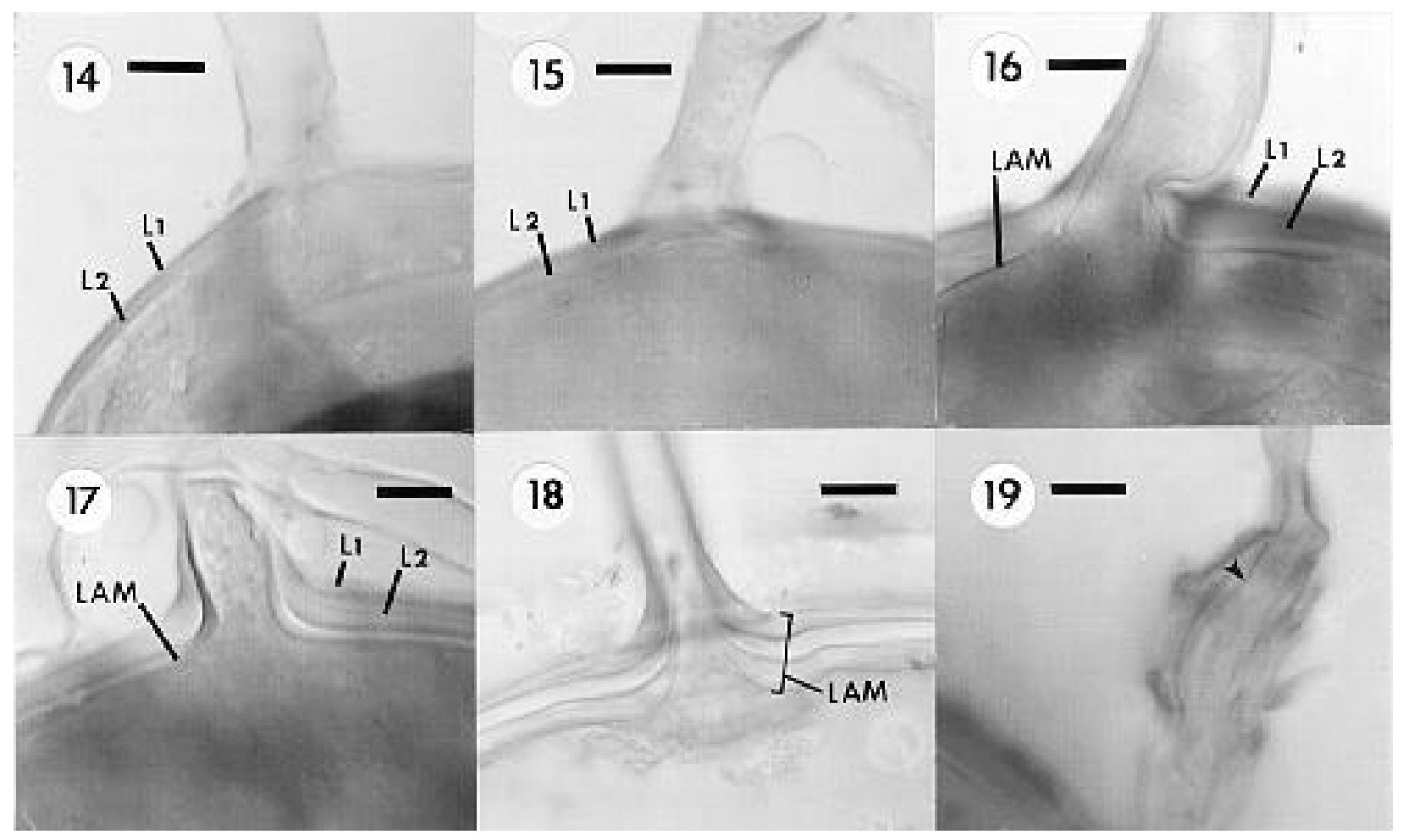

Figs. 14-19 Glomus intraradices KS906 - stages in the differentiation of spore wall layers in spores mounted in PVLG + Melzer's reagent $(1: 1, \mathrm{v} / \mathrm{v})$. Numbers in brackets refer to voucher slides deposited at INVAM. 14. Most juvenile spore (stage 1) with an outer mucilaginous layer (L1) and a hyaline semiflexible layer (L2) present, both originating concurrently in the wall of the subtending hypha [S2136]. 15. Juvenile spore at the end of stage 1 showing an increase in thickness of L1 and L2 of the spore wall [S2136]. 16. Juvenile spore (stage 2A) with a spore wall consisting of L1, L2 and the first sublayer of a pale yellow laminate layer (LAM) arising concurrently in the subtending hyphal wall (arrow) [S2138]. 17. Juvenile spore (stage 2B) with added sublayers in LAM [S2136]. 18. Mature spore (stage 2C) with remnants of degraded L1 and L2 and separable sublayers of a fully differentiated LAM [S2695]. 19. Germ tube (arrow) growing through the lumen of the subtending hypha [S2981]. Scale bars $=5 \mu \mathrm{m}$. 


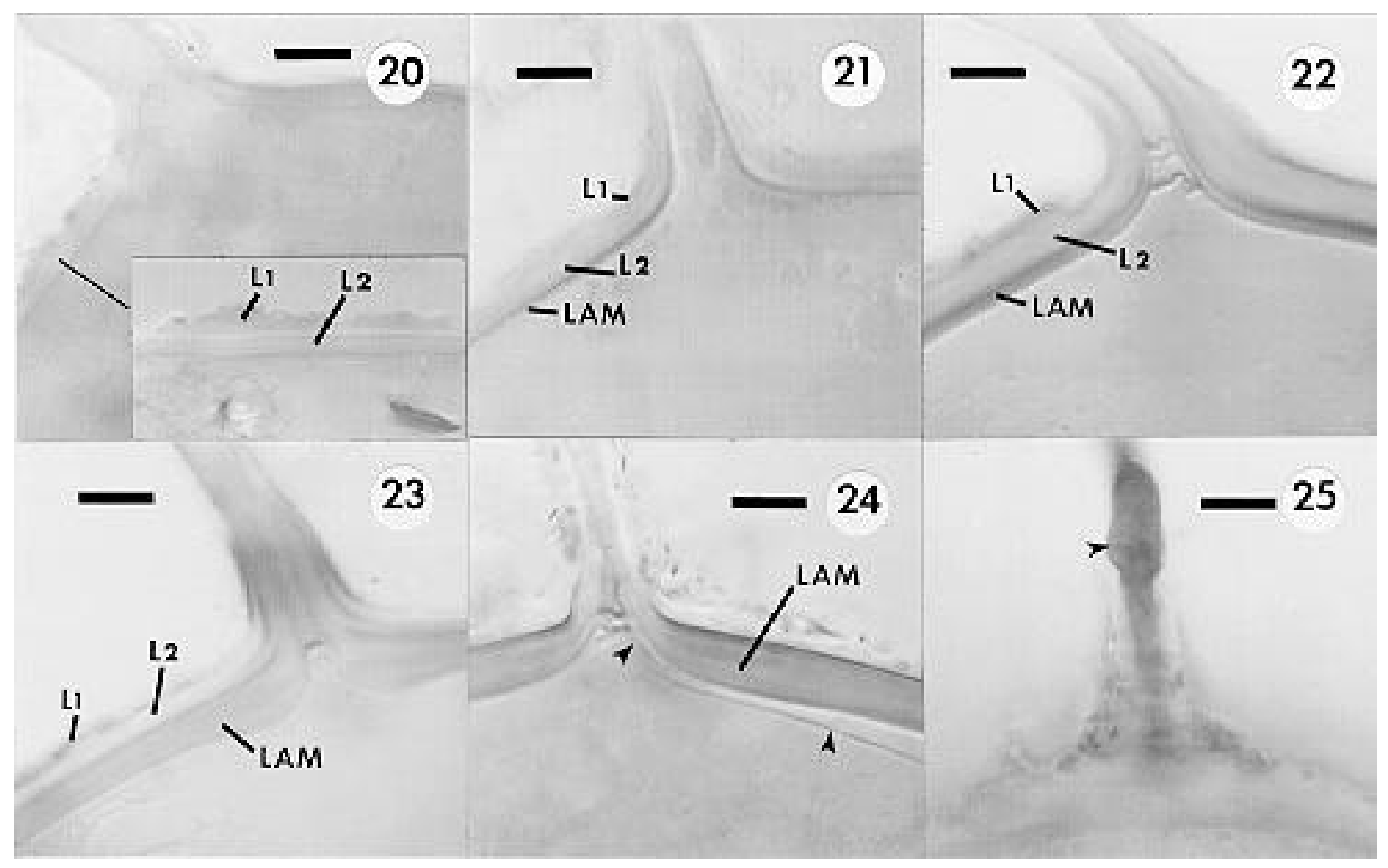

Figs. 20-25 Glomus claroideum BR147A- stages in the differentiation of spore wall layers in spores mounted in PVLG + Melzer's reagent $(1: 1, \mathrm{v} / \mathrm{v})$. Numbers in brackets refer to voucher slides deposited at INVAM. 20. Most juvenile spore (stage 1) with mucilaginous layer (L1) and a hyaline semiflexible layer (L2) present, both arising concurrently in the wall of the subtending hypha [S2718], insert shows a magnified view of layers [S2684]. 21. Juvenile spore (stage 2A) with spore wall consisting of L1, L2 and the first sublayer of the laminate layer (LAM=L3) that originate concurrently in the subtending hyphal wall (arrow) [S2718]. 22. Juvenile spore (stage 2B) with added sublayers in L3 [S2719]. 23. Mature spore (stage 2C) with L1 and L2 intact and a fully differentiated laminate layer [S2720]. 24. Another mature spore showing a thin layer (L4) (arrow) detaching from the laminate layer (L3) and remnants of L1 and L2 [S2686]. 25. Germ tube (arrow) emerging through the lumen of the subtending hypha [S2979]. Scale bars $=5 \mu \mathrm{m}$. 
CHAPTER TWO

TAXONOMIC REINTERPRETATION OF MORPHOLOGICAL

CHARACTERS IN ACAULOSPORACEAE BASED ON DEVELOPMENTAL

PATTERNS IN TWO ACAULOSPORA

AND ONE ENTROPHOSPORA SPECIES 


\section{INTRODUCTION}

The family Acaulosporaceae diverges morphologically from other families in Glomales (Glomaceae, Gigasporaceae) by synthesis of spores on or within the neck of a transitory terminal spore-like structure on a sporogenous hypha known as a "sporiferous saccule" (Walker et al., 1984; Morton and Benny, 1990). Acaulosporaceae contains two genera, Acaulospora Gerd. \& Trappe and Entrophospora Ames \& Schneider, that so far contain 33 and four species, respectively.

Two hypotheses have been proposed to explain the evolutionary relationships of Acaulosporaceae relative to other families in Glomales. Based on morphological patterns of divergence, Acaulosporaceae is considered a sister group of Glomaceae (Morton, 1990). Molecular patterns, in contrast, suggest that this family is more closely related to Gigasporaceae (Simon et al., 1993). The occurrence of two taxa with both a glomus-like and acaulospora-like spore morphotypes (Morton et al., 1997) supports the former hypothesis. The conflict between morphological and molecular characters is cause for a study of developmental patterns in Acaulosporaceae to better interpret morphological characters in relation to their origin and transformational states and to determine if similarities in appearance represent homologous (phylogenetically informative) versus analogous (phylogenetically uninformative) traits (Patterson, 1982).

Mosse (1970a, 1970b, 1970c) was the first to conduct detailed studies of ontogeny of spores in Acaulospora laevis Gerd. \& Trappe. She described the mode of spore formation of this species and the differentiation of spore subcellular structures, but no comparisons were made with other species. Subsequent work with other fungi in Acaulosporaceae has focused only on events preceding differentiation of spore subcellular structure (Wu et al., 1995). In this study, I reexamine spore development in two selected species of Acaulospora and one species in Entrophospora and compare patterns with those published for species in Glomaceae (Morton, 1996; Stürmer and Morton, 1997) and Gigasporaceae (Franke and Morton, 1994; Bentivenga and Morton, 1995; Morton, 1995). All three species compared in this study are redescribed based on developmental interpretations of morphological characters.

\section{MATERIAL AND METHODS}

\section{Experimental isolates}

Isolates used in this study were obtained from the International Culture Collection of Arbuscular and Vesicular-arbuscular Mycorrhizal Fungi (INVAM, West Virginia University). Reference isolates of each species (see Morton, 1996) were chosen: Acaulospora laevis AU211 (from C. Gazey, Australia); A. spinosa WV861A (from J. Morton, West Virginia, U.S.A.); and, Entrophospora colombiana CL356 (from E. Sieverding, Colombia). Bulk inoculum for each isolate was prepared according to standardized protocols for all culture propagation in INVAM (Morton et al., 1993).

\section{Experimental design}

Whole inoculum of each isolate was diluted 1:10 with a sterile potting media and placed in seven $4 \times 21 \mathrm{~cm}$ cone-tainers ${ }^{\mathrm{TM}}$ (Stuewe and Sons, Inc., Corvallis, Oregon). Five to ten surface sterilized sudangrass seeds were placed in each cone-tainer and grown in a growth room under fluorescent lights with a photon flux density of $245 \mu \mathrm{mol} \mathrm{m} \mathrm{m}^{-2} \mathrm{~s}^{-1}$ at pot level and a 14-hour photoperiod. Room temperature ranged from 19 to $30^{\circ} \mathrm{C}$ during the culture period. Spores were 
extracted from cone-tainers at weekly intervals between four and eight weeks after seedling emergence.

A second culture procedure was to transplant 10-week-old mycorrhizal sudangrass from a cone-tainer into the center of a $15-\mathrm{cm}$ diameter pot. Sterile potting medium surrounding the cone-tainer was seeded with sudangrass and the plants were grown under conditions specified above. A soil core was removed from the newly seeded area each week between four and eight weeks after seedling emergence.

Spores were extracted by wet-sieving a sample through nested sieves with $500 \mu \mathrm{m}$ and 38 $\mu \mathrm{m}$ openings, followed by sucrose-density gradient centrifugation (20 and $60 \%$ sucrose gradient) at $900 \times \mathrm{x}$ for 2 minutes. Suspended spores were washed with tap water, transferred to a petri dish, and collected manually under a stereomicroscope.

\section{Stages of spore development}

Spores of all fungi studied could be separated in distinct maturity classes based on color and opacity of spore content. Color was estimated by comparing spores and the INVAM color chart illuminated simultaneously with a two-branch fiber optic illuminator at $3400 \mathrm{~K}$. Color is expressed as a formula based on the relative proportion of cyan, magenta, yellow and black. Spores were collected into three maturity classes under a stereomicroscope according to the following criteria. Maturity class I (most juvenile) contained spores with opaque contents and pale color: A. laevis and A. spinosa spores were light orange-brown (0-20-60-0); and, E. colombiana spores were cream-colored (0-10-20-0). Maturity class II spores were of similar color to that of mature spores but contents still were somewhat opaque. In maturity class III (fully mature), spores had attained full pigmentation and contents were translucent.

After collection, spores were mounted on slides in both PVLG (polyvinyl alcohol, lactic acid, glycerin) and PVLG mixed with Melzer's reagent (1:1, v/v). They were stored at room temperature for a minimum of 7 days while mountants cured and spore contents cleared. All prepared slides were deposited in the permanent voucher collection of INVAM.

Stages in spore differentiation were distinguished by the synthesis of a new structure in spores of each maturity class or by discrete phenotypic changes in appearance or histochemical staining reaction of a structure during its development. Terminology of spore subcellular characters follows that of Franke and Morton (1994). Color versions of all figures in this paper are accessible on the World Wide Web URL http://invam.caf.wvu.edu.

\section{RESULTS}

Differentiation of spore subcellular characters was discrete enough to recognize, separate and compare stages of development in all species (Fig. 1). Spore development did not begin until the sporiferous saccule was fully inflated. Contents of both saccule and spore remained dense until the spore neared its final size, after which the saccule contents disintegrated and the saccule collapsed. Spore development proceeded in three separate phases similar to those of Scutellospora species (Franke and Morton, 1994) that differentiated functionally different spore components: a spore wall; flexible inner walls; and, a germination orb. Despite similar stages of differentiation, component structures formed in each stage differed among species, so that each will be described separately. 


\section{Differentiation of Acaulospora laevis spores}

Saccules of this species form blastically from a hyphal tip and range in size from 140-260 $\mu \mathrm{m}($ mean $=220 \mu \mathrm{m})$ when fully expanded (Fig. 2). Color of saccule contents ranges from white to light orange (0-20-60-0). The saccule wall is a single layer 0.6 to $3.1 \mu \mathrm{m}$ thick.

The spore initially buds from the hypha subtending the saccule neck and passes through seven discontinuous stages of ontogenesis (Fig. 1). Stage 1 is recognized by the presence of an outer layer (1), 0.6-3.1 $\mu \mathrm{m}$ thick (mean=1.56 $\mu \mathrm{m}$ ) that is continuous with the saccule neck (Fig. 2 ). Stage 2 begins with the synthesis of a rigid second layer (2) from cytoplasmatic contents inside the spore (Fig. 3). This stage was arbitrarily separated in two intergrading substages distinguished by thickness of layer 2. Stage 2A occurs in spores of maturity class I and most of spores still are attached to the neck of the sporiferous saccule. Spores at this stage are light orange (0-20-60-0), with both spore wall layers (1 and 2) together 0.5-1.5 $\mu \mathrm{m}$ (mean $=0.9 \mu \mathrm{m})$. In stage $2 \mathrm{~B}$, spores are in maturity class II and are pale orange brown (0-30-60-0) to dark orange brown (0-60-100-0). Layer 2 is thicker, 1.5-4.4 $\mu \mathrm{m}($ mean $=2.8 \mu \mathrm{m})$ (Fig. 3). Spores now are fully pigmented but their contents are still condensed. Stage 3 begins with the synthesis of a third hyaline layer (3) in the spore wall that becomes 0.6-1.8 $\mu \mathrm{m}$ thick at maturity (Fig. 4). Spores now have fully expanded, ranging from $180-260 \mu \mathrm{m}$ in diameter.

The first hyaline bilayered flexible inner wall (iw1) is formed in stage 4 (Fig. 5). At maturity, the outer layer (1) of iw1 is 0.5-0.6 $\mu \mathrm{m}$ thick and the inner layer (2) is 0.6-2.5 $\mu \mathrm{m}$ thick (mean $=1.0 \mu \mathrm{m})$. A second hyaline, flexible inner wall (iw2) is synthesized in stage 5 and it is formed by two very thin adherent layers. This inner wall undergoes further differentiation in stage 6 (Fig. 6), the outer layer (1) of iw2 is 0.5-0.6 $\mu \mathrm{m}$ thick and covered with granular excrescence ("beads"); the inner layer (2) is $0.6-1.5 \mu \mathrm{m}$ thick. The inner layer of iw2 usually in nonreactive in Melzer's reagent, but in a few spores acquires a faint pink coloration. By this stage, the outermost layer of the spore wall usually has completely sloughed.

Once all flexible inner walls are fully mature, then stage 7 is initiated with synthesis of a germination orb (Spain, 1992) on the surface of the second innermost flexible wall (Fig. 7). The germination orb was detectable only in older spores in which the contents had fused and were transparent, mainly because outer boundaries of the orb are not often sharply defined or visible.

\section{Differentiation of Acaulospora spinosa spores}

Saccules of this species ranged in color from white to orange brown (0-40-100-0) (Fig. 8). At the time of harvest, they measured between $80-160 \mu \mathrm{m}$ in diameter. The saccule wall is composed of a single layer 0.6-1.8 $\mu \mathrm{m}$ thick (mean $=1.2 \mu \mathrm{m})$.

Seven distinct stages were recognized during spore ontogenesis that paralleled those in spores of A. laevis (Fig. 1). The outer layer formed in stage 1 was hyaline, robust, continuous with the wall of the saccule neck, and was 0.6-4.3 $\mu \mathrm{m}$ thick (Fig. 8). The second rigid layer (2) forming in stage 2 formed spine-like projections early in differentiation (stage 2A) when spores were pale orange (0-20-60-0) and composite spore wall thickness (layers 1 and 2) was only 0.3$1.8 \mu \mathrm{m}$ thick (Fig. 9). Layer 2 thickened during stage 2B with synthesis of additional sublayers basal to the spines. At maturity, this layer is $3-7 \mu \mathrm{m}$ thick, including spines that are $0.8-2.5 \mu \mathrm{m}$ in height. A thin inner layer (3), 0.5-0.8 $\mu \mathrm{m}$ thick, forms as part of the spore wall in stage 3 (Fig. 10). Because this layer is so thin, it tends to fold with applied pressure and thus may be mistaken 
for a flexible inner wall. With maturation of all three layers of the spore wall, full size and pigmentation have been attained. Spores are $140-180 \mu \mathrm{m}$ in diameter $($ mean $=150 \mu \mathrm{m})$ and cream (0-10-20-0) to pale orange brown (0-30-60-0) in color.

The first hyaline flexible inner wall (iw1) then forms (stage 4), with an outer layer (1) less than $0.5 \mu \mathrm{m}$ thick and an inner layer (2) 0.5-1.2 $\mu \mathrm{m}$ thick at maturity (Fig. 11). Once it is fully formed, then a second hyaline, flexible inner wall (iw2) is synthesized (stage 5), in which both of its layers undergo visible transformations. Initially, the outer layer (1) of iw2 is smooth and the inner layer (2) does not react in Melzer's reagent (Fig. 12). In stage 6, the outer layer then becomes covered with granular excrescences ("beads") and thickens to 0.5-0.8 $\mu \mathrm{m}$. The inner layer becomes more reactive in Melzer's reagent, staining pink (0-30-20-0) to purplishpink (0-60-20-0) at maturity and thickens to 0.6-1.5 $\mu \mathrm{m}$ (Fig. 13). Stage 7 was not observed in the spores examined, but it would consist of synthesis of a germination orb on the surface of iw2.

\section{Differentiation of Entrophospora colombiana spores}

Saccules of E. colombiana are formed blastically and expand in size to $160 \mu \mathrm{m}$ (Fig. 14). They are white to a pale orange-cream (0-30-60-0) in color with a wall consisting of a single layer 0.6-1.5 $\mu \mathrm{m}$ thick (mean $=1.3 \mu \mathrm{m})$.

Stages of spore differentiation paralleled those of Acaulospora species (Fig. 1) except for the omission of stage 3 (synthesis of a third layer in the spore wall). As the spore begins to expand within the neck of the sporiferous saccule (stage 1), the spore wall is $0.6-1.2 \mu \mathrm{m}$ (mean $=0.8 \mu \mathrm{m}$ ) thick and is contiguous with the saccule neck wall (Fig. 14). Delimitation of the spore as a discrete structure begins in stage 2 with deposition of an additional layer (2) that thickens with the addition of sublayers and becomes pigmented (Fig. 15). In this stage, spores pass from maturity class I to class II, expand in diameter to 130-160 $\mu \mathrm{m}$ (range of mature spores), and change color from pale orange brown (0-40-60-0) to dark orange-brown (0-10-60-0). Outwardly at the end of stage 2, immature and mature spores are indistinguishable except for presenceabsence of attached saccule, because the spore wall has completed differentiation.

The synthesis of two flexible inner walls follows a pattern identical to that of Acaulospora species (Fig. 1), first with the synthesis of a bilayered wall (iw1 in stage 3, Figs. 16 and 17) and then a second bilayered wall (iw2 in stage 4; Fig. 18). However, the inner layer of iw2 undergoes more of a transformation (stage 5) than the corresponding structure in spores of either of the two Acaulospora species studied. The outer layer of iw 2 follows the same pattern of being initially smooth (Fig. 18) and then synthesizing surface excrescences that give it a beaded appearance (Fig. 19). The inner layer of iw2 thickens and becomes more plastic (or amorphous) concomitant with a change in reaction to Melzer's reagent from none to light pink (such as found in A. laevis) to purplish-pink (0-60-20-0) (such as found in A. spinosa) to dark red-purple (40-80-60-0) (Fig. 19). The terminal stage (stage 6) was not observed, but conserved patterns in other species would indicate synthesis of a germination orb on the surface of iw2.

\section{Taxonomic Analysis}

Spore size of A. laevis AU211 is within the range described by Gerdemann \& Trappe (1974). The authors describe the spore wall as 'formed of three layers: outer thick and yellow to brown, inner two colorless and membranous.' The outer layer they describe is reinterpreted here as the laminate layer (layer 2) of the spore wall. The outer sloughing layer continuous with the wall of the saccule neck (layer 1) and the inner laminate layer (layer 3) of the spore wall were 
not described. The other two 'membranous' layers are synonymous with the first (iw1) and second (iw2) flexible inner walls, each of which is clearly bilayered.

Spores of the A. spinosa isolate WV861A have a narrower size range $(140-180 \mu \mathrm{m})$ than those reported by the holotype of Walker and Trappe (1981), which were 100-298 $\times 100-335 \mu \mathrm{m}$ in diameter. Subcellular structure of spores also is interpreted differently. Walker and Trappe (1981) misinterpreted the outer layer (layer 1) of the spore wall as an amorphous material encrusting the spines of the second (laminate) layer, a condition commonly observed as this layer degrades on mature spores. The thin inner layer (layer 3) of the spore wall was not described. The 'two membranous hyaline walls' are synonymous with the first (iw1) and second (iw2) bilayered flexible inner walls reported in this paper. The light pink to purplish-pink reaction of the inner layer of iw2 in Melzer's reagent was not described in the protologue.

Spores of E. colombiana CL356 were larger $(130-160 \mu \mathrm{m})$ than those of the holotype described by Schenck et al. (1984), which were 100-115 $\mu \mathrm{m}$ in diameter. Subcellular structure of the spore conforms to the description except that the 'outer spore wall' and 'wall two' are reinterpreted as layers 1 and 2 of the spore wall, 'wall three' is the first inner wall (iw1), and 'wall four' and 'wall five' are layers of the second inner wall (iw2).

\section{DISCUSSION}

The developmental sequences observed in spores of the Acaulospora and Entrophospora species examined in this study parallel those in all other genera of Glomales in which functionally distinct subcellular structures differentiate separately, but interdependently, in a linear sequence: spore wall component layers form concomitant with spore expansion from outer to inner surface. Only after the spore wall is formed and expansion has ceased does the sequential differentiation of two bilayered inner flexible walls occur. As a result, spores appearing to be mature under a dissecting microscope may contain a mixture of any or all developmental stages involving formation of flexible inner walls. A similar pattern is found with Scutellospora species (Franke and Morton, 1994; Morton, 1995), the only other genus with true flexible inner walls. Formation of a germination orb is the terminal event in spore ontogenesis, and occurs only after all other walls are fully differentiated. The germination orb is structurally, positionally, and functionally similar to the germination shield formed in spores of Scutellospora (Gigasporaceae) species, but the orb is evolutionarily analogous because it fails tests of similarity that establish hypotheses of homology (Patterson, 1982; Wagner, 1989) in that: (i) the spore within which it is synthesized is formed uniquely; and, (ii) earlier stages of spore ontogenesis involve different structures (spore wall with additional layers, an inner flexible wall with unique properties). The rarity of germination orbs in newly mature spores also is in direct contrast to abundant shield formation in spores of most Scutellospora species. Spain (1992) finds a visible germination orb most frequently in older spores in which the contents have undergone some plasmolysis.

Each of the major structures formed during differentiation (spore wall, flexible inner walls) resolved taxa at different taxonomic levels. Species-level differences resided solely with properties of the spore wall (color, size, ornamentation patterns, etc.). A similar pattern is evident among fungal species in Gigasporaceae (Bentivenga and Morton, 1995; Morton, 1995) and Glomaceae (Stürmer and Morton, 1997), indicating universality within Glomales. Properties of layers of flexible inner walls differed between species examined, but each phenotype is shared by two or more species in each genus and therefore group species into supraspecific taxa not 
delimited in the current classification. The conservativeness of different flexible inner wall properties also grouped species of Scutellospora together (Morton, 1995), suggesting this pattern also is universal within Glomales.

The two flexible inner walls in spores of the species in the present study consisted of two layers that appeared to differentiate sequentially rather than concurrently. This pattern is evidenced by the gradual change in the inner layer of the second flexible inner wall of $E$. colombiana in Melzer's reagent, shifting from non-reactive to dark red-purple at full maturity. Differentiation of bilayered walls in Acaulosporaceae is similar to that in spores of Scutellospora, the other genus in Glomales forming inner walls (Franke and Morton, 1994; Morton, 1995). Ultrastructural observations (Mosse, 1970c) appear to support this pattern. Mosse (1970c) was able to resolve the various layers of the spore wall and to show that the two layers of at least one flexible inner wall (iw2) formed sequentially rather than concurrently. In most ultrastructural studies, however, details of flexible structures like inner walls are confounded by fixation difficulties (Maia and Kimbrough, 1993).

The phylogenetic relationship between Acaulosporaceae and other families in Glomales differs with the character set used. Morphological data of the whole fungus indicate this family is more closely related to Glomaceae than Gigasporaceae (Morton, 1990). Sequence data of genes for the small-subunit rRNA, in contrast, suggests Acaulosporaceae is a sister group of Gigasporaceae (Simon et al., 1993; Simon, 1996). Ontogenetic evidence in this study provides some clues to help resolve the conflict, but also raises additional questions because the Acaulosporaceae has many unique traits as well as some traits that are similar to those of both other families.

The sporiferous saccule has obvious glomus-like properties and branches to form glomus-like spores in primitive taxa that also form a Glomus synanamorph, such as Acaulospora gerdemannii (Morton et al., 1997) and Glomus gerdemannii (Dr. J.B. Morton, personal communication). The saccule has no apparent function in spore development. Mosse (1970a) described the contents of the saccule as migrating to the spore as the saccule collapsed and the spore formed. However, DAPI-stained nuclei of saccules with attached spores shows that many nuclei do not migrate as spores differentiate (Dr. J.B. Morton, personal communication).

The outer layer of the spore wall is transitory in both Acaulosporaceae and Glomaceae. All subsequent layers of the spore wall are newly formed during spore expansion and differentiation. In Glomaceae, layers of the subtending hypha differentiate concurrently with layers of the spore wall (Stürmer and Morton, 1997). In Acaulosporaceae, additional spore wall layers are formed only within the spore and in the region of attachment to the neck of the sporiferous saccule. In contrast, both layers of the spore and subtending hyphal walls in fungi of Gigasporaceae are present in the most juvenile stages and differentially thicken in the spore during later stages of spore wall differentiation (Franke and Morton, 1994; Bentivenga and Morton, 1995; Morton, 1995).

Superficially, the flexible inner walls of Acaulospora and Entrophospora are similar to those in spores of Scutellospora, but such similarities are interpreted as convergent design constraints imposed on structures of identical function. Some differences exist, however, between genera in Acaulosporaceae and Scutellospora. Only two flexible inner walls consistently are formed in the former, but the number ranges from one to three in the latter (Bentivenga and Morton, 1996). Layers of each inner wall also are more divergent in their 
properties among Scutellospora species. In spores of all species in Acaulosporaceae compared to date, layers of the first inner wall (iw1) are thin and of similar thickness and do not react in Melzer's reagent. The outer layer of the second inner wall (iw2) is uniquely "beaded" (Morton, 1990), even though some descriptions would indicate otherwise (e.g., Sieverding and Toro, 1987; Wu et al., 1995).

This array of both similar and unique properties among families in Glomales does not provide the definitive solutions to resolving evolutionary questions in Glomales. Other data sets should be examined such as life history traits (Biermann and Linderman, 1983), other molecules such as sterols (Weete and Gandhi, 1998) or fatty acids (Bentivenga and Morton, 1996), other structural components such as cell wall carbohydrates (Gianinazzi et al., 1994) and most especially sequences of genes other than those coding for the small rRNA subunit (Simon et al., 1993; Simon, 1996).

\section{LITERATURE CITED}

Bentivenga, S.P., and J.B. Morton. 1995. A monograph of the genus Gigaspora, incorporating developmental patterns of morphological characters. Mycologia 87:719-731.

Bentivenga, S.P., and J.B. Morton. 1996. Congruence of fatty acid methyl ester profiles and morphological characters of arbuscular mycorrhizal fungi in Gigasporaceae. Proceedings of the National Academy of Sciences of USA 93:5659-5662.

Biermann, B., and R.G. Linderman. 1983. Use of vesicular-arbuscular mycorrhizal roots, intraradical vesicles and extraradical vesicles as inoculum. New Phytologist 95:97-105.

Franke, M., and J. Morton. 1994. Ontogenetic comparisons of arbuscular mycorrhizal fungi Scutellospora heterogama and Scutellospora pellucida: Revision of taxonomic character concepts, species descriptions, and phylogenetic hypotheses. Canadian Journal of Botany 72:122-134.

Gerdemann, J.W., and J.M. Trappe. 1974. The Endogonaceae of the Pacific Northwest. Mycologia Memoir 5:1-76.

Gianinazzi-Pearson, V., M-C. Lemoine, C. Arnould, A. Gollote, and J.B. Morton. 1994. Localization of $B 1,3$ glucans in spore and hyphal walls of fungi in the Glomales. Mycologia 86:478-485.

Maia, L.C., and J.W. Kimbrough. 1993. Ultrastructural studies of spore walls of Acaulospora morrowiae and A. scrobiculata. Mycoogical Research 97:1183-1189.

Morton, J.B. 1990. Evolutionary relationships among arbuscular mycorrhizal fungi in the Endogonaceae. Mycologia 82:192-207.

Morton, J.B. 1995. Taxonomic and phylogenetic divergence among five Scutellospora species based on comparative developmental sequences. Mycologia 87:127-137.

Morton, J.B. 1996. Redescription of Glomus caledonium based on correspondence of spore morphological characters in type specimens and a living reference culture. Mycorrhiza 6:161-166.

Morton, J.B., and G.L. Benny. 1990. Revised classification of arbuscular mycorrhizal fungi (Zygomycetes): A new order, Glomales, two new suborders, Glomineae and Gigasporineae, and two new families, Acaulosporaceae and Gigasporaceae, with an emendation of Glomaceae. Mycotaxon 37:471-491.

Morton, J.B., S.P. Bentivenga, and W.W. Wheeler. 1993. Germ plasm in the International Collection of Arbuscular and Vesicular-arbuscular Mycorrhizal Fungi (INVAM) and procedures for culture development, documentation and storage. Mycotaxon 48:491-528. 
Morton, J.B., J.D. Bever, and F.L. Pfleger. 1997. Taxonomy of Acaulospora gerdemannii and Glomus leptotichum, synanamorphs of one anamorphic fungus in Glomales. Mycological Research 101:625-631.

Mosse, B. 1970a. Honey-coloured, sessile Endogone spores I. Life history. Archives of Mikrobiology 70: 167-175.

Mosse, B. 1970b. Honey-coloured, sessile Endogone spores: II. Change in fine structure during spore development. Archives of Mikrobiology 74:129-145.

Mosse, B. 1970c. Honey-coloured, sessile Endogone spores. III. Wall structure. Archives of Mikrobiology 74:146-159.

Patterson, C. 1982. Morphological characters and homology. Pp. 21-74. In: Problems of phylogenetic reconstruction. Eds., K.A. Joysey, and A.E. Friday. Academic Press, London.

Schenck, N.C., J.L. Spain, E. Sieverding, and R.H. Howeler. 1984. Several new and unreported vesicular-arbuscular mycorrhizal fungi (Endogonaceae) from Colombia. Mycologia 76:685-699.

Sieverding, E., and Toro, S.T. 1987. Acaulospora denticulata sp. nov. and Acaulospora rehmii sp. nov. (Endogonaceae) with ornamented spore walls. Angew. Botanik 61:217-223.

Simon, L. 1996. Phylogeny of the Glomales: deciphering the past to understand the present. New Phytologist 133:95-101.

Simon, L., J. Bousquet, R.C. Levesque, and M. Lalonde. 1993. Origin and diversification of endomycorrhizal fungi and coincidence with vascular land plants. Nature 363:67-69.

Spain, J. 1992. Patency of shields in water mounted spores of four species in Acaulosporaceae (Glomales). Mycotaxon 43:331-339.

Stürmer, S.L., and J.B. Morton. 1997. Developmental patterns defining morphological characters in spores of four species in Glomus. Mycologia 89:72-81.

Wagner, G.P. 1989. The origin of morphological characters and the biological basis of homology. Evolution 43:1157-1171.

Walker, C., and J.M. Trappe. 1981. Acaulospora spinosa sp. nov. with a key to the species of Acaulospora. Mycotaxon 12:515-521.

Walker, C., L.E. Reed, and F.E. Sanders. 1984. Acaulospora nicolsonii, a new endogonaceous species from Great Britain. Transaction of British mycological Society 82:360-364.

Weete, J.D., and S.R. Gandhi. 1998. Sterols of the phylum Zygomycota: Phylogenetic implications. Lipids 32:1309-1316.

Wu, C-.G., Y-.S. Liu, and L-.L. Hung. 1995. Spore development of Entrophospora kentinensis in an aeroponic system. Mycologia 87:582-587. 


\section{Phase I}

Phase II

Phase III

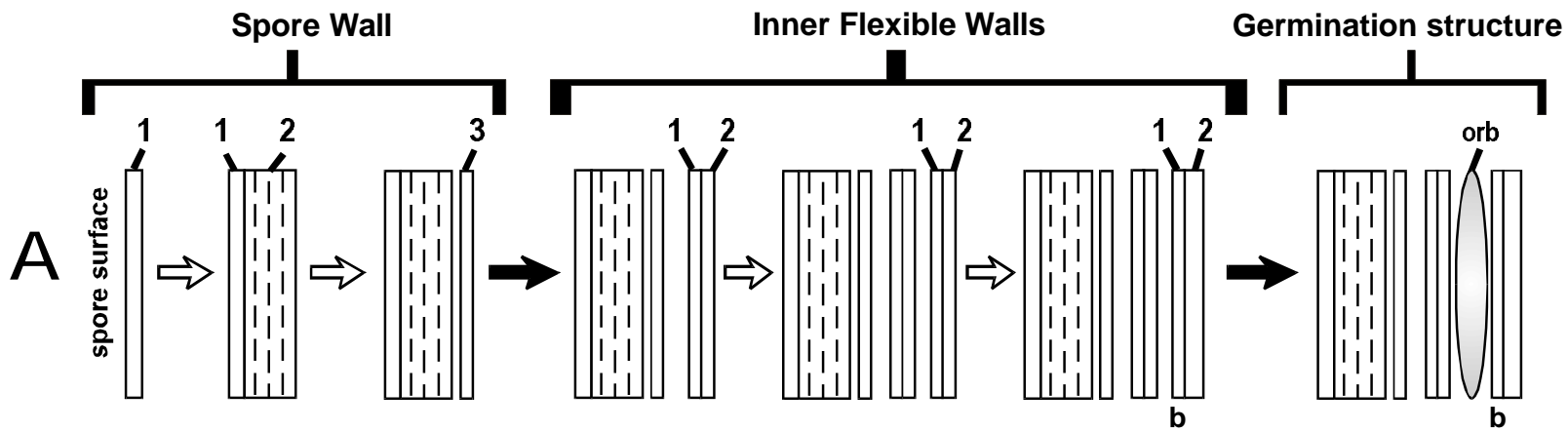

Stage 1 Stage 2 Stage 3

\section{Stage 4}

Stage 5

Stage 6

Stage 7

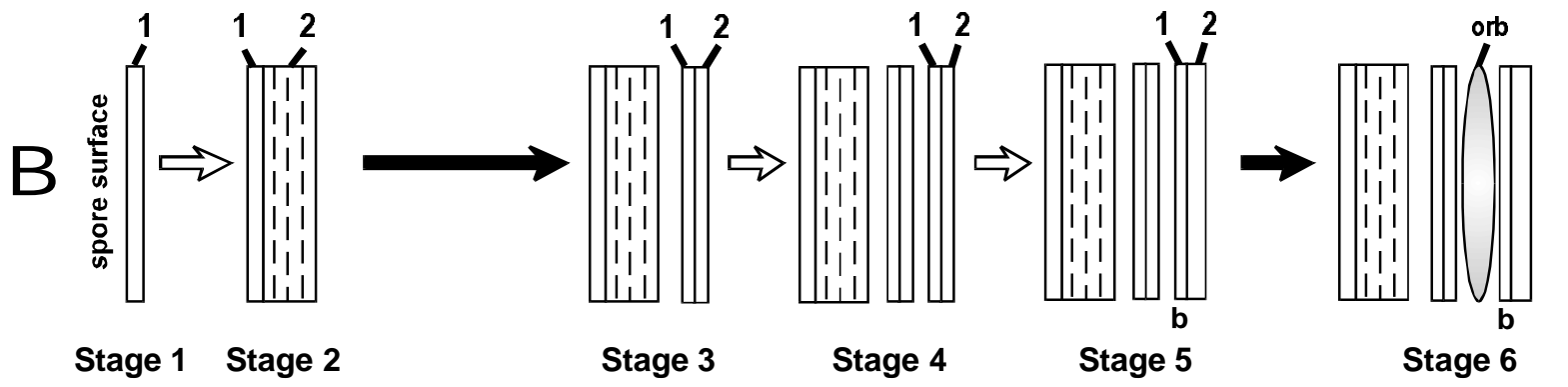

Fig. 1 Murographic representation of the sequence of development of layers in spores of (A) Acaulospora laevis and A. spinosa, and (B) Entrophospora colombiana. Numbers represent phenotypically discrete layers designated numerically in the order they were synthesized in each separate structure. Dashed vertical lines filling rectangles represent sublayers of a laminate layer present forming the spore wall. Filled arrows indicate transition between phases identified by differentiation of a spore wall, inner flexible walls and a germination structure; hollow arrows indicate transitions between discrete and stable stages during spore development. $\mathrm{b}=$ "beaded" layer. 

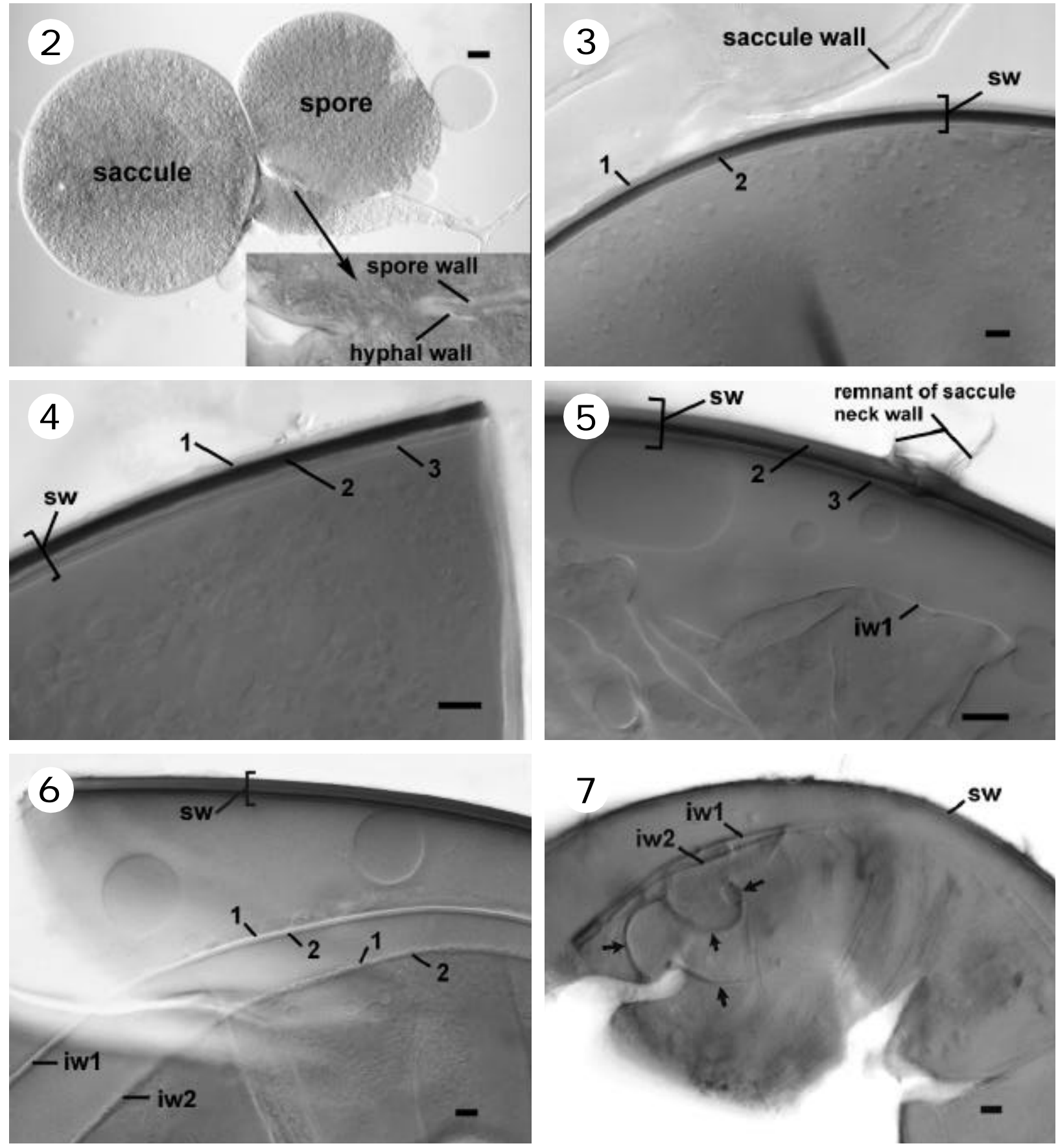

Figs. 2-7 Acaulospora laevis AU211 - stages in the differentiation of spore wall and inner walls layers in spores mounted in PVLG + Melzer's reagent $(1: 1, \mathrm{v} / \mathrm{v})$. 2. Most juvenile spore (stage 1) with spore attached to the side of the neck of the sporiferous saccule. Spore wall is formed by only one layer continuous with the hyphal wall of the saccule neck (insert). Bar $=25 \mu \mathrm{m}$. 3. Juvenile spore (stage 2) with spore wall (sw) composed of an outer layer (1) and an inner orange-brown laminate layer (2). Bar $=5 \mu \mathrm{m}$. 4. Juvenile spore (stage 3) with the spore wall (sw) completely differentiated and formed by an outer layer (1), an orange-brown laminated layer (2) and a colorless laminate layer (3). Bar = $10 \mu \mathrm{m}$. 5. Stage 4 of spore development characterized by the presence of the first inner wall (iw1). Bar $=10 \mu \mathrm{m}$. 6. Spore in stage 6 showing the first (iw1) and the second (iw2) inner wall each formed by two adherent layers ( 1 and 2 ). Bar $=5 \mu \mathrm{m}$. 7. Mature spore (stage 7) showing the germination orb (arrows) formed between iw1 and iw2. Bar $=10 \mu \mathrm{m}$. 

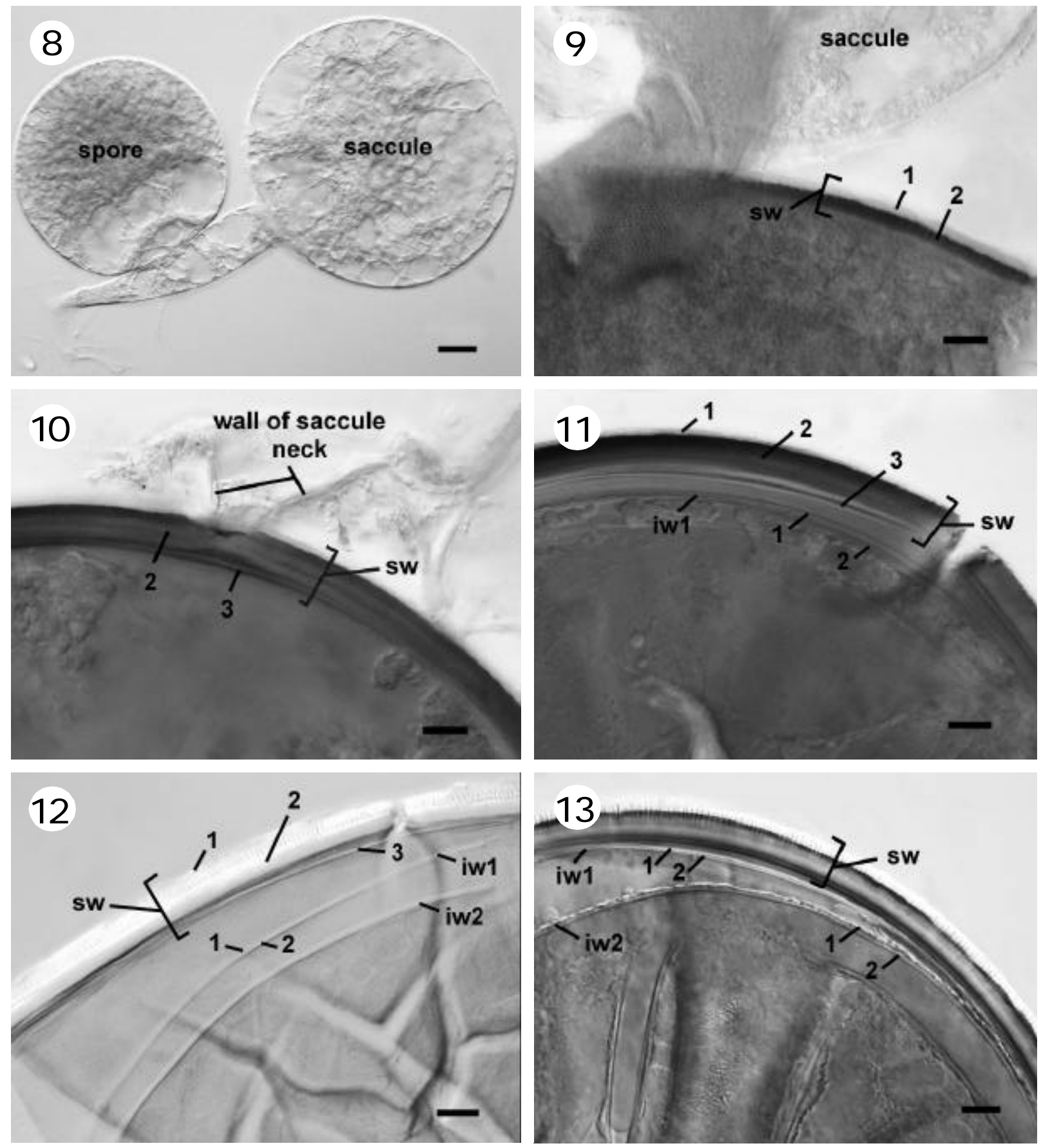

Fig. 8-13 Acaulospora spinosa WV861A - stages in the differentiation of spore wall and inner walls layers in spores mounted in PVLG + Melzer's reagent (1:1, v/v). 8. Most juvenile spore (stage 1) with spore wall formed by only one layer continuous with the neck of the sporiferous saccule. Bar $=25 \mu \mathrm{m}$. 9. Juvenile spore (stage 2) with spore wall composed by an outer layer (1) and the first sublayers of a laminate layer (2) ornamented with spiny projections. Bar $=10 \mu \mathrm{m} .10$. Juvenile spore (stage 3 ) with additional sublayers in layer 2 and a third thin layer (3) formed. Bar $=10 \mu \mathrm{m}$. 11. Juvenile spore (stage 4) with a fully differentiated spore wall (sw) and the first inner wall (iw1) synthesized and formed by two layers (1 and 2). Bar $=10 \mu \mathrm{m}$. 12. Mature spore (stage 5) showing the spore wall (sw), the first bilayered inner wall (iw1) and the second inner wall (iw2) formed by two thin adherent layers. Bar $=$ $10 \mu \mathrm{m}$. 13. Mature spore (stage 6) showing iw2 completely differentiated. The first layer (1) now is "beaded" and the second (2) reacts in Melzer's reagent turning pinl to purplish-pink. Bar $=10 \mu \mathrm{m}$. 

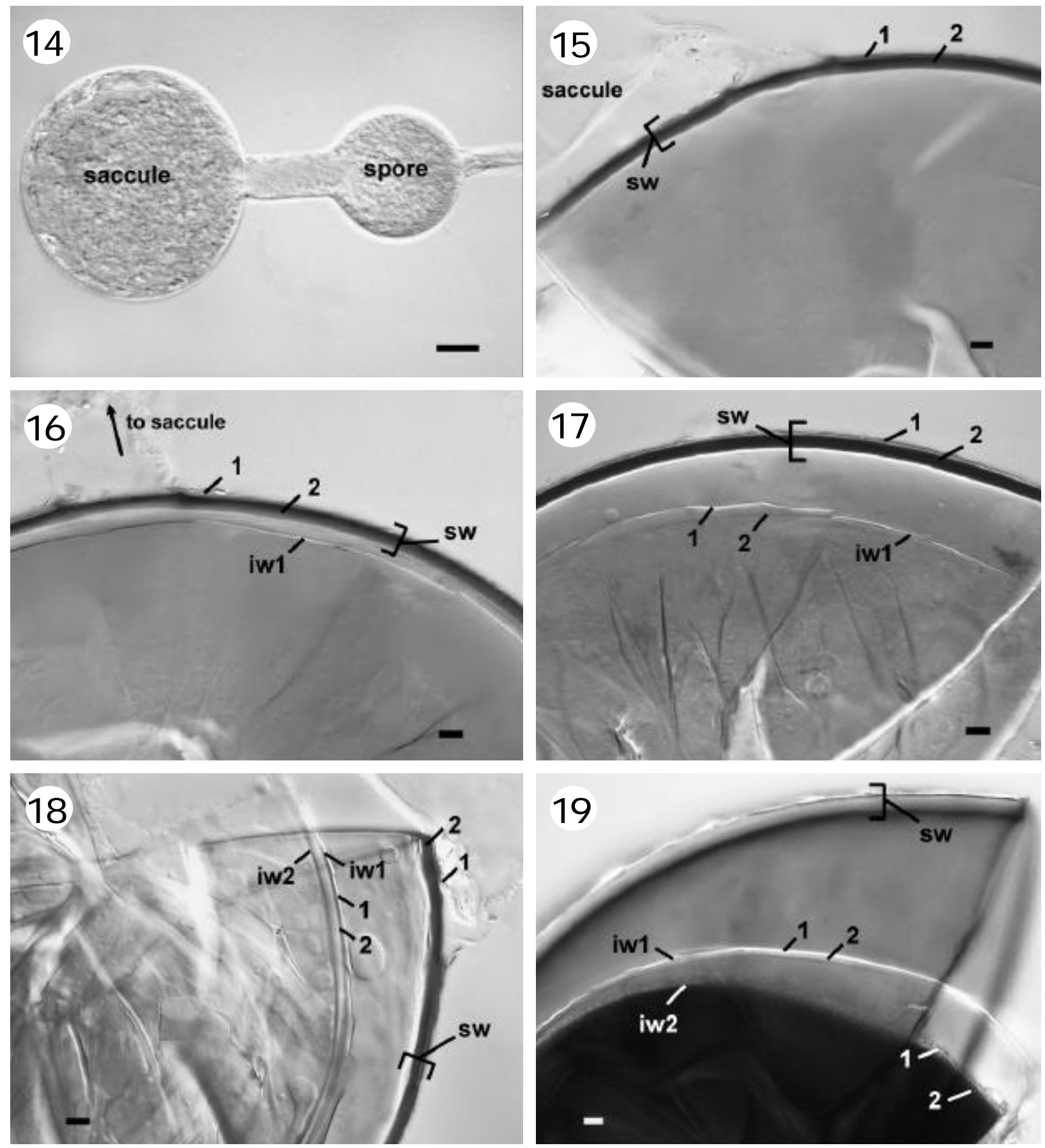

Figs. 14-19 Entrophospora colombiana CL356 - stages in the differentiation of spore wall and inner walls layers in spores mounted in PVLG + Melzer's reagent (1:1, v/v). 14. Most juvenile spore (stage 1) with spore wall formed by a layer continuous with the neck of the saccule. Bar $=30 \mu \mathrm{m}$. 15. Juvenile spore (stage 2) with spore wall consisting of an outer layer (1) and a pale to dark orange-brown laminate layer (2). Bar $=5 \mu \mathrm{m}$. 16. Juvenile spore (stage 3 ) with fully developed spore wall and the first inner wall (iw1) formed by only one layer. Bar $=5 \mu \mathrm{m}$. 17. Spore with iw 1 fully differentiated and formed by two layers ( 1 and 2). Bar $=5 \mu \mathrm{m}$. 18. Spore in stage 4 of development with spore wall (sw), first inner wall (iw1) and second inner wall (iw2) each formed by two thin adherent layers. Bar $=5 \mu \mathrm{m}$. 19. Spore (stage 5) with iw2 fully differentiated showing the "beaded" outer layer (1) and the innermost layer (2) that turns dark red-purple in Melzer's reagent. Bar $=5 \mu \mathrm{m}$. 
CHAPTER THREE

\section{DIVERSITY OF ARBUSCULAR MYCORRHIZAL FUNGI \\ IN SELECTED HABITATS USING TRAP \\ CULTURES METHODOLOGY}




\section{INTRODUCTION}

Arbuscular mycorrhizal fungi (Zygomycetes, Glomales) are ubiquitous soil-borne organisms associated with plant roots in a variety of ecosystem worldwide. They have been reported in natural plant communities such as deserts, sand dunes, tropical forests, salt marshes and managed systems such as pastures, orchards and field crops (Brundrett, 1991). These organisms are ancient, as evidenced by their detection in roots of the fossil plant Aglaophyton dating from the Devonian period (Taylor et al., 1995). Molecular clock estimates based on the small-subunit rRNA sequence also support the origin of arbuscular fungi about 400 million years ago (Simon et al., 1993). Therefore, it is not surprising that glomalean fungi are present in most soils given the long geologic time they have had to co-evolve with plants and to disperse.

The diversity of AMF in many ecosystems has been measured with respect to host plants, seasonal variation, soil nutritional gradients, crop rotation and plant successional stages (Koske, 1987; Gemma et al., 1989; Anderson et al., 1984; Johnson et al., 1991a). The most widespread approach to measure and analyze species diversity of arbuscular mycorrhizal fungi $(\mathrm{AMF})$ is to recover, count and identify spores from the field. However, many problems are associated with this approach. First, spores recovered from the field usually are in low numbers and too parasitized for accurate species identification, especially those of Gigaspora and Glomus species. Second, only those fungi sporulating in the rhizosphere of a given plant at the time of sampling are recovered. It is not uncommon to find nonsporulating (cryptic) species colonizing plants in the field based on trap culture results (Bever et al., 1996; Stutz and Morton, 1996) and PCR products from field-collected roots (Clapp et al., 1995). Reliance only on spore counts from the field, therefore, usually underestimates species diversity of AMF in plant communities.

Trap cultures provide a non-molecular approach to baiting cryptic species of AMF present in plant communities. In the mycorrhizal literature, few diversity studies have incorporated this approach. Miller et al. (1985) recovered 14 species of AMF under apple plantations around the United States that were present only in pot cultures with Sorghum and Coleus. More recently, 23 species of AMF were detected from a $75 \mathrm{~m}^{2}$ region of a mown field with Sorghum trap cultures or field plants transplanted into trap cultures (Bever et al., 1996). In an arid ecosystem, Stutz and Morton (1996) recovered 15 more species than those detected in the field after three cycles of trap cultures. These data are limited and indicate a need to determine the applicability of trap cultures methods to bait AMF in a variety of ecosystems.

Diversity and distribution of AMF species have been explained mainly as a result of contemporary ecological processes acting upon the fungal or plant communities. Factors such as soil $\mathrm{pH}$, soil $\mathrm{P}$, temperature and plant host genotype often have been considered determinants of the distribution of AMF species at local or regional levels. For example, interpretation of the distribution of fungal species in a Cedar Creek grassland was attributed to different successional stages in a old field (Johnson et al., 1991a). Porter et al. (1987) observed differential occurrence of a Glomus sp. and Acaulospora laevis in Australia and concluded that soil $\mathrm{pH}$ was the main factor influencing distribution of these species. Historical processes such as speciation and dispersal have been largely ignored (Ricklefs and Schuluter, 1993).

Interpretation of the possible causal factors determining and maintaining AMF communities may be quite different when historical processes are considered (Morton et al., 1995). 
Separation of ecological factors from historical factors requires that comparisons are made among sites with similar habitats from distinct geographical regions (Ricklefs and Schuluter, 1993). Sand dunes represent one example of a habitat that may share similar plant communities and soil characteristics in widely separated areas. Koske and Tews (1987) calculated similarity coefficients between mycorrhizal communities of sand dunes in the U.S.A., Italy, Australia and Scotland and found values ranging from 0 (no similarity) up to 0.39 .

In this study, I measured the taxonomic diversity of arbuscular mycorrhizal fungi in different plant communities. Baiting methods were used to recover fungi from five geographically separated plant communities in the United States and from four sand dune sites from different countries. Species were recovered by successive trap cultures to induce sporulation of cryptic AMF species. I tested three hypotheses: (i) species diversity of AMF increases after successive trap culture cycles; (ii) taxa overlap among similar habitats; and, (iii) community structure of AMF will change from a broken stick model in the field to a log series model after two cycles of trap cultures.

Results provided additional data on the efficacy of trap culture methodologies to measure fungal community structure in different ecosystems. Moreover, additional information on AMF species distribution important for assessing biogeographical data were obtained.

\section{MATERIAL AND METHODS}

\section{AMF in Five Soils}

\section{Study sites}

Species diversity of AMF were measured at five sites within the United States representing different habitats. A site in California (CA-D) was from a desert sampled at Harper's Well near the Anza-Borrego Desert State Park in Imperial County (collected by Dr. J. Stutz, Arizona State University). Soil was collected under the rhizosphere of mesquite Prosopis glandulosa Torr. Another site from California (CA-R) included a revegetated site with no management in Shasta County (collected by Dr. Vic Claassen, University of California). The plant community at this site was dominated by black oak Quercus kellogii Japson and poison oak Ceonothus lemonii Parry with an understory of wild oats Bromus mollis L. A site in Kansas (KS) at the Konza Prairie Research Natural Area in Riley County consisted of a natural tallgrass prairie community (collected by Dr. G. Wilson, Kansas State University). Dominant plant species were big bluestem Andropogon gerardii Vitm., prairie cordgrass Spartina pectinata Link and indian grass Sorghastrum nutans (L.) Nash. In Minnesota (MN), an agricultural plot was sampled at the University of Minnesota Southwestern Experiment Station at Redwood County (collected by Dr. F.L. Pfleger, University of Minnesota). The site has been cultivated continuously with corn for over 10 years. The last site was an abandoned mine site at the Coopers Rock State Forest, Monongalia County in West Virginia (WV) (collected by me). Soil was sampled under Andropogon virginicus L. with other plant species present being red maple Acer rubrum Torr \& Gray ex K. Koch and black birch Betula lenta L. At each site, three plants present in a $100 \mathrm{~m}^{2}$ area were pulled out from the soil and the rhizosphere soil shaken into a plastic bag. This sample therefore consisted of soil from the root zone and some detached fine roots. Soil chemical properties and environmental conditions for each site are shown in Table 1. 


\section{Experimental procedure}

Pooled sample from each site was diluted 1:1 (v:v) with a sterile potting medium consisting of a sandy loam soil (Lily series) premixed with quartzite sand $(1: 2, \mathrm{v} / \mathrm{v})$. This mixture was placed in 15-cm diameter plastic pots and each seeded with 50-60 seeds of sudangrass, Sorghum sudanense (Piper) Staph. For alkaline soils (CA-D- and KS), the final soil $\mathrm{pH}$ of the potting medium was 7.2, while for more acid soils, the potting medium $\mathrm{pH}$ was 6.2. Three pots were set up with soil inocula from each site. Plants were grown in a growth room under fluorescent lights with a photon flux density of $245 \mu \mathrm{mol} \mathrm{m} \mathrm{m}^{-2}$ at pot level, a 14hour photoperiod, and an ambient temperature of $21-28^{\circ} \mathrm{C}$. After 3 months, watering was suspended and pot contents were dried in situ for 8-14 days. Shoots were excised and two 50 $\mathrm{cm}^{3}$ soil aliquots was sampled from each pot and stored at $4^{\circ} \mathrm{C}$ until processing. The root ball and attached soil for each pot was manually chopped and the contents of all three pooled, mixed and stored at $4^{\circ} \mathrm{C}$ for at least one month. A second trap culture cycle was started by mixing stored inocula with $300 \mathrm{~cm}^{3}$ of sterile potting media. Host and seeding rates were the same as in the first trap cycle, and plants were grown for another 3 months-period under similar growth-room conditions. At harvest, cultures were processed similarly. Three pots containing only sterile potting media seeded with sudangrass were interspersed between trap cultures in each cycle to monitor for possible air-borne contamination.

\section{Infectivity Assay}

Infectivity of fungi in the field soil and at the end of each trap cycle was measured by the mean infection percentage (MIP) assay (Moorman and Reeves, 1979). For trap cultures, $100 \mathrm{~cm}^{3}$ was sampled after the three replicate pots were pooled. Soil samples were mixed $(1: 1$, $\mathrm{v} / \mathrm{v}$ ) with the same potting media described above and placed in $50 \mathrm{~cm}^{3}$ cone-tainers TM (Stuewe and Sons, Inc., Corvallis, Oregon). Three red clover (Trifolium pratense L.) seedlings, pre-germinated in sterile soil, were transplanted into each cone-tainer and watered with a suspension of Rhizobium trifolii (LiphaTec, Inc., Milwaukee, Wisconsin). Four cone-tainers were set up for each soil and plants were harvested after 4 weeks. Roots were gently separated from the soil, washed, and stained using the method of Koske and Gemma (1989). Infectivity was assessed as percentage of mycorrhizal colonization by the grid-line intersect method (Giovannetti and Mosse, 1980).

\section{Spore Extraction}

Spores were extracted from $50 \mathrm{~cm}^{3}$ of soil from the field or from each trap pot by blending in two 10-second bursts and passing this material through nested sieves with 500 and $45 \mu \mathrm{m}$ openings. Material retained on the $45 \mu \mathrm{m}$ sieve was transferred to a $50 \mathrm{~cm}^{3}$ tube containing a 20/60\% sucrose gradient and centrifuged at $900 \mathrm{x} g$ for 1 minute. Supernatant was passed through a $45 \mu \mathrm{m}$ sieve and the material retained was washed under tap water for at least 30 seconds and transferred to a Petri dish. Under the dissecting microscope, spores of each morphotype were collected and counted separately. Spores also were mounted on glass slides in PVLG (Polyvinyl alcohol, lactic acid, glycerol) and PVLG mixed with Melzer's reagent for identification and preservation as voucher specimens. 


\section{AMF in Sand Dunes}

\section{Study sites}

Diversity of AMF species was measured in sand dune habitats in different geographical regions. Samples were obtained from four countries on separate continents. In the United States, sand dune samples were collected from Ammophila breviligulata Fern. at Bass River Beach, Massachusetts (collected by Dr. Joseph Morton, West Virginia University). In Brazil, a sample was collected from Spartina ciliata Brongn. in Joaquina Beach, Santa Catarina state (collected by Dr. Margarida de Mendonça, Universidade Federal de Santa Catarina). In the Netherlands, samples were obtained from Ammophila arenaria (L.) Link growing in the sand dunes of the Island of Terschelling (collected by Dr. Thomas Kuyper, Wageningen Agric. University). In Japan, samples came from Elymus mollis Trin. growing at Hasaki Beach, Ibaraki Prefecture (collected by Dr. Jun-ichi Abe, University of Tsukuba). At each site, rhizosphere soil was collected from three separate plants in a $100 \mathrm{~m}^{2}$ area. Plants were pulled out from the soil and roots shaken to remove attached soil into a plastic bag, which also included some detached fine root fragments. All samples were collected between September and October, 1996, dried and shipped to Morgantown, WV. Soil chemical properties and environmental conditions of each site are summarized in Table 2.

\section{Experimental procedure}

Field samples from sand dunes were mixed 1:1 (v/v) with sterile quartzite sand (average grain size $=0.9 \mathrm{~mm}$ ) and placed in $15-\mathrm{cm}$ diameter plastic pots. Sudangrass was seeded in each pot at a rate of 50-60 seeds per pot and seeds covered with a 2-cm layer of sterile sand. Three pots were set up for each site and plants were grown in a growth room under conditions described above. Three additional pots containing only sterile sand were placed randomly among other pots to check for air-borne contamination. Plants were fertilized when needed with a 25-5-20 (N-P-K) solution. After 3 months, shoots were removed and two sand samples (ca. $250 \mathrm{~cm}^{3}$ after pooling) from opposite sides of each pot were collected and stored at $4^{\circ} \mathrm{C}$ until processing. Empty portions of the pots after sampling were filled with sterile sand and each pot was reseeded for a second propagation cycle. Spores were extracted and processed as described previously. In this experiment, two different approaches relative to experiment 1 was taken: (i) pot contents were not disturbed between propagation cycles to avoid major breakdown of the fungal hyphal network established in the soil; and, (ii) pots were individualized in the sense that spore counts and identification and infectivity assay were done in the same pot in both propagation cycles.

\section{Infectivity Assay}

Infectivity of fungal propagules (hyphae, roots, spores) was measured in the field soil and after each trap culture cycle by the mean infection percentage (MIP) assay (Moorman and Reeves, 1979). Samples from the field and from each trap culture were diluted (1:1, v/v) with sterile quartzite sand and placed in 100-ml plastic cone-tainers. Each cone-tainer was sown with three surface-sterilized seeds of sudangrass and thinned to one plant after emergence. Each assay consisted of four replicate cone-tainers and plants were grown for 3 weeks under growth room conditions as described previously. Harvested roots were stained and fungal colonization measured as described previously. In order to statistically measure any relationship between mycorrhizal infectivity and number of spores and species, pots were assayed separately. 


\section{Statistical Analyses}

The number of spores produced for each species in the field and after two propagation cycles was plotted in a species rank-log abundance graph to depict fungal community structure. The curves were tested against theoretical curves of the log series and the broken stick models according to the procedures explained by Magurran (1988). Two goodness-of-fit tests were used: the log likelihood ratio, or G test (Sokal and Rohlf, 1981) and the Kolmogorov-Smirnov test (Tokeshi, 1983). The number of species recovered in each habitat was low and precluded a more accurate testing of these models, therefore, for each experiment, number of species recovered in the field and in the second trap culture was pooled from all habitats. Before analysis of variance of the infectivity assay, data on percentage of colonization were transformed using the arcsine square root transformation and screened for homogeneity of variance using Levene's test. A t-test then was used for comparison of group means. Linear regression was used to determine if number of spores and species number were a good predictor of the mycorrhizal infectivity levels obtained on trap cultures. Stepwise regression was used to determine which soil or environmental factors was influencing most the number of AMF species. Hierarchical cluster analysis was performed on the soil and environmental characteristics of sand dunes samples through the application of the average linkage method. Statistical tests were performed using $\mathrm{JMP}^{\circledR}$ (SAS, 1995)

\section{RESULTS}

\section{Species diversity in five soils}

For most soils, the number of sporulating species of AMF did not increase after the first trap culture cycle (Fig. 1). In the Kansas soil, however, three additional species sporulated in the second trap culture. Only one species sporulated in the first trap cycle in the soils from the desert site in California and the Kansas site. For all other soils, the first cycle of trap culture detected $33-46 \%$ of the total number of species recovered. No spores were detected in the control pots.

In total, 30 AMF species were detected, 13 of which could not be placed into described taxa (Tables 3-6). Fungi in the families Glomaceae and Acaulosporaceae were detected in $100 \%$ and $80 \%$ of the soils, respectively. The family Gigasporaceae was represented by only one species, Scutellospora calospora, which was detected only from the revegetated site from California (Table 3). At the genus level, Glomus was dominant in both number of species in each trap culture and in abundance of spores. The most common species sporulating in three of the five soils were Glomus intraradices, Glomus occultum and Glomus microaggregatum. For all soils, total number of spores tended to increase from the field to the first trap culture and declined thereafter.

The number of species detected in each soil varied according to the habitat (Tables 3-6). The soil from the California desert represents one extreme where only G. microaggregatum was detected. This species sporulated so prolifically after the first cycle that spore counting was done by dilution; number of spores reached 50,022 \pm 11,622 (mean \pm standard error) per $30 \mathrm{ml}$ of soil. At the other extreme were soils from Kansas and Minnesota where 10 and 13 species were detected, respectively.

Similarity among AMF species for all five soils ranged from no similarity at all up to 0.26 (Table 7). Highest similarity was found between the sites in Minnesota and Kansas 
$(\mathrm{C}=0.26)$ and between the two sites in California $(\mathrm{C}=0.25)$. The five habitats did not share any common plant species and therefore the similarity among habitats considering plant community was zero.

The structure of AMF communities in the field and after two propagation cycles approached a log series model (Fig. 2). Testing the curves against theoretical models shows that both curves are significantly different from the broken stick model, but not different from the log series model using the $\mathrm{G}$ test or the Kolmogorov-Smirnov test.

\section{Infectivity in five soils}

Infectivity of mycorrhizal fungi followed the same trend in most soils: highest infectivity after the first trap culture followed by a decline in the second cycle of culture (Fig. 3). The West Virginia soil differed in that the lowest infectivity was observed in the first trap while infectivity was higher in the field and in the second trap culture cycle (Fig. 3). No statistical analyses were carried out to detect significant differences between means because of lack of replication.

\section{Species diversity in sand dunes}

Results from the average linkage method shows that the four sand dunes sites did not form only one cluster (Fig. 4). Sand dunes from U.S.A. and Brazil formed one cluster while dunes from Japan and Netherlands formed another cluster

Number of AMF species recovered in trap cultures exceeded that in the field and often reached a plateau after the first propagation cycle (Fig. 5). The Netherlands soil was exceptional in that three additional species sporulated during the second propagation cycle. No spores were detected in the field soil from Japan and only one and two additional species were detected in traps that were not present in the field soil for U.S.A. and Brazil, respectively (Fig. 5). Based on the total number of species detected at each site from all samples, trap cultures detected 15-30\% of AMF species in dunes of U.S.A. and Brazil and 75-100\% for dunes in Netherlands and Japan. No spores were detected in control pots.

Eighteen species of AMF were recovered in this study, three of which are putatively new species. Members of all three families of Glomales were detected in soils from Brazil and U.S.A., while only members of Glomaceae were detected in Netherlands and Japan (Tables 811). All species sporulating in trap cultures were in the genus Glomus, except the occurrence of A. trappei from the Brazil soil (Table 8). When present, spores of Scutellospora and Gigaspora species were detected in the field soil and were fewer in number after trapping. Glomus intraradices was the only species detected in all four sand dunes habitats. For all soils, total number of spores tended to increase from the field to the second trap culture cycle.

Coefficients of similarity between AMF communities indicated that dunes of Brazil and Japan shared the greatest number of species $(\mathrm{C}=0.40)$ followed by dunes of Japan and the Netherlands $(\mathrm{C}=0.36)$ (Table 12). However, coefficients of similarity for the plant communities of all four sand dunes habitats were zero.

The structure of AMF community in the field was not significantly different between the broken stick and the log series models (Fig. 6). However, the community structure of the second trap culture cycle fit only the log series model (Fig. 6). 


\section{Infectivity in dunes}

Infectivity did not differ significantly between individual pots within each propagation cycle. Therefore, data from the three pots were pooled to compare changes in infectivity between propagation cycles. Infectivity measured at the field soil and after each trap culture generation followed the same trend among soils: infectivity was low in the field and after the first trap culture and increased after the second trap culture (Fig. 7). Infectivity in the field and first trap ranged from $0.5 \%$ to $5.3 \%$. After the second cycle, trap from Japan had the highest infectivity (32.6\%) while traps from Brazil and U.S.A. had similar levels (Fig. 7).

\section{Regression models of fungal diversity in dunes}

Data for the sand dunes soils were pooled to carry out two types of analyses. First, the relation between total sporulation/species richness and infectivity within the same soil or propagation cycle. In further analysis, only spore number of the most abundant species for the sand dune habitats were examined. Second, the effect of infectivity on sporulation and species richness of the subsequent propagation cycle also was explored. Results of the second analyses, however, showed the same trend and therefore are not reported.

Within the same soil or propagation cycle, no significant relationship was observed between species richness and infectivity $\left(\mathrm{r}^{2}<0.01, \mathrm{P}=0.93\right)$ (Fig. 8), but total spore numbers accounted for about $52 \%$ of the variability in infectivity $\left(\mathrm{r}^{2}=0.52, \mathrm{P}<0.01\right)$ (Fig. 9).

The number of spores of Glomus clarum and G. pustulatum, separately or combined, was a good predictor of the infectivity levels for the U.S.A. soil (Table 13). The number of spores of $G$. intraradices alone or with other fungal species predicted infectivity levels of the Japanese soil. Infectivity for the site in Brazil was predicted only from spore numbers of Acaulospora scrobiculata (Table 13).

Stepwise regression could detect only mean annual temperature as a good predictor of the number of AMF species recovered in each soil $\left(\mathrm{r}^{2}=0.54, \mathrm{P}=0.02\right)$ (Table 14). Further analyses considering all possibel pairs of soil and environmental factors indicated that phosphorus (P) and potassium (K) paired account for $69 \%$ of the variability found in the number of species, followed by potassium/organic matter, and mean annual temperature/organic matter (Table 15).

\section{DISCUSSION}

Successive cycles of trap cultures led to the detection of AMF species not sporulating in a wide range of habitats. One or two propagation cycles were needed to detect these additional species, corroborating patterns observed in an old field in North Carolina (Bever et al., 1996) and arid sites of southwestern U.S.A. (Stutz and Morton, 1996). However, the number of cryptic species detected by trapping varied between habitats. For example, only Glomus microaggregatum was detected in the soil from Arizona whereas as many as six species were detected after two trapping cycles of dunes from the Netherlands and soils from Minnesota.

Disparity between sites clearly depends on the actual number of species present in the soil. However, sampling methodology also may have been a major limitation that influenced the number of species detected. Soil inoculum used to establish trap cultures consisted of rhizosphere soil and excluded a majority of plant roots. This approach could exclude fungal species that were growing predominantly within the roots or species whose propagules were 
infective only when attached to mycorrhizal roots. Moreover, rare species that sporulated infrequently or had limited growth within roots may have been excluded.

A much higher number of species is expected to be detected in the trap cultures than field soil if plant roots are a major component of the soil inoculum used to start trap cultures. Failing to consider this factor during sampling, therefore, can explain the disparity between the total number of AMF species found using trap cultures with that reported in the literature for the same habitats. Abe et al. (1994), sampling from the same area and host plant in Japan sand dunes, found $S$. gregaria and Acaulospora sp. sporulating in the field, two species that were not recovered by trap cultures. Stürmer and Bellei (1994) recovered 13 AMF species from Brazilian sand dunes, while only 7 species were detected in this present study. Also, only two additional species were detected in this study compared to 11 species found in a corn field by Johnson et al. (1991b).

Disparity on the number of species recovered among habitats also may depend on the extent to which culture conditions approximate those of source habitat. The low number of species recovered from the desert site in California was not expected. Stutz and Morton (1996) detected six to seven species after two cycles of trapping soils from a similar habitat in the same region. In their study, however, trap cultures were grown in a greenhouse at Arizona State University where light and temperature may more closely approximated site conditions than did the greenhouse at West Virginia University.

Light and temperature are dominant variables that impact plant growth, mycorrhizal colonization and fungal sporulation. Hayman (1974) observed that mycorrhizal colonization in onion roots was reduced and consisted of fewer arbuscules and external hyphal under lowered light intensity. Sporulation by an isolate of Glomus fasciculatum was greatest at $30^{\circ} \mathrm{C}$, which coincided with the optimum temperature for the host plant (Ferguson and Menge, 1982). Light conditions for trap cultures did not appear to be a limiting factor because sporulation by a wide range of INVAM fungal isolates on the same host used in this study consistently is adequate to high (Dr. J.B. Morton, personal communication). Temperature is more likely a critical variable if it influences the physiological activity of the propagules present in the original inoculum to initiate colonization (Sieverding, 1983). Temperature also can influence secondary mycorrhizal colonization so that certain species might not achieve that minimum level of colonization necessary to trigger sporulation (Franke and Morton, 1994) and, therefore, remain undetected. In the Californian desert soil, lower temperatures at the growth room relative to the field soil may have selected only G. microaggregatum to establish colonization. However, the largest differences between temperature at the field and growth room conditions of this study occurred for the Minnesota and Netherlands soil, where the highest number of species sporulating in trap cultures were detected (six species). This result suggests that higher temperatures in the growth room where traps were maintained could have activated propagules of certain species that were not sporulating in the field.

Temperature is certainly one of the major environmental factors influencing AMF species distribution in the field. Schenck and Schroder (1974) observed that sporulation and mycelia growth of a Gigaspora sp. was optimized at the higher temperatures within the range of temperatures tested. The authors correlated the affinity of the fungus for high temperature with its presence and abundance in summer rather than spring or winter crops. Koske (1987) observed that some AMF species were more abundant in northern cooler regions than in southern warmer regions within a latitudinal temperature gradient. He also found that 
frequency of some species such as Scutellospora weresubiae and Glomus tortuosum was correlated with higher temperatures. When each factor was considered alone in the present study, stepwise regression detected the mean annual temperature as the only factor explaining number of AMF species in each site, which supports the role of temperature on species diversity.

Soil factors also have been implicated as regulators of AMF species diversity. For example, Porter et al. (1987) found a correlation between soil $\mathrm{pH}$ and the occurrence of a Glomus sp. and Acaulospora laevis, the latter tending to dominate in more acid soils. Johnson et al. (1991a) found species richness to be positive correlated with total $\mathrm{P}$ in the soil and negative correlated with soil $\mathrm{pH}$, although the correlation coefficients were not significant. In the present study, phosphorus, potassium and organic matter could explain a great portion of the variability on AMF species richness. One of the possible reason for this correlation is the direct effect of these factors on plant growth, increasing the amount of root biomass and providing the niche necessary for more fungi to colonize and sporulate. Alternatively, it is well known that fertilization can limit fungal development within the roots. Thus, fertilization could limit colonization by more aggressive fungi so that other slow growing fungal species can colonize and sporulate as well under field conditions. In the literature, contradictory results are commonly found when the influence of soil factors upon species diversity is evaluated. One of the drawbacks to interpreting these result is that regression analyses may not reflect cause and effect relationships. Also, these analyses do not consider that species diversity is a function of historical processes that ultimate determine which species may be present in a given habitat, each with possibly their unique life history traits.

Sporulation of cryptic species in trap culture suggests that a minimum threshold level of fungal colonization in the roots may be necessary for sporulation to be triggered. Gazey et al. (1992) observed such a threshold for an isolate of Acaulospora laevis, which sporulated only after $5.7 \mathrm{~cm}$ of root was colonized. Similarly, Franke and Morton (1994) measured a minimum level of mycorrhizal root length necessary to trigger sporulation of Scutellospora pellucida and S. heterogama. This level seemed to vary with host species as well. Containerization of trap cultures favors accumulation of abundant root biomass in a confined space, which likely favors infection and colonization by cryptic species. Continuous growth and rapid turnover of plant roots in the field may impact the rate at each fungal species colonize the roots, so that only the more aggressive fungi are able to sporulate. Spatial heterogeneity within the rhizosphere environment also may account for lack of recovery of some species during sampling. Species not detected in field sampling in this study may be colonizing and sporulating in other regions of the plant rhizosphere that were excluded by the sampling regime. Seasonal variation on sporulation patterns by mycorrhizal species has been studied extensively (Gemma et al., 1989) and represents another possible reason for not detecting AMF species in the field. Trapping field soil collected over seasons (Bever et al., 1996) represents an alternative strategy to recover more species in a habitat when complete characterization of an AMF community is a goal.

In all habitats studied, Glomus species were the predominant sporulators in trap cultures. With few exceptions, most of the Glomus species were hyaline to light colored, with thin spore walls and small spores $(<150 \mu \mathrm{m}$ diameter). Species of Gigaspora and Scutellospora, when present, were detected sporulating in the field and number of spores decreased with successive trap culture cycles. Three hypotheses may explain this pattern. First, the genus Glomus circumscribes $56 \%$ of the described species in Glomales, and is widely 
distributed worldwide (INVAM Biogeography Database, unpublished), such a broad dispersal increases the probability of Glomus species being found in most plant communities. Second, genera differ greatly in types of infective propagules and the biology of mycorrhizal establishment. In Glomus, all parts of the fungus (spores, pieces of colonized roots and hyphal fragments in soil) are totipotent and capable of initiating colonization (Biermann and Linderman, 1983; Jasper et al., 1989). In Gigaspora and Scutellospora, conversely, only spores from disturbed soils are able to initiate new infections in roots (Biermann and Linderman, 1983; Pearson and Schweiger, 1994). Third, trap culture environment may be more conducive to colonization and sporulation of Glomus species given their broader range of infective propagules and lower demand on the host for carbon during sporulation. Spores of Gigaspora and Scutellospora tend to be larger in diameter than spores of Glomus and thus more carbon must be allocated by the plant to each spore of the former compared to the latter. As a result of the sampling regime, the level of infective propagules (spores) of Gigaspora and Scutellospora may have been diluted or excluded so that extensive root colonization and sporulation could not occur in trap cultures.

Infectivity bioassays measure the inoculum potential of mycorrhizal fungi and is the result of cumulative interactions between propagule density, host preference, and environmental variables conducive to colonization. Two trends were observed in infectivity assays carried out with field soil and soil at the end of each trap culture cycle: infectivity was greatest in the first trap culture cycle, decreasing in the second trap cycle of the five soils, whereas infectivity increased from field soils to the second trap cycles of sand dunes samples. Variation in culture regimes between soil and sand dunes experiments is the likely cause. For soils, contents of each pot culture were chopped and thoroughly mixed between propagation cycles. Mixing of soils in the first experiment undoubtedly disrupted established hyphal networks in each pot. Hyphae are more sensitive to disturbance than other propagules of mycorrhizal fungi (Jasper et al., 1989, 1991) and, therefore, such disruptions reduced inoculum potential. Moreover, spores contributed only a small proportion of the total infectivity, corroborating the role of hyphal networks in initiating colonization. In contrast, pot contents of sand dune cultures were left undisturbed from one propagation cycle to the next.

West Virginia soil was an exception to the general pattern among the five soils examined in that inoculum potential increased markedly from the first to the second culture cycle. Colonization in the bioassay plants was dominated by Glomus clarum. This fungus forms extensive thick-walled external mycelium that may be more tolerant to soil disturbance. If this is true, then fungal species composition may exert considerable influence on effects of soil disturbance.

The number of spores tended to be much higher in trap cultures established with the five soils than with sand dunes, which may be a consequence of the diluent soil used to establish trap cultures. A sandy loam soil:sand mixing was used in the first experiment with soils while pure quartzite sand was used in sand dune soils of the second experiment. Different diluents were used to mimic original soil conditions from each broad habitat. Higher number of spores in the first experiment thus may be a result of indirect effect of physical and chemical soil properties (nutrient levels, CEC, watering holding capacity, etc.) upon the plants rather than directly on the fungi. Sand as a diluent is low in nutrients and added nutrients are more likely to leach due to poor water retention capacity. One trap culture pot from a sand dune habitat was set up with soil as diluent and the number of spores was much higher than in sand, 
but the number of species was not affected (data not shown). Based on this result, the use of a soil-based medium for a diluent when setting up trap cultures is recommended, as its nutritional condition and buffering properties are conductive to plant and fungal growth.

The community structure, depicted by the species rank-log abundance curves, showed that AMF community in the second trap culture followed a log series model distribution in both experiments. This indicates that niche pre-emption by some more aggressive species takes place in trap cultures, which in turn leads to dominance of one or two species that sporulate prolifically. A log series model distribution suggests that trap cultures are selective for some fungal species and may limit detection of less aggressive or rare species. Niche pre-emption also may occur in the field as suggested by the community structure of field species in soils within the U.S.A. which fit only the log series model. In sand dunes, the field community fit both broken stick and log series model. Lack of statistical separation may partly be due to the relatively small numbers of species (12) available for analysis. With few species allocated to abundance classes detection of differences between observed and expected distribution becomes difficult (Magurran, 1988). Alternatively, AMF community structure in the field may fit a broken stick model because they are associated with slow grower plants that are found in isolated patches in the sand dunes. Therefore, niche pre-emption may not occur and less aggressive fungi also are able to colonize roots and sporulate. Species abundance models as depicted for AMF in this study must be viewed and interpreted carefully, as these models have been developed from study of animals where functional individuals are readily identified (Magurran, 1988). Arbuscular mycorrhizal fungi are modular organisms and their abundance is not reflected by spore numbers, although spores are the portion of the fungal organism used to identify and quantify a species. The rank-abundance models, however, can reflect indirectly carbon allocation by each species of fungus to sporulation (Morton et al., 1995; Stürmer and Bellei, 1994).

No relationship was observed between the number of AMF species and infectivity of propagules at the end of a propagation cycle. Results suggest that a community with a high species diversity is not needed for high inoculum potential in a given soil. Clearly, infectivity is more a function of the activity of total propagules and aggressiveness of species in a fungal community than the number of species. The lack of correlation in a wide variety of soil conditions and habitats indicates this phenomena may be widespread in natural systems.

In the present study, spore propagules accounted for $52 \%$ of the variability in infectivity assays. In Australia, spore numbers accounted for $37 \%$ of the variability in the infectivity assay from 21 soils from undisturbed and disturbed habitats (Brundrett et al., 1996). Spore counts of the most abundant species accounted for even more variability in total infectivity (see Table 13), suggesting that the most prolific sporulators in some soils may be responsible for most of the initial fungal propagules. For example, the two most abundant species in the U.S.A. soil accounted for $79-85 \%$ of the infectivity, although this relationship must be interpreted cautiously because this significant relation was caused by only one data point in the analyses. While the contribution of spores is important, a large proportion of infectivity must be caused by other infective propagules such as extraradical mycelium and colonized root pieces.

In some soils, a high number of spores was not accompanied by high infectivity. Spores may not have germinated readily and, therefore, would not take part in early root colonization. Alternatively, high sporulation might reflect an " $r$ " strategy adopted by some species that 
allocate most of the host-derived carbon to sporulation at the expense of vegetative growth. These species may not be rapid colonizers and, therefore, would not contribute as much to total infectivity. Moreover, some species, such as Glomus occultum, produce intraradical mycorrhizal structures that stain so faintly in trypan blue that they often are undetected and lead to underestimation of infectivity (Morton, 1985).

The similarity index calculated for all sites served as a conservative indicator of processes regulating AMF species diversity in natural systems. Habitats sharing abiotic characteristics, such as soil chemical properties, would be expected to have similar AMF species if ecological processes are important determinants in mycorrhizal community structure (Ricklefs and Schuluter, 1993). Host plant and soil fertility levels have been implicated in some studies as important variables regulating species diversity (Porter et al., 1987; Johnson et al., 1992). Very few examples in the literature can be found where AMF species diversity from different sites is compared over a wide range of similar habitats. Koske and Tews (1987) calculated a similarity index between AMF species from sand dunes and they obtained values in the same range as that reported in this study. Nevertheless, the similarity indices found in the present study can be considered high given the disparity on soil and environmental properties between habitats as well as plant communities. When disparate habitats from geographically different areas converge in their species composition, historical processes such as speciation or dispersal can be implicated as causal factors explaining distribution of a particular group of organisms (Ricklefs and Schuluter, 1993). For AMF, it is not surprising that, given the time since their evolution about 400 million years ago (Taylor et al., 1995), dispersal could account for the widespread distribution of species over a range of natural ecosystems.

Measurements of species diversity in several habitats are informative in assessing the distribution of AMF species, which provides a foundation for further investigations on the biogeography of these organisms. The extensive surveys of habitats found in the literature provide some information on species distributions, but despite the methodological limitations in this study, results suggest that AMF diversity often is underestimated. Trap cultures provide an important tool for detecting species not sporulating in the field or in detecting additional species when samples are collected at only one point in time. Moreover, trap cultures also render abundant and healthy spores for establishing single isolate cultures, a prerequisite to testing physiological diversity of a mycorrhizal community by effectivity assays (see Chapter 4). This study indicates that: (i) trap cultures of field soils should be incorporated in surveys where measurement of AMF taxonomic structure is desired; (ii) sampling procedures must insure that plant root biomass is a major component of the inocula used to start trap cultures; and, (iii) two or more plant host may need to be used to assess any signs of differential host preference for certain fungal species which may result in a higher number of AMF species detected.

\section{LITERATURE CITED}

Abe, J.P., G. Masuhara, and K. Katsuya. 1994. Vesicular-arbuscular mycorrhizal fungi in coastal dune plant communities. I. Spore formation of Glomus spp. predominates under a patch of Elymus mollis. Mycoscience 35:233-238. 
Anderson, R.C., A.E. Liberta, and L.A. Dickman. 1984. Interaction of vascular plants and vesicular-arbuscular mycorrhizal fungi across a soil moisture-nutrient gradient. Oecologia 64:111-117.

Bever, J.D., J. Morton, J. Antonovics, and P.A. Schultz. 1996. Host-dependent sporulation and species diversity of arbuscular mycorrhizal fungi in a mown grassland. Journal of Ecology 84:71-82.

Biermann, B.J., and R.G. Linderman. 1983. Use of vesicular-arbuscular mycorrhizal roots, intraradical vesicles and extraradical vesicles as inoculum. New Phytologist 95:97-105.

Brundrett, M.C. 1991. Mycorrhizas in natural ecosystems. Advances in Ecological Research 21:171-213.

Brundrett, M.C., N. Ashwath, and D.A. Jasper. 1996. Mycorrhizas in the Kakadu region of tropical Australia I. Propagules of mycorrhizal fungi and soil properties in natural habitats. Plant and Soil 184:159-171.

Clapp, J.P., J.P.W. Young, J.W. Merryweather, and A.H. Fitter. 1995. Diversity of fungal symbionts in arbuscular mycorrhizas from a natural community. New Phytologist 130:259-265.

Ferguson, J.J., and J.A. Menge. 1982. Factors that affect production of endomycorrhizal inoculum. Proceedings Florida State Horticulture Society 95:37-39.

Franke, M., and J. Morton. 1994. Ontogenetic comparisons of arbuscular mycorrhizal fungi Scutellospora heterogama and Scutellospora pellucida: revision of taxonomic character concepts, species descriptions, and phylogenetic hypotheses. Canadian Journal of Botany 72:122-134.

Gazey, C., L.K. Abbott, and A.D. Robson. 1992. The rate of development of mycorrhizas affects the onset of sporulation and production of external hyphae by two species of Acaulospora. Mycological Research 96:643-650.

Gemma, J.N., R.E. Koske, and M. Carreiro. 1989. Seasonal dynamics of selected species of VA mycorrhizal fungi in a sand dune. Mycological Research 92:317-321.

Giovannetti, M., and B. Mosse. 1980. An evaluation of techniques for measuring vesicular arbuscular mycorrhizal infection in roots. New Phytologist 84:489-500.

Hayman, D.S. 1974. Plant growth responses to vesicular-arbuscular mycorrhiza. VI. Effect of light and temperature. New Phytologist 73:71-80.

Jasper, D.A., L.K. Abbott, and A.D. Robson. 1989. Soil disturbance reduces the infectivity of external hyphae of vesicular-arbuscular mycorrhizal fungi. New Phytologist 112:93-100.

Jasper, D.A., L.K. Abbott, and A.D. Robson. 1991. The effect of soil disturbance on vesicular-arbuscular mycorrhizal fungi in soils from different vegetation types. New Phytologist 118:471-476.

Johnson, N.C., D. Tilman, and D. Wedin. 1992. Plant and soil controls on mycorrhizal fungal communities. Ecology 73:2034-2042.

Johnson, N.C., D.R. Zak, D. Tilman, and F.L. Pfleger. 1991a. Dynamics of vesiculararbuscular mycorrhizae during old field succession. Oecologia 86:349-358.

Johnson, N.C., F.L. Pfleger, R.K. Crookston, S.R. Simmons, and P.J. Copeland. 1991b. Vesiscular-arbuscular mycorrhizas respond to corn and soybean cropping history. New Phytologist 117:657-663.

Koske, R.E. 1987. Distribution of VA mycorrhizal fungi along a latitudinal temperature gradient. Mycologia 79:55-68. 
Koske, R.E., and L.L. Tews. 1987. Vesicular-arbuscular mycorrhizal fungi of Wisconsin sandy soils. Mycologia 79:901-905.

Koske,R.E., and J.N. Gemma. 1989. A modified procedure for staining roots to detect V-A mycorrhizas. Mycological Research 92:486-488.

Magurran, A.E. 1988. Ecological Diversity and Its Measurements. Princeton University Press, Princeton, New Jersey. 179 pp.

Miller, D.D., P.A. Domoto, and C. Walker. 1985. Mycorrhizal fungi at eighteen apple rootstocks plantings in the United States. New Phytologist 100:379-391.

Moorman, T., and F.B. Reeves. 1979. The role of endomycorrhizae in revegetation practices in the semi-arid West. II. A bioassay to determine the effect of land disturbance on endomycorrhizal populations. American Journal of Botany 66:14-18.

Morton, J.B. 1985. Underestimation of most probable numbers of vesicular-arbuscular mycorrhizae endophytes because of non-staining mycorrhizae. Soil Biology and Biochemistry 17:383-384.

Morton, J.B., S.P. Bentivenga, and J.D. Bever. 1995. Discovery, measurement, and interpretation of diversity in arbuscular endomycorrhizal fungi (Glomales, Zygomycetes). Canadian Journal of Botany 73(suppl. 1):S25-S32.

Pearson, J.N., and P. Schweiger. 1994. Scuttelospora calospora (Nicol. and Gerd.) Walker and Sanders associated with subterranean clover produces non-infective hyphae during sporulation. New Phytologist 127:697-701.

Porter, W.M., A.D. Robson, and L.K. Abbott. 1987. Factors controlling the distribution of VAM fungi in relation to soil pH. Journal of Applied Ecology 24:663-672.

Ricklefs, R.E., and D. Schuluter. 1993. Species Diversity: an Introduction to the Problem. Pp. 1-10. In: Species Diversity in Ecological Communities - Historical and Geographical Perspectives. Eds. R.E. Ricklefs and D. Schuluter. The University of Chicago Press, Chicago.

Schenck, N.C., and V.N. Schroder. 1974. Temperature response of Endogone mycorrhiza on soybean roots. Mycologia 66:600-605.

SAS. 1995. JMP® Statistics and Graphics Guide. SAS Institute Inc., Cary, NC.

Sieverding, E. 1983. Influence of soil water regimes on vesicular-arbuscular mycorrhizae II. Effect of soil temperature and water regime on growth, nutrient uptake, and water utilization of Eupatorium odoratum L. Z. Acker. Pflanzenbau. 152:56-67.

Simon, L., J. Bousquet, R.C. Levesque, and M. Lalonde. 1993. Origin and diversification of endomycorrhizal fungi and coincidence with vascular land plants. Nature 363:67-69.

Sokal, R.R., and F.J. Rohlf. 1981. Biometry. W.H. Freeman and Company, New York. 859 pp.

Stürmer, S.L., and M.M. Bellei. 1994. Composition and seasonal variation of spore populations of arbuscular mycorrhizal fungi in dune soils on the island of Santa Catarina, Brazil. Canadian Journal of Botany 72:359-363.

Stutz, J.C., and J.B. Morton. 1996. Successive pot cultures reveal high species richness of arbuscular endomycorrhizal fungi in arid ecosystems. Canadian Journal of Botany 74:1883-1889.

Taylor, T.N., W. Remy, H. Hass, and H. Kerp. 1995. Fossil arbuscular mycorrhizae from the Early Devonian. Mycologia 87:560-573.

Tokeshi, M. 1993. Species abundance patterns and community structure. Advances in Ecological Research 24:111-186. 
Table 1 Environmental and soil chemical properties of the 5 selected sites within the U.S.A. $\mathrm{CEC}=$ Cation Exchange Capacity, BS $=$ Base Saturation .

\begin{tabular}{cccccc}
\hline Properties & California-D & California-R & Kansas & Minnesota & $\begin{array}{c}\text { West } \\
\text { Virginia }\end{array}$ \\
\hline Mean Annual Temp. $\left({ }^{\circ} \mathrm{C}\right)$ & 22 & 17 & 13 & 1 & 9 \\
Mean Annual Rainfall $(\mathrm{mm})$ & 65 & 1595 & 835 & 697 & 1417 \\
pH & 8.0 & 6.2 & 7.2 & 5.8 & 4.1 \\
P (ppm) & 33.5 & 3.5 & 57 & 32 & 4 \\
K (ppm) & 477 & 9.5 & 203 & 87 & 28 \\
Ca (ppm) & 8285 & 1280 & 5815 & 2320 & 70 \\
Mg (ppm) & 287 & 137 & 139 & 483 & 10.5 \\
Organic Matter $(\%)$ & 0.7 & 2.3 & 3.2 & 3.4 & 2.4 \\
CEC \& B.S. (meq/100g) & 45 & 10 & 31 & 18 & 10 \\
\hline
\end{tabular}


Table 2 Environmental and soil chemical properties of the sand dunes habitats studied. CEC = Cation Exchange Capacity, BS = Base Saturation.

\begin{tabular}{ccccc}
\hline Properties & Brazil & U.S.A. & Japan & Netherlands \\
\hline Mean Annual Temp. $\left({ }^{\circ} \mathrm{C}\right)$ & 20 & 12 & 15 & 9 \\
Mean Annual Rainfall $(\mathrm{mm})$ & 1350 & 1112 & 1558 & 750 \\
pH & 7.1 & 6.0 & 9.2 & 8.0 \\
P (ppm) & 3.5 & 13.5 & 26 & 12 \\
K (ppm) & 9.5 & 8.5 & 174 & 13 \\
Ca (ppm) & 100 & 115 & 1965 & 4210 \\
Mg (ppm) & 28 & 12.5 & 196 & 74 \\
Organic Matter $(\%)$ & 0.1 & 0.1 & 0.8 & 0.8 \\
CEC \& BS (meq/100g) & 1 & 2 & 12 & 22 \\
\hline
\end{tabular}


Table 3 Spore abundance of AMF fungal species present in a revegetated site in California (CA-R), as detected from field soil and over 2 cycles of trap cultures. Values represent the mean of two replicate samples from field soil and three replicate samples from trap culture pots (mean \pm s.e.).

\begin{tabular}{|c|c|c|c|}
\hline Species & Field soil & $\mathbf{1}^{\text {st }}$ trap & $2^{\text {nd }}$ trap \\
\hline \multicolumn{4}{|l|}{ Glomaceae } \\
\hline G. microaggregatum Koske, Gemma \& Olexia & - & $336 \pm 49.4$ & $88 \pm 8.3$ \\
\hline Glomus sp. 1 (like G. spurcum) & - & $653 \pm 78.1$ & $390 \pm 32.5$ \\
\hline Glomus sp. 2 (like G. intraradices) & - & $346 \pm 69.5$ & - \\
\hline \multicolumn{4}{|l|}{ Acaulosporaceae } \\
\hline Acaulospora koskeii Blaskowski & $22 \pm 1.5$ & $6 \pm 0.6$ & $1 \pm 0.3$ \\
\hline Acaulospora sp. 1 (like A. scrobiculata) & $60 \pm 4.5$ & $88 \pm 19.5$ & $8 \pm 1.4$ \\
\hline Acaulospora sp. 2 & $35 \pm 4.5$ & $8 \pm 3.5$ & $5 \pm 1.0$ \\
\hline \multicolumn{4}{|l|}{ Gigasporaceae } \\
\hline Scutellospora calospora Koske \& Walker & $2 \pm$ & - & - \\
\hline Total & 119 & 1440 & 495 \\
\hline
\end{tabular}


Table 4 Spore abundance of AMF fungal species present in a prairie site in Kansas, as detected from field soil and over 2 cycles of trap cultures. Values represent the mean of two replicate samples from field soil and three replicate samples from trap culture pots (mean \pm s.e.).

\begin{tabular}{|c|c|c|c|}
\hline Species & Field soil & $1^{\text {st }}$ trap & $2^{\text {nd }}$ trap \\
\hline \multicolumn{4}{|l|}{ Glomaceae } \\
\hline Glomus intraradices Schenck \& Smith & $139 \pm 17$ & - & - \\
\hline G. occultum Walker & $12 \pm 0.5$ & $15,422 \pm 1372$ & $466 \pm 105.7$ \\
\hline G. geosporum (Nicol. \& Gerd.)Gerd. \& Trappe & $17 \pm 1.5$ & $23 \pm 2.2$ & $8 \pm 1.0$ \\
\hline G. mosseae (Nicol. \& Gerd.)Gerd. \& Trappe & $2 \pm 0$ & $2 \pm 0.9$ & $7 \pm 2.4$ \\
\hline G. claroideum Schenck \& Smith & $2 \pm 0.5$ & $29 \pm 7.0$ & $3 \pm 0.9$ \\
\hline G. aggregatum Koske & - & - & $30 \pm 29.8$ \\
\hline G. microaggregatum Koske, Gemma \& Olexia & - & - & $42 \pm 14.6$ \\
\hline Glomus sp. 3 (like G. clarum) & - & $50 \pm 12.8$ & $9 \pm 4.8$ \\
\hline Glomus sp. 4 & - & - & $74 \pm 11.4$ \\
\hline \multicolumn{4}{|l|}{ Acaulosporaceae } \\
\hline Entrophospora infrequens Hall & $3 \pm 0$ & $9 \pm 1.2$ & $1 \pm 0.5$ \\
\hline Total & 175 & 15,536 & 645 \\
\hline
\end{tabular}


Table 5 Spore abundance of AMF fungal species present in a corn field in Minnesota, as detected from field soil and over 2 cycles of trap cultures. Values represent the mean of two replicate samples from field soil and three replicate samples from trap culture pots (mean \pm s.e.).

\begin{tabular}{|c|c|c|c|}
\hline Species & Field soil & $1^{\text {st }}$ trap & $2^{\text {nd }}$ trap \\
\hline \multicolumn{4}{|l|}{ Glomaceae } \\
\hline G. mosseae (Nicol. \& Gerd.) Gerd. \& Trappe & $9 \pm 0.5$ & $3 \pm 1.7$ & $2 \pm 0.7$ \\
\hline G. fasciculatum Walker \& Koske & $9 \pm 5.5$ & $4 \pm 1.6$ & - \\
\hline G. brasilianum Spain \& Miranda & - & $14 \pm 2.1$ & $2 \pm 0.6$ \\
\hline G. occultum Walker & - & $1,003 \pm 237$ & $503 \pm 127$ \\
\hline G. tenue (Greenall) Hall & - & $5,041 \pm 1061$ & $166 \pm 35.7$ \\
\hline G. intraradices Schenck \& Smith & - & $3 \pm 0.6$ & - \\
\hline Glomus sp. 5 & $5 \pm 4.0$ & $8 \pm 4.9$ & $62 \pm 11.2$ \\
\hline Glomus sp. 6 (like G. claroideum) & $14 \pm 5.5$ & $4 \pm 0.7$ & - \\
\hline Glomus sp. 7 & $4 \pm 3.0$ & - & - \\
\hline Glomus sp. 8 (like G. leptotichum) & - & $6 \pm 1.7$ & - \\
\hline \multicolumn{4}{|l|}{ Acaulosporaceae } \\
\hline Acaulospora spinosa Walker \& Trappe & $3 \pm 1.5$ & $6 \pm 3.6$ & $3 \pm 1.0$ \\
\hline A. trappei Ames \& Linderman & $1 \pm 1.0$ & & \\
\hline A. gerdemanni Schenck \& Nicolson & - & $3 \pm 2.8$ & \\
\hline Total & 45 & 6095 & 738 \\
\hline
\end{tabular}


Table 6 Spore abundance of AMF fungal species present in a abandoned mine site in West Virginia, as detected from field soil and over 2 cycles of trap cultures. Values represent the mean of two replicate samples from field soil and three replicate samples from trap culture pots (mean \pm s.e.).

\begin{tabular}{lccc}
\hline \multicolumn{1}{c}{ Species } & Field soil & $\mathbf{1}^{\text {st }}$ trap & $2^{\text {nd }}$ trap \\
\hline $\begin{array}{l}\text { Glomaceae } \\
\text { Glomus } \text { occultum Walker }\end{array}$ & $258 \pm 12.5$ & $109 \pm 12.6$ & $806 \pm 205.3$ \\
$\begin{array}{l}\text { Glomus clarum Nicol. \& Schenck } \\
\text { Glomus sp. } 9\end{array}$ & $50 \pm 24.5$ & $697 \pm 123.7$ & $406 \pm 64.3$ \\
Acaulosporaceae & - & $159 \pm 33.1$ & - \\
$\begin{array}{l}\text { Acaulospora dilatata } \text { Morton } \\
\text { A. lacunosa } \text { Morton }\end{array}$ & $172 \pm 49.5$ & $6 \pm 1.1$ & - \\
$\begin{array}{l}\text { Entrophospora } \text { sp. } 1 \\
\text { T }\end{array}$ & $86 \pm 12.0$ & - & - \\
\hline
\end{tabular}


Table 7 Similarity coefficients for AMF from five habitats within the U.S.A. Coefficient was calculated as $\mathrm{C}=2 \mathrm{w} / \mathrm{a}+\mathrm{b}$, where " $\mathrm{w}$ " is the total number of species common for both soils, "a" is the number of species in one soil, and " $b$ " is the number of species in the other soil. See text for abbreviations.

\begin{tabular}{lcccc}
\hline & CA-D & CA-R & KS & MN \\
\hline CA-R & 0.25 & - & - & - \\
KS & 0.18 & 0.23 & - & - \\
MN & 0 & 0 & 0.26 & - \\
WV & 0 & 0 & 0.12 & 0.10 \\
\hline
\end{tabular}


Table 8 Spore abundance of AMF fungal species present in a sand dune site in Brazil, extracted from field soil and two cycles of trap cultures. Values represent the mean of three replicates (mean \pm s.e.).

\begin{tabular}{|c|c|c|c|}
\hline Species & Field soil & $1^{\text {st }}$ trap & $2^{\text {nd }}$ trap \\
\hline \multicolumn{4}{|l|}{ Glomaceae } \\
\hline Glomus spurcum Pfeiffer, Walker \& Bloss & $25 \pm 0.8$ & - & $9 \pm 1.5$ \\
\hline G. pustulatum Koske, Friese, Walker \& Dalpé & $19 \pm 5.3$ & $130 \pm 48.2$ & $368 \pm 202$ \\
\hline G. brasilianum Spain \& Miranda & $2 \pm 0.3$ & $6 \pm 3.6$ & $6 \pm 1.7$ \\
\hline G. intraradices Schenck \& Smith & - & $2 \pm 2.3$ & $10 \pm 1.0$ \\
\hline \multicolumn{4}{|l|}{ Acaulosporaceae } \\
\hline Acaulospora scrobiculata Trappe & $13 \pm 2.4$ & $2 \pm 0.3$ & $33 \pm 16.8$ \\
\hline A. trappei Ames \& Linderman & - & $7 \pm 2.0$ & $54 \pm 21.3$ \\
\hline \multicolumn{4}{|l|}{ Gigasporaceae } \\
\hline \multirow[t]{2}{*}{ Gigaspora albida Schenck \& Smith } & $28 \pm 2.1$ & $9 \pm 1.0$ & $21 \pm 1.7$ \\
\hline & 87 & 153 & 501 \\
\hline
\end{tabular}


Table 9 Spore abundance of AMF fungal species present in a sand dune site in U.S.A., extracted from field soil and over two cycles of trap cultures. Values represent the mean of three replicates (mean \pm s.e.).

\begin{tabular}{lccc}
\hline \multicolumn{1}{c}{ Species } & Field soil & $\mathbf{1}^{\text {st }}$ trap & $2^{\text {nd }}$ trap \\
\hline $\begin{array}{l}\text { Glomaceae } \\
\quad \text { Glomus clarum Nicolson \& Schenck }\end{array}$ & $35 \pm 5.5$ & $19 \pm 8.5$ & $102 \pm 67.9$ \\
$\begin{array}{l}\text { G. } \text { intraradices Schenck \& Smith } \\
\text { Acaulosporaceae }\end{array}$ & - & $257 \pm 36.6$ & $453 \pm 160.3$ \\
$\begin{array}{l}\text { Acaulospora spinosa Walker \& Trappe } \\
\text { A. morrowiae Schenck, Spain, Sieverding \& Howeler }\end{array}$ & $1 \pm 0$ & $7 \pm 5.9$ & - \\
$\begin{array}{l}\text { Gigasporaceae } \\
\text { Scutellospora erythropa } \text { Koske \& Walker }\end{array}$ & $18 \pm 2.0$ & $3 \pm 0.3$ & $1 \pm 0.8$ \\
$\begin{array}{l}\text { Gi. gigantea } \text { (Nicol. \& Gerd.) Gerd. \& Trappe } \\
\text { Total }\end{array}$ & $9 \pm 2.0$ & $3 \pm 1.4$ & $1 \pm 0.6$ \\
\hline
\end{tabular}


Table 10 Spore abundance of AMF fungal species present in a sand dune site in Japan, extracted from field soil and over two cycles of trap cultures. Values represent the mean of three replicates (mean \pm s.e.).

\begin{tabular}{|c|c|c|c|}
\hline Species & Field soil & $1^{\text {st }}$ trap & $2^{\text {nd }}$ trap \\
\hline \multicolumn{4}{|l|}{ Glomaceae } \\
\hline Glomus intraradices Schenck \& Smith & - & $746 \pm 303.6$ & $2220 \pm 88.3$ \\
\hline G. pustulatum Koske, Friese, Walker \& Dalpé & - & $105 \pm 19.8$ & $28 \pm 22.6$ \\
\hline G. tortuosum Schenck \& Smith & - & $7 \pm 4.0$ & $14 \pm 8.3$ \\
\hline Total & 0 & 858 & 2262 \\
\hline
\end{tabular}


Table 11 Spore abundance of AMF fungal species present in a sand dune site in the Netherlands, extracted from field soil and over two cycles of trap cultures. Values represent the mean of three replicates (mean \pm s.e.).

\begin{tabular}{|c|c|c|c|}
\hline Species & Field soil & $1^{\text {st }}$ trap & $2^{\text {nd }}$ trap \\
\hline \multicolumn{4}{|l|}{ Glomaceae } \\
\hline Glomus intraradices Schenck \& Smith & - & $105 \pm 71.9$ & $51 \pm 22.2$ \\
\hline G. pustulatum Koske, Friese, Walker \& Dalpé & - & $5 \pm 4.5$ & $30 \pm 27.1$ \\
\hline Glomus clarum Nicolson \& Schenck & - & - & $3 \pm 1.3$ \\
\hline Glomus sp. 6 (like G. claroideum) & $4 \pm 2.3$ & $19 \pm 12.5$ & $16 \pm 9.2$ \\
\hline Glomus sp. 10 & $27 \pm 6.0$ & - & - \\
\hline Glomus sp. 11 & - & $20 \pm 18.3$ & $306 \pm 211.2$ \\
\hline Glomus sp. 12 (like G. etunicatum) & - & - & $2 \pm 0.3$ \\
\hline Glomus sp. 13 & - & - & $91 \pm 45.1$ \\
\hline Total & 31 & 149 & 499 \\
\hline
\end{tabular}


Table 12 Similarity coefficients for AMF from four sand dune habitats. Coefficient was calculated as $\mathrm{C}=2 \mathrm{w} / \mathrm{a}+\mathrm{b}$, where " $\mathrm{w}$ " is the total number of species common for both soils, "a" is the number of species in one soil, and " $b$ " is the number of species in the other soil.

\begin{tabular}{lccc}
\hline & Brazil & U.S.A. & Japan \\
\hline U.S.A. & 0.15 & - & - \\
Japan & 0.40 & 0.22 & - \\
Netherlands & 0.26 & 0.28 & 0.36 \\
\hline
\end{tabular}


Table 13 Summary of simple and multiple linear regressions of spore number of the most abundant species in each soil considered singly or in combination to predict levels of colonization in infectivity assays. ns=not significant.

\begin{tabular}{|c|c|c|c|}
\hline & $\mathbf{r}^{2}$ & $\mathbf{F}$ & $\mathbf{P}$ \\
\hline \multicolumn{4}{|l|}{ Brazil } \\
\hline G. pustulatum & 0.007 & 0.03 & ns \\
\hline A. scrobiculata & 0.67 & 10.44 & 0.02 \\
\hline A. trappei & 0.12 & 0.68 & ns \\
\hline Gi. albida & 0.31 & 2.27 & ns \\
\hline All 4 species & 0.74 & 1.4 & ns \\
\hline \multicolumn{4}{|l|}{ U.S.A. } \\
\hline G. clarum & 0.85 & 30.63 & 0.002 \\
\hline G. pustulatum & 0.79 & 18.85 & 0.007 \\
\hline Both species & 0.89 & 17.47 & 0.01 \\
\hline \multicolumn{4}{|l|}{ Netherlands } \\
\hline G. intraradices & 0.06 & 0.34 & ns \\
\hline Glomus sp. 11 & 0.06 & 0.35 & ns \\
\hline Glomus sp. 13 & 0.35 & 2.75 & ns \\
\hline All 3 species & 0.39 & 0.57 & ns \\
\hline \multicolumn{4}{|l|}{ Japan } \\
\hline G. pustulatum & 0.28 & 2.00 & ns \\
\hline G. intraradices & 0.75 & 15.05 & 0.01 \\
\hline Both species & 0.88 & 15.73 & 0.01 \\
\hline
\end{tabular}


Table 14 Summary of stepwise regression of soil and environmental characteristics to predict number of AMF species in all nine habitats studied. Probability for a factor to enter the model was set as 0.75 .

\begin{tabular}{lcc}
\hline & $\mathbf{r}^{\mathbf{2}}$ & $\mathbf{P}$ \\
\hline Temperature & 0.54 & 0.02 \\
Organic matter & 0.62 & 0.29 \\
Potassium $(\mathrm{K})$ & 0.72 & 0.24 \\
Rainfall & 0.84 & 0.15 \\
Phosphorus $(\mathrm{P})$ & 0.92 & 0.15 \\
Magnesium $(\mathrm{Mg})$ & 0.97 & 0.16 \\
Calcium $(\mathrm{Ca})$ & 0.98 & 0.68 \\
\hline
\end{tabular}


Table 15 Summary of stepwise regression considering two factors together influencing number of AMF species in all nine soils studied. Only the three most significant factors are shown. $\mathrm{P}=$ phosphorus, $\mathrm{K}=$ potassium, MAT = mean annual temperature, and $\mathrm{O} . \mathrm{M} .=$ organic matter.

\begin{tabular}{lccc}
\hline & $\mathbf{r}^{\mathbf{2}}$ & $\mathbf{F}$ & $\mathbf{P}$ \\
\hline P and K & 0.69 & 6.86 & 0.02 \\
K and O.M. & 0.67 & 6.16 & 0.03 \\
MAT and O.M. & 0.62 & 5.01 & 0.05 \\
\hline
\end{tabular}




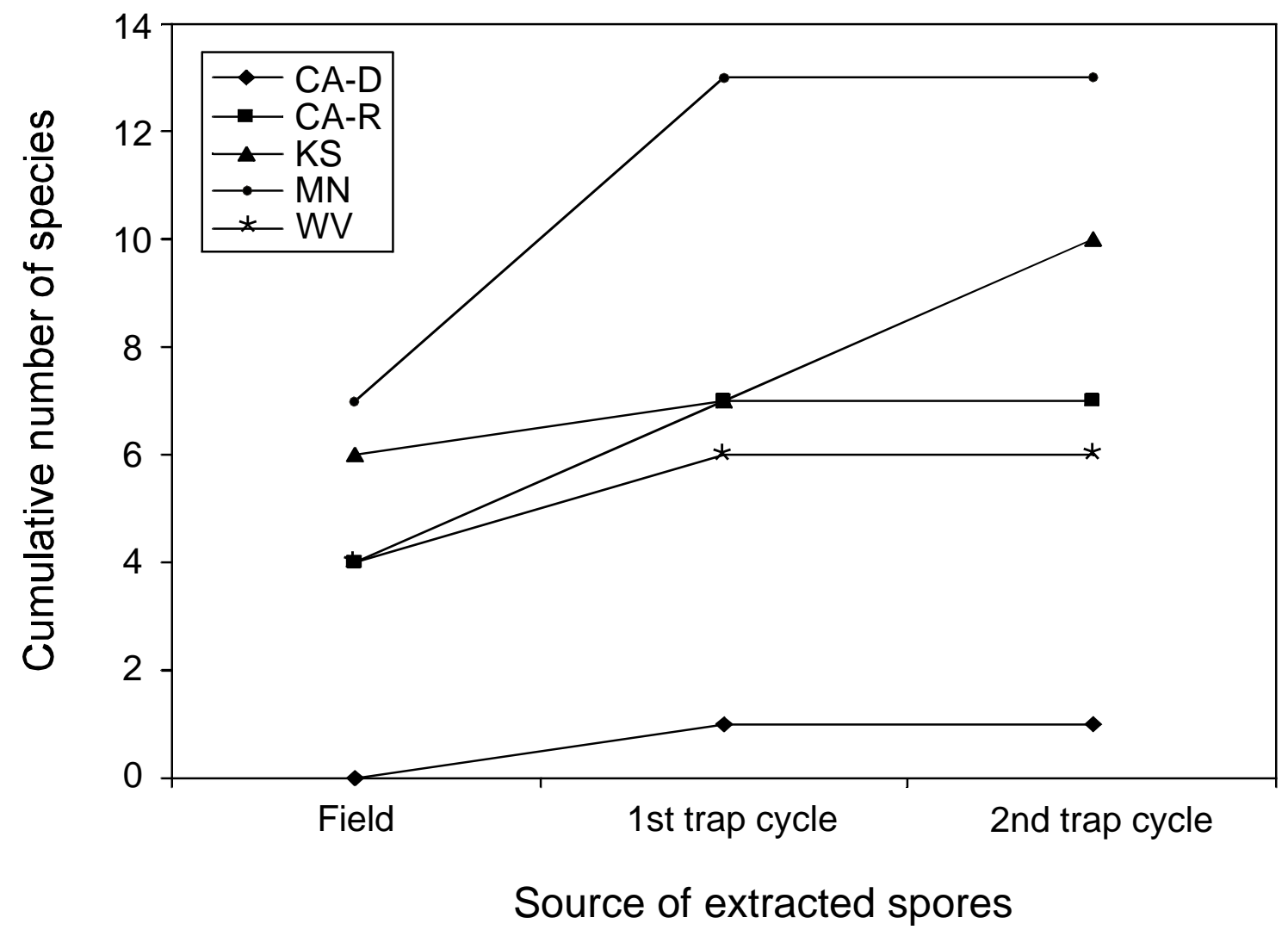

Fig. 1 Number of AMF species recovered from the field and after successive propagation cycles of trap cultures from 5 habitats in the United States. 


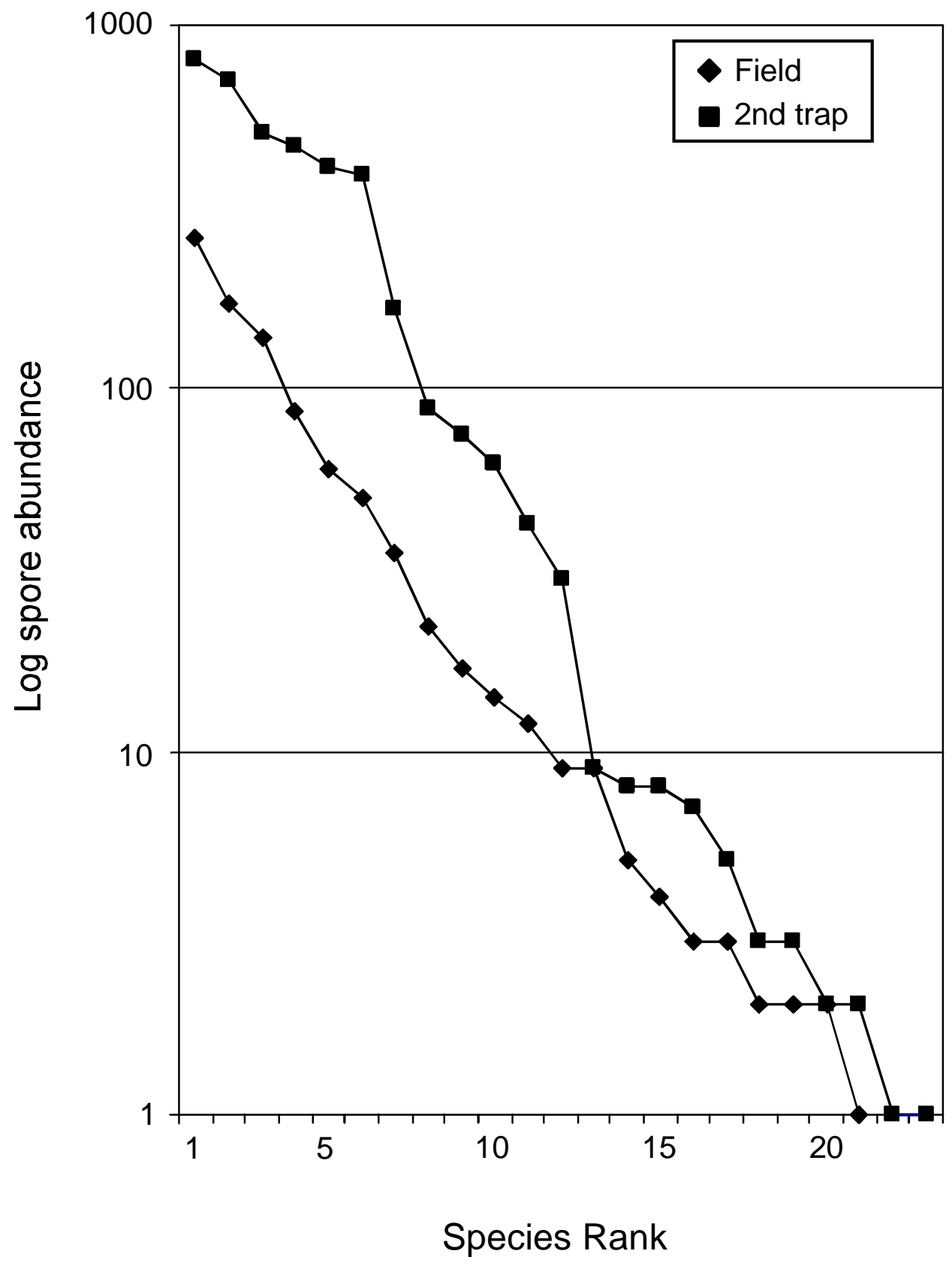

Fig. 2 Species rank-log abundance curves for AMF community recovered in the field and after two cycles of trap cultures for the five habitats within the U.S.A. 


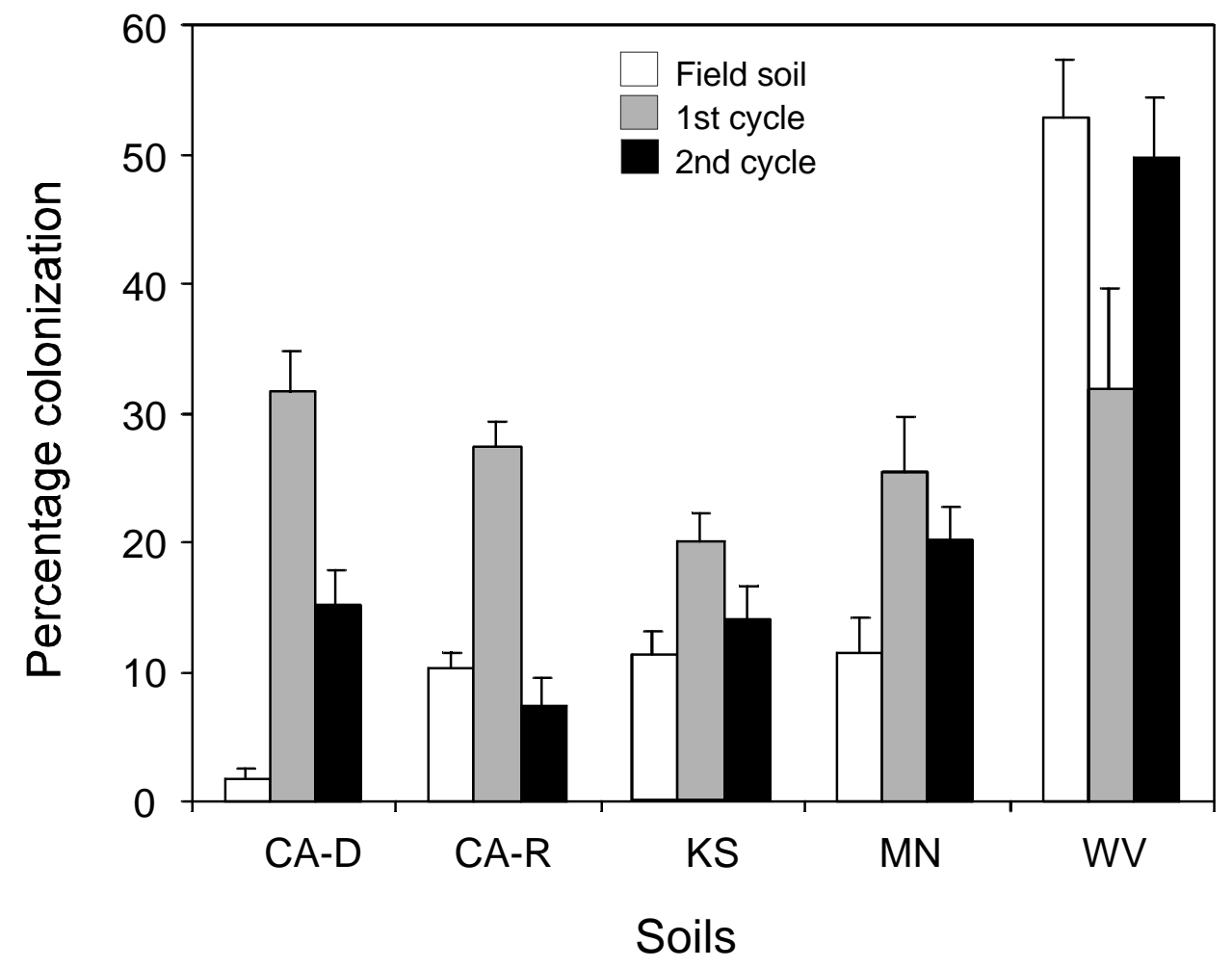

Fig. 3 Arbuscular mycorrhizal colonization after 21-day infectivity assays for field soil, first and second trap cycle from five habitats in the U.S.A. Bars represent mean of four replicates, lines represent standard error. See text for abbreviation of soils. 


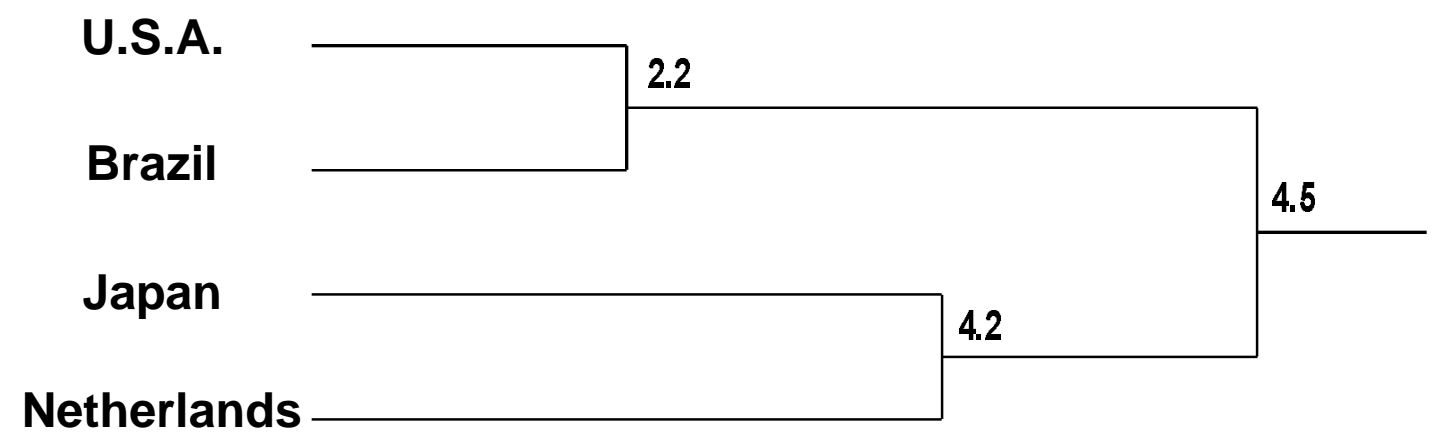

Fig. 4 Cluster analysis resulting from the average method of soil chemical and environmental properties for the sand dune habitats. Numbers indicate distance between branch points. 


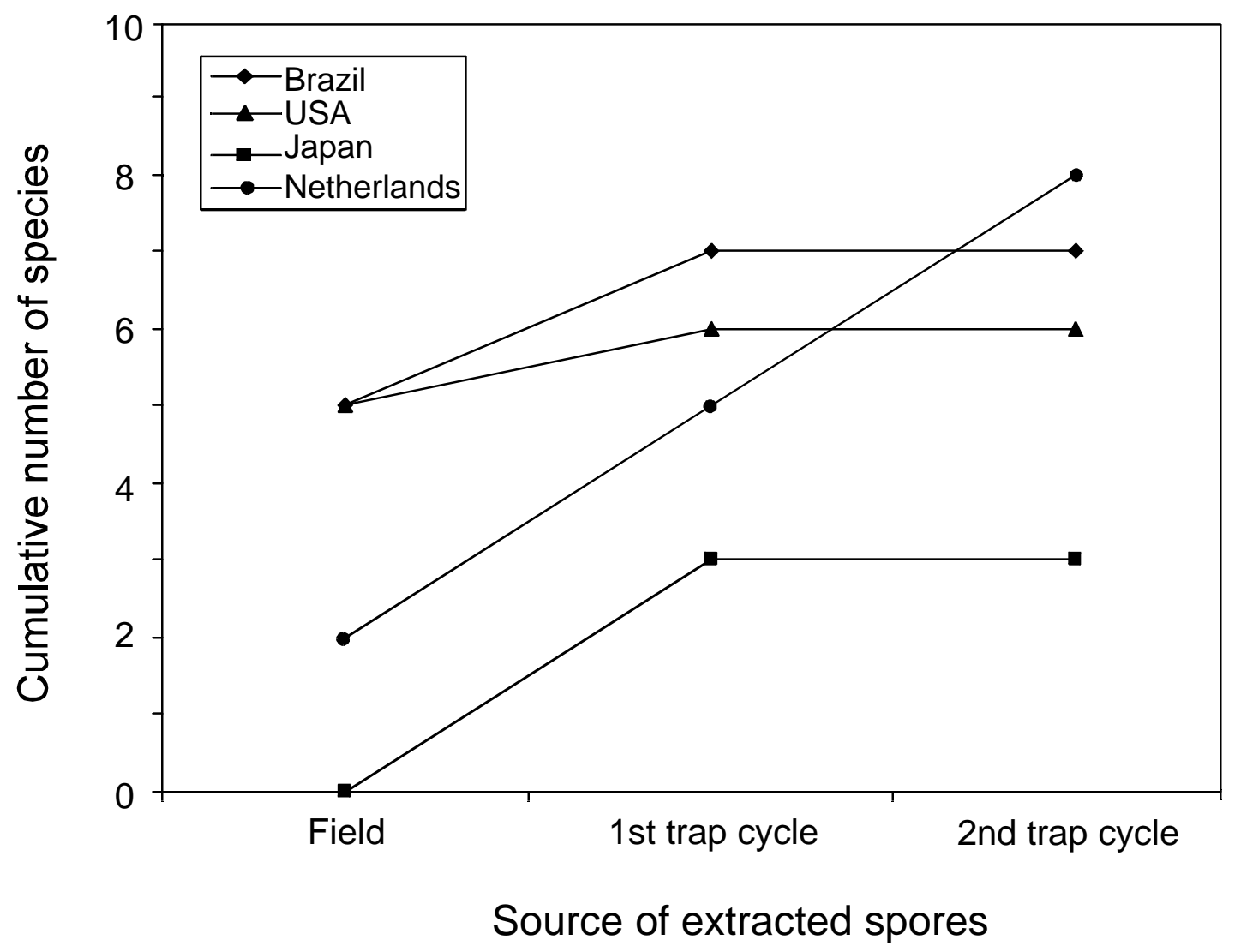

Fig. 5 Number of AMF species recovered from the field and after successive cycles of trap cultures from sand dunes habitats in four countries. 


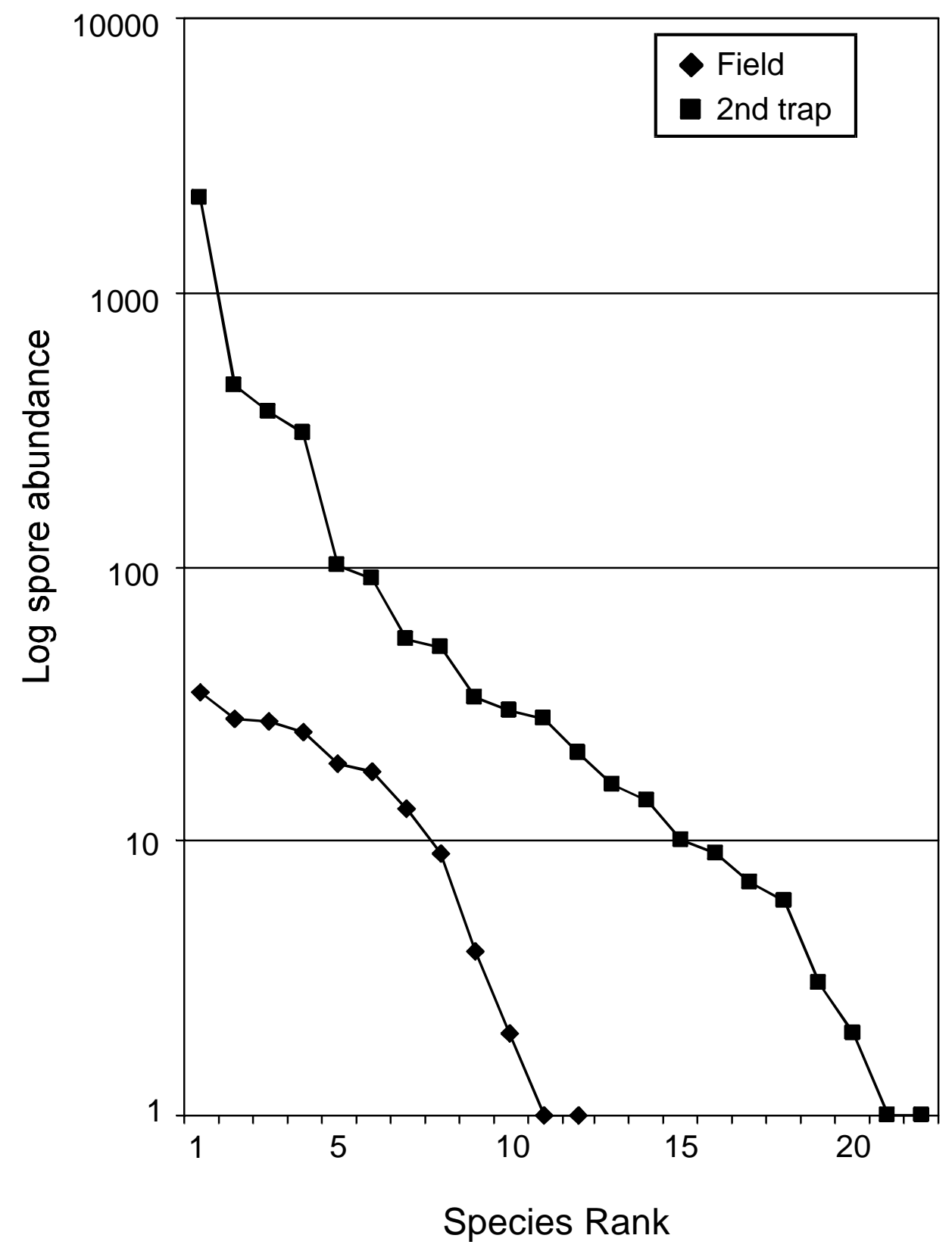

Fig. 6 Species rank-log abundance curves for AMF community recovered in the field and after two cycles of trap cultures for all sand dunes habitats. 


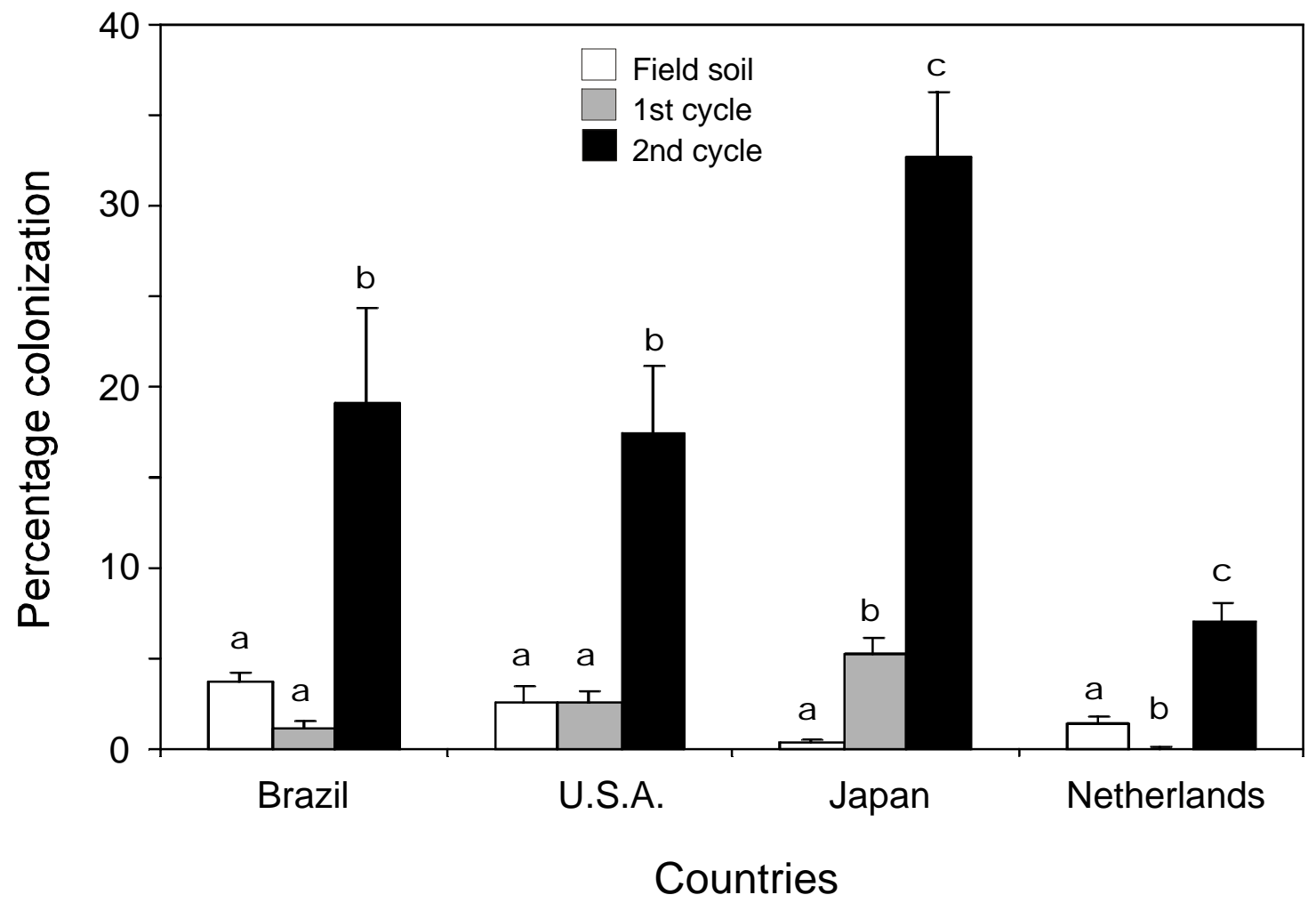

Fig. 7 Mycorrhizal colonization after 21-day infectivity assays for field soil, first and second trap cycle from four sand dunes habitats. Different letters within each soil represent statistically different means. Bars represent mean of five replicates for the field soil and nine replicates for each trap cycle. Lines represent standard error. 


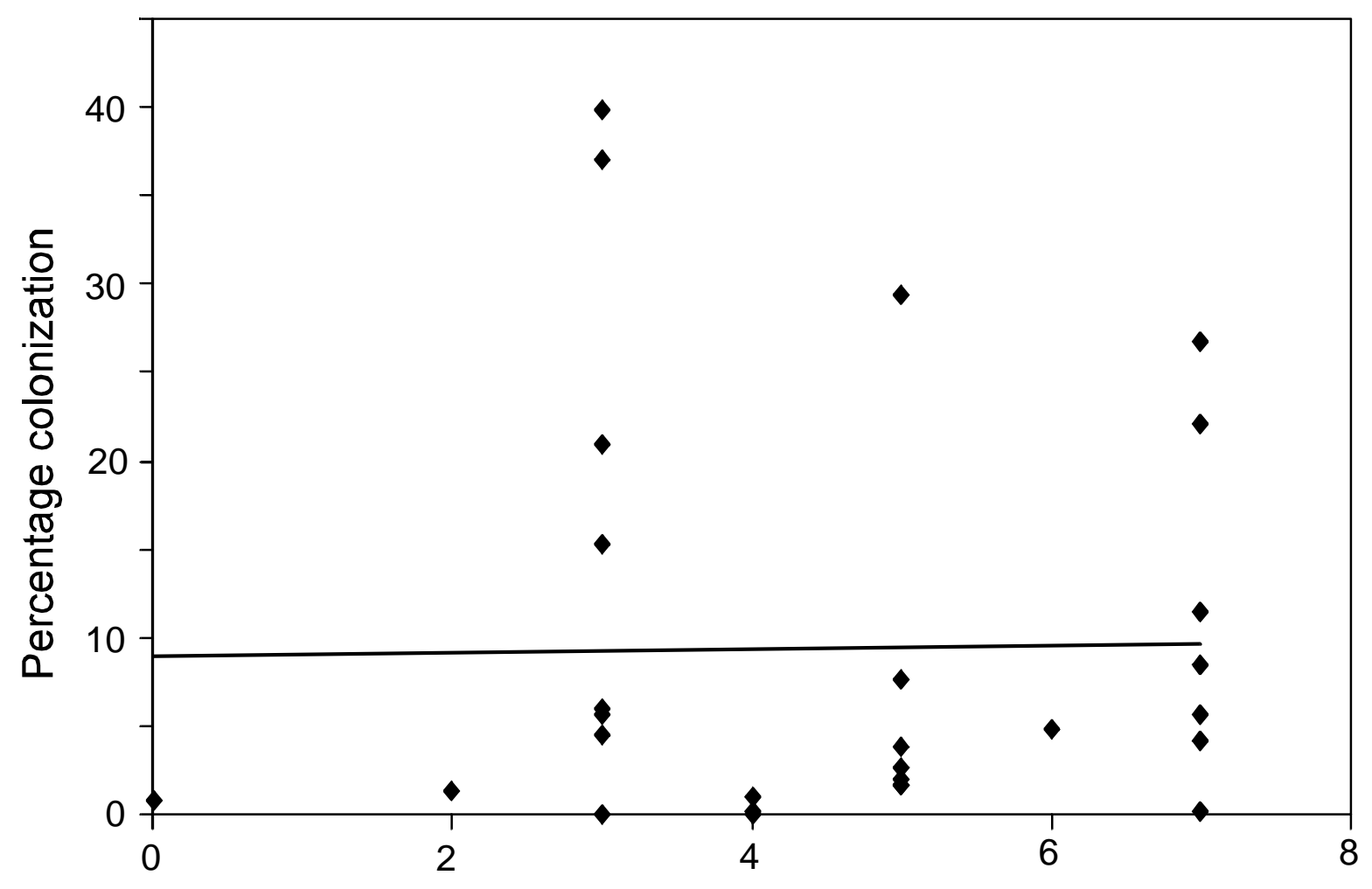

Number of species

Fig. 8 The relationship between the number of AMF species and the percentage colonization of 21 days infectivity assays within the same propagation cycle for sand dunes soils studied $\left(r^{2}<0.01, P=0.93\right)$. 


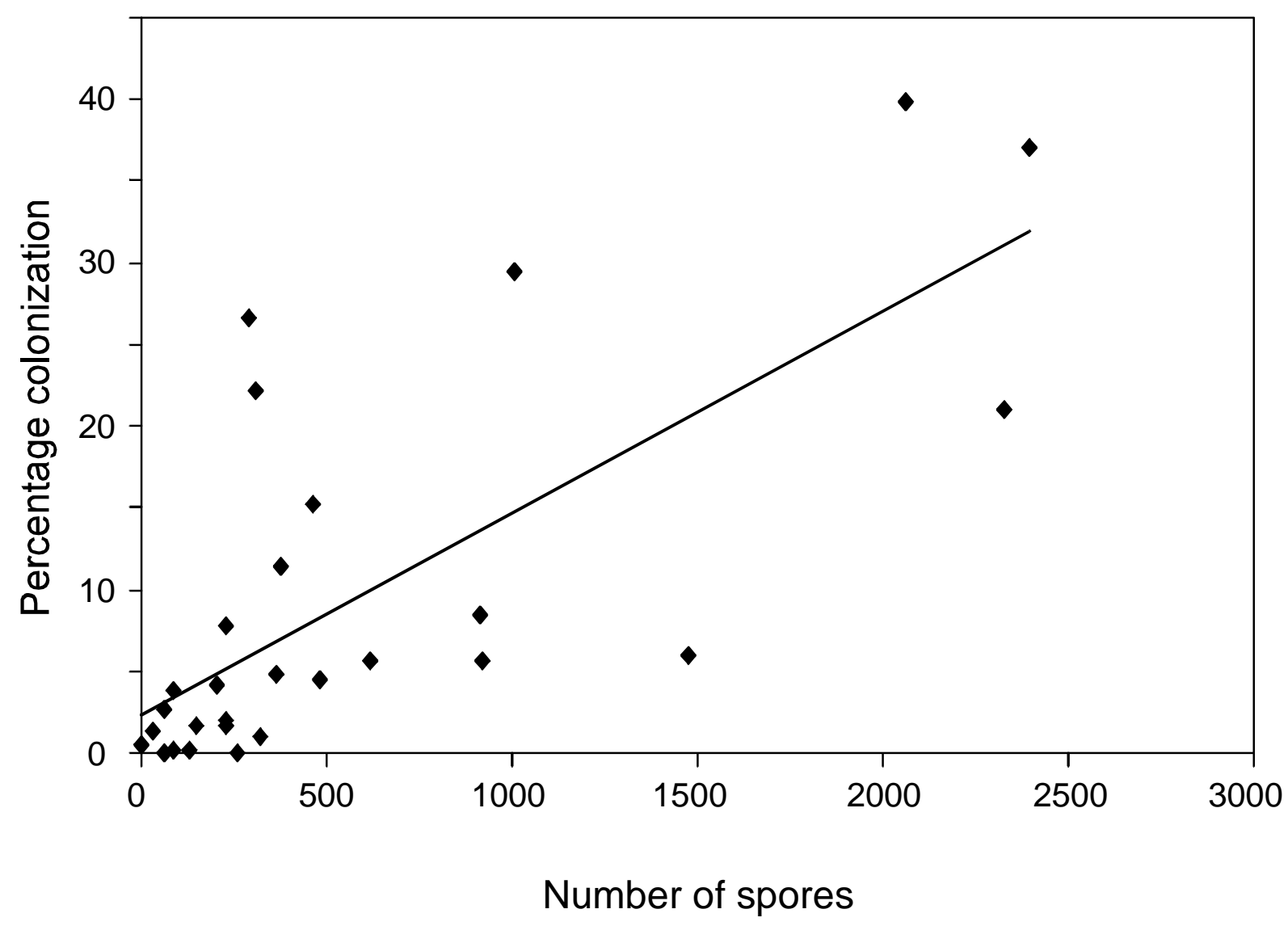

Fig. 9 The relationship between the percentage colonization of 21-day infectivity assays and number of spores detected within the same propagation cycle for sand dunes soils studied $\left(\mathrm{r}^{2}<0.52, \mathrm{P}<0.01\right)$ 
CHAPTER FOUR

EFFECT OF DIFFERENT FUNGAL ISOLATES

FROM THE SAME MYCORRHIZAL COMMUNITY

ON PLANT GROWTH AND PHOSPHORUS UPTAKE

IN SOYBEAN AND RED CLOVER 


\section{INTRODUCTION}

Among the benefits arbuscular mycorrhizal fungi (AMF) provide to native plants and crop species are improved shoot growth and reproductive potential (Smith and Read, 1997). These benefit is attributed primarily to increased uptake and transport of phosphorus by fungal hyphae beyond root depletion zones in soil. The plant host, in turn, provides the sole source of carbon for fungal growth and reproduction (Smith and Gianinazzi-Pearson, 1988). The relative ability of AMF isolates to improve plant growth and/or reproduction in a phosphate-deficient soil is termed symbiotic effectiveness (Abbott and Robson, 1981). Differences in effectiveness among AMF isolates are affected by a multitude of variables, such as rate of root colonization (Abbott and Robson, 1981), abundance of external hypha in the soil and hyphal distribution (Graham et al., 1982) and hyphal activity and longevity (Sylvia, 1988). Soil properties, such as pH (Skipper and Smith, 1979), temperature (Schenck and Smith, 1982) and P content (Schubert and Hayman, 1986) also impact effectiveness.

In many studies, effectiveness has been interpreted as a species-level property, but large differences between isolates of the same species have been identified and measured. For example, seven isolates of Glomus macrocarpum differed significantly in their ability to promote growth of pepper (Hass and Krikun, 1985). Similarly, different geographic isolates of Glomus mosseae varied in improving water relations of Agropyron smithii (Stahl and Smith, 1984). Two isolates of G. mosseae from an arid and a mesic environment improved soybean dry matter production relative to the control plants, but this benefit was not measured for an isolate from a semi-arid environment (Bethlenfalvay et al., 1989).

In most studies, effectiveness has been measured in single isolates propagated alone. However, fungi form complex communities within a root system in the field (Brundrett, 1991). Experiments involving more than one isolate on a single host would more likely reflect processes occurring naturally. Interspecific competition has been measured as a function of differential sporulation (Daft, 1983; Daft and Hogarth, 1983) and differential entry point formation in colonizing roots (Wilson, 1984). In spite of these interactions, a mixture of fungal isolates has been shown to provide more growth benefit than isolates colonizing alone (Daft, 1983).

In studies involving mixtures of fungi, isolates being compared often originated from different habitats rather than from the same community. The results, therefore, provide no information on the relative proportion of effective and noneffective fungi within a mycorrhizal community. Dissecting a mycorrhizal fungal community and testing the relative effectiveness of each fungal member has important implications. First, the net impact of fungal communities on their plant hosts determines the stability of the symbiosis over time. Morton (1997) hypothesized that the fungal community must have a net positive effect on plants (the higher unit of selection) for the symbiosis to be maintained on $80 \%$ of all plant lineages for over 400 million years. A net negative effect on some plant lineages may explain why the symbiosis was sporadically lost in more recent times (Trappe, 1987). Second, manipulation of fungi to optimally benefit agricultural or natural ecosystems involves either management of indigenous communities or introduction of a fungal inoculum. Each strategy depends on a complete understanding of the effectiveness of native or introduced fungal genotypes.

For fungi that are likely to be used as inocula (singly or as a "fungal community"), a paramount question is whether effectiveness on an assay host will hold true for other hosts and 
the environments in which they are intended to grow. Only one study involving fungal isolates tested on different soils in seven separate greenhouses from Maryland to Florida has addressed this issue (Sylvia et al., 1993). Results showed that only isolates with extremes in effectiveness (those that were highly effective and those that were ineffective) did not vary significantly with changes in host or greenhouse environments. Isolates of intermediate effectiveness varied with host or greenhouse environments.

In the present study, fungal isolates from three different communities were established in culture and then used as inocula to assess physiological diversity as expressed by relative effectiveness on a common assay host. The following specific hypotheses were tested: i) at least one isolate from each community will effectively promote plant growth; ii) highly effective or ineffective fungi will express similar responses regardless of host environment; iii) non-effective isolates will not be detrimental to plant growth when an effective fungal symbiont also is present in a mycorrhiza; and, iv) a mixture of AMF isolates from the same community will enhance plant growth and phosphorus nutrition more than each isolate colonizing alone.

\section{MATERIAL AND METHODS}

\section{Experimental isolates}

Fungal isolates used in this study were obtained from the International Culture Collection of Arbuscular and Vesicular-arbuscular Mycorrhizal Fungi (INVAM, West Virginia University). Twelve isolates were obtained from three separate mycorrhizal fungal communities designated as JA205, MN414 and VA105 (Table 1). Single species cultures were established from spores retrieved after trapping native fungi from field soil at each of three sites according to methods described in Chapter 3. Inoculum of all isolates were bulked by growing them with sudangrass in $1.2 \mathrm{~kg}$ plastic pots for 3-4 months with a growth substrate defined below. Pots containing only sterile substrate also were seeded with sudangrass to produce nonmycorrhizal inocula for effectiveness assays.

\section{Growth medium}

The growth medium used on inoculum production pots and on effectiveness assays was a sandy loam (Lily series) soil mixed (1:2, v/v) with quartzite sand (average grain size $=0.9$ $\mathrm{mm}$ ), steam sterilized twice for one hour with a 24 hour cooling period between cycles. After sterilization, the substrate was wetted and dried in two cycles to reduce available Mn levels in the soil elevated by steaming. Calcium carbonate $\left(\mathrm{CaCO}_{3}\right)$ was added to the soil to attain a final $\mathrm{pH}$ of 6.1-6.3. Soil was amended with 21 and $40 \mathrm{mg} / \mathrm{kg}^{-1} \mathrm{KH}_{2} \mathrm{PO}_{4}$ for experiments 1 and 2 , respectively.

\section{Infectivity assay}

Inoculum potential of each isolate was measured by the mean percentage method (Moorman and Reeves, 1979) (Chapter 3) and then adjusted by soil dilution to equalize infectivity at the outset of each effectiveness assay. For experiment 1 , inoculum of each isolate was diluted 1:1 with sterile substrate and the mixture placed in $100 \mathrm{~cm}^{3}$ cone-tainers ${ }^{\mathrm{TM}}$ (Stuewe and Sons, Inc., Corvallis, Oregon). Three seeds of sorghum (Sorghum vulgare L.) were placed in each cone and thinned to one plant after seedling emergence. After three weeks, plant roots were gently separated from the growth medium by immersing the entire cone contents in water. Roots were placed in tissue capsules and stained according to the method of Koske and Gemma 
(1989). Roots were spread over a Petri plate with a 0.5 inch grid etched in the bottom and mycorrhizal colonization estimated using the grid-line intersect method (Giovannetti and Mosse, 1980).

Inocula of each isolate to be used in experiment 2 was diluted 1:5 (v/v) with sterile substrate, placed in $100 \mathrm{~cm}^{3}$ cone-tainers and seeded with red clover (Trifolium pratense L.). Seedlings were thinned to three per cone after emergence and watered with a solution containing a commercial inoculum of Rhizobium trifolii (LiphaTec, Inc., Milwaukee, Wisconsin). Plants were grown for 21 days and roots processed and scored for mycorrhizal colonization as described above.

\section{Experiment 1}

An effectiveness assay was set up with the Ark Centennial variety of soybean (Glycine $\max$ L.) as the assay host, the growth medium described earlier, and 12 isolates of mycorrhizal fungi from three communities. Inoculum of each of the 12 isolates was diluted 1:5 (v/v) with sterile substrate and placed in $750 \mathrm{~cm}^{3}$ Deepots (Stuewe and Sons, Inc., Corvallis, Oregon). Inoculum of control pots consisted of pot contents of 3-month old sudangrass grown in the growth medium without AMF. An "artificial community" (AC) was established by mixing $150 \mathrm{ml}$ of each of the following isolates: Acaulospora mellea CL358, Glomus mosseae FL156, Glomus clarum FL979A and Gigaspora gigantea NC119A. This AC was included as a positive control.

Three seeds were sown in each pot and thinned to one plant after emergence. Seedlings were watered with a commercial solution of Bradyrhizobium inoculant for soybean (LiphaTec, Inc., Milwaukee, Wisconsin). Plants were grown for 7 weeks in a greenhouse with supplementary lights $\left(130 \mu \mathrm{mol} \mathrm{m} \mathrm{m}^{-2}\right.$ at pot level) and ambient temperature ranging from $15^{\circ} \mathrm{C}$ (night) to $35^{\circ} \mathrm{C}$ (day). The treatments were arranged in a complete randomized design with 14 treatments and 5 replicates per treatment. The exception was Acaulospora mellea MN414A, whose inoculum potential was so low that only 3 replicates could be established.

At harvest, shoots were cut at the soil line and dried in a convection oven at $65^{\circ} \mathrm{C}$ for 4 days. Roots were separated gently from the soil and immersed in water to remove soil particles and debris. Roots were blot-dried and $0.5 \mathrm{~g}$ fresh weight of root was sampled randomly for root colonization estimates. Remaining roots were dried in a convection oven at $65^{\circ} \mathrm{C}$ for 4 days. Fresh root samples were stained according to the method of Koske and Gemma (1989) and mycorrhizal colonization measured by the grid-line intersect method (Giovannetti and Mosse, 1980). Mycorrhizal root length was calculated for the entire pot based on total root dry mass.

Shoot phosphorus content was measured using the sealed chamber digestion method (Anderson and Henderson, 1986) with some modifications. Approximately $0.25 \mathrm{~g}$ of ovendried shoot material was placed in a heavy-walled teflon vessel, $3 \mathrm{ml}$ of concentrated $\mathrm{HNO}_{3}$ and $0.5 \mathrm{ml}$ of $\mathrm{H}_{2} \mathrm{O}_{2}$ added and the mixture incubated at room temperature for 15 minutes. Vessels were placed in a microwave and programmed for complete tissue digestion. Deionized water was added to the final digest to $25 \mathrm{ml}$ and this slurry was filtered through Whatman \#42 paper. The phosphorus digest was analyzed with a inductively-coupled argon plasma (ICAP). 


\section{Experiment 2}

Effectiveness assays of isolates alone or in combination were conducted using red clover (Trifolium pratense L.) as the host plant. Isolates were selected based on their $\mathrm{P}$ uptake benefit in soybean (see experiment 1). Treatments were: VA105B and VA105D singly or together (VA105B + D), and MN414B, MN414C and MN414D singly or in all possible combinations (MN414B +C, MN414B+D and MN414C+D). Two additional treatments, designated VA105 community and MN414 community, were included by combining isolates from each community. Pots were arranged in a complete randomized design with 12 treatments and 5 replicates per treatment.

Inoculum of each treatment was increased for 3 months with red clover before starting of the effectiveness assay. Each inoculum then was diluted 1:5 (v/v) with the sterile growth medium and placed in $750 \mathrm{~cm}^{3}$ Deepots. Red clover was sown and thinned to three plants per deepot after emergence. At this time, seedlings were watered with a suspension of Rhizobium trifolii. Plants were cultivated in a growth room $\left(245 \mu \mathrm{mol} \mathrm{m} \mathrm{s}^{-1}\right.$ at pot level, a 14-hour photoperiod, and ambient temperature ranging from $21-28^{\circ} \mathrm{C}$ ).

At harvest, shoot and roots were processed as described above for soybean, except that 0.25 grams of roots were used to measure mycorrhizal colonization. Shoot phosphorus was analyzed by the Kjedahl method using concentrated sulfuric acid $\left(\mathrm{H}_{2} \mathrm{SO}_{4}\right)$ and hydrogen peroxide $\left(\mathrm{H}_{2} \mathrm{O}_{2}\right)$ for digestion of plant tissues in a block digester (Lowther, 1980). After digestion, phosphorus was measured by flow injection analysis colorimetry in a Lachat Quickchem 8000L.

\section{Statistical analyses}

Data were screened for homogeneity of variance according to Levene's test before analysis of variance. Percentage of phosphorus in the shoots were arcsine square root transformed before analysis. When homogeneity of variance was not achieved even after transformation, data were ranked and analyses were performed on the ranks. All statistical analyses were done using $\mathrm{JMP}^{\circledR}$ (SAS Inst. Inc., 1995).

\section{RESULTS}

\section{Experiment 1}

Mycorrhizal colonization was observed in plant roots of all pots except the controls and those with Gi. gigantea VA105C (Table 2). Gigaspora gigantea lost infectivity during the experiment and was removed from the statistical analyses. Mycorrhizal root length was greatest in plants inoculated with Glomus clarum VA105D and Entrophospora sp. VA105E, obtaining lengths of 2663 and $1164 \mathrm{~cm}$, respectively.

All three isolates of the JA205 community improved shoot dry mass of soybean relative to control plants (Fig. 1). Shoot dry mass of plants colonized by any isolate from the MN414 community did not differ significantly from that of non-mycorrhizal controls. Only Glomus clarum from the VA105 community significantly increased shoot dry mass relative to the nonmycorrhizal control (Fig. 1).

Mycorrhizal colonization had a greater impact on phosphorus uptake than shoot dry mass on soybean (Fig. 2). All isolates of the JA205 community, except A. trappei, increased P 
uptake in shoots (Fig. 2). Two isolates of each MN414 and VA105 communities significantly improved percentage of $\mathrm{P}$ on soybean shoots relative to control plants (Fig. 2).

In each fungal community, at least two isolates improved either shoot dry matter or foliar phosphorus content of soybean relative to control plants. Colonization by the "artificial community" significantly improved both shoot dry mass and phosphorus in soybean (Figs. 1 and 2).

\section{Experiment 2}

Plants in the control treatments showed no evidence of forming mycorrhizae and the highest levels of colonization were observed for plants with VA105 community, Glomus clarum VA105D and Gigaspora gigantea MN414D and (Table 3). For most fungi, mycorrhizal root length ranged from 36 to $80 \mathrm{~cm}$.

In the VA105 community, red clover colonized by Scutellospora verrucosa and Glomus clarum significantly produced more shoot dry mass and increased $\mathrm{P}$ uptake percentage than controls (Fig. 3 and 4). Glomus sp. and Gigaspora gigantea from the MN414 community also produced more shoot dry mass and had higher $\mathrm{P}$ content in the shoots than control plants. Colonization by $S$. calospora MN414C significantly improved phosphorus uptake, but not shoot dry weight in red clover (Figs. 3 and 4).

Co-inoculation of two isolates did not always produced greater benefit than single isolates. Shoot dry matter of plants colonized with S. verrucosa VA105B + Glomus clarum VA105D was significantly different from plants inoculated with $S$. verrucosa alone, but not from plants associated with G. clarum (Fig. 3). Plants colonized with isolates VA105B + VA105D, however, had significantly higher phosphorus content in the shoots relative to plants colonized by either isolate alone (Fig. 4). Plants associated with Glomus sp. MN414B + S. calospora MN414C significantly produced more biomass and had a higher phosphorus content than plants associated with $S$. calospora alone, but they were not different from plants inoculated with Glomus sp. alone (Figs. 3 and 4). Both shoot dry matter and phosphorus content of plants colonized by Glomus sp. MN414B + Gigaspora gigantea MN414D did not differ significantly from these values for plants colonized by either isolate alone. Plants colonized with $S$. calospora MN414C + Gi. gigantea MN414D were not different from plants inoculated with $S$. calospora alone, but produced significantly less shoot dry matter than plants treated with Gi. gigantea alone (Fig. 3). Conversely, phosphorus content of plants grown with isolates MN414C + MN414D was not different from those grown with MN414D, but were higher than those with MN414C alone (Fig. 4).

Colonization with fungi from the VA105 community improved dry matter accumulation more than colonization with $S$. verrucosa VA105B alone, but not more than colonization with G. clarum VA105D (Fig. 3). Foliar phosphorus content was significantly higher in plants treated with VA105 community than in those associated with either VA105B or VA105D alone. Plants associated with MN414 community were not different in shoot dry matter or P content from plants colonized by either MN414B or MN414D alone and they had higher shoot dry matter and phosphorus content than MN414C alone (Figs. 3 and 4).

\section{DISCUSSION}

The effectivity assay on soybean tested the hypothesis that at least one isolate in each mycorrhizal fungal community effectively promotes dry matter production. Plant biomass and 
phosphorus uptake are common measurements evaluated when mycorrhizal effectiveness is tested (Abbott and Robson, 1984). Using dry matter production as one criterion, all isolates of the JA205 community and $G$. clarum from the VA105 community were effective relative to the controls. None of the fungi in the MN414 community showed evidence of effectiveness. In contrast, shoot $\mathrm{P}$ content increased with mycorrhizal colonization by at least two isolates from each of the three fungal communities. These results suggest that the net benefit of the mycorrhizal symbiosis in which all fungi in each community are assumed to colonize roots will be positive in either one or both of these parameters.

Differential responses in plants inoculated with different fungi in each of the two variables measured is becoming increasingly recognized. For example, three co-occurring AMF differentially influenced size and clonal growth traits of two Prunella species: $G$. geosporum and another Glomus species produced a similar total leaf area response, but the number of stolon branches were higher in plants colonized by the former when compared to the latter fungus (Streitwolf-Engel et al., 1997). In soybean, Acaulospora trappei JA205B promoted plant growth but not $\mathrm{P}$ content whereas Acaulospora mellea MN414A promoted $\mathrm{P}$ uptake but had no measurable effect on shoot dry matter production.

Part of the reason for differential host-fungus interactions is likely to be compatibility between plant and fungal genotypes. Soybean typically is grown in soils either with high $\mathrm{P}$ or with high $\mathrm{P}$ fertilizer applications. The JA205 fungal community was unusual in that all of its members effectively increased soybean growth and/or P uptake. This community originated from an experimental station where soil phosphorus levels $(24 \mathrm{ppm})$ were relatively higher than from the two other communities ( $<15 \mathrm{ppm})$, so isolates may be more adapted to conditions favorable to soybean growth and reproduction. If this is true, the results contradict Johnson's (1993) hypothesis that fertilization selects for less beneficial fungal mutualists over time. However, soybean effectiveness assays measure benefit directly whereas Johnson based her results on presence and abundance of sporulation as a measure of colonization and potential benefit.

Results of biomass and $\mathrm{P}$ content responses in both soybean and red clover support the hypothesis that either extreme in effectiveness by a fungal isolate (highly effective/ineffective) is conserved in changing host-soil environments. For example, G. clarum VA105D was strongly effective at promoting shoot growth and P uptake in both soybean and clover whereas S. calospora MN414C was equally ineffective for shoot growth measured in the two host species. The comprehensive study conducted by Sylvia et al. (1993) emphasizes conservativeness of only the extremes in effectiveness or ineffectiveness. Intermediate responses were more variable and could not be predicted from any given assay. It is the magnitude of effectiveness that may explain why a fungal isolate differs between host species (Streitwolf-Engel et al., 1997) or in different soils (Anderson et al., 1994).

The hypothesis that ineffective fungal isolates would not inhibit plant growth when cocolonizing with an effective fungus is supported by the red clover experiment, where selected isolates were tested alone or together from different fungal communities. An additive effect on foliar P content was evident when S. verrucosa VA105B and Glomus clarum VA105D formed mycorrhizae together. Contrasting trends were observed with the MN414 fungal isolates, where the effective Glomus sp. MN414B together with the ineffective Scutellospora calospora MN414C produced similar shoot dry mass to red clover plants colonized by Glomus sp. alone. 
These data suggest that interactive processes which impact effectiveness responses may occur among AMF isolates co-colonizing a root system. Part of these interactions undoubtedly involves extent of mycorrhizal development, which would affect the magnitude of host response. One fungal isolate can form mycorrhizae disproportionate to another by pre-empting root space available for colonization (Wilson, 1984). In the red clover experiment, the less effective isolate of the MN414 community may be a faster grower than the effective isolate. Differences in the rate of infection unit formation also may be a factor in differential mycorrhizal development (Wilson and Trinick, 1983), although it should have been made negligible in the red clover experiment by equalizing infectivity of all isolates. Interactions between mycorrhizal fungi are certain to occur in nature where they form complex communities or when isolates are co-inoculated. The nature and intensity of these interactions depends as much on intrinsic properties of each fungus as the effects of soil and host environments. These are hard to measure, since the fungus cannot be separated from its host plant.

The performance of plants associated with all members of each fungal community was equal or better than that of plants colonized by the most effective isolate in each community, based on shoot biomass, foliar P content, or both. These data, however, are not sufficiently robust to conclude that fungal mixtures consistently will benefit plants more than single isolates. Clearly, dual inoculations sometimes produced additive responses, suggesting that results are strongly dependent on the composition of each mixture. Other research suggests that combining isolates may eliminate a poor performance by single isolates and give more consistent results (Daft and Hogarth, 1983). Testing the effectiveness of isolates separately and together is a necessary approach to fully characterize the performance of any inoculum mixture for application to field settings.

Dissection of a mycorrhizal community by culturing all of its fungal members and testing each isolate individually or in selected mixtures is a difficult task, explaining the absence of such an approach to date. Gavito and Varela (1995), for example, set out to culture and test 14 species in a fungal community associated with corn, but they were successful with only two species. In this study, only three species were isolated from each fungal community, but it is likely that other less aggressive, nonsporulating fungi also may have been present in the original community since three to five species is a relatively simple community (Morton et al., 1995). Nonetheless, results indicate that effective fungi are present in all of the communities examined thus far, suggesting that management of native fungi may be a more widely useful strategy in most habitats than the introduction of nonindigenous species in commercial inocula. From a practical viewpoint, net effectiveness of the whole fungal community can be tested from trap culture inoculum (see Chapter 3), which obviates the necessity of culturing and testing each fungal species separately. If a mixed inoculum tests ineffective, then more work can be done with member fungi to determine effectiveness and infectivity of each isolate.

\section{LITERATURE CITED}

Abbott, L.K., and A.D. Robson. 1981. Infectivity and effectiveness of five endomycorrhizal fungi: competition with indigenous fungi in field soils. Australian Journal of Agricultural Research 32:621-630. 
Abbott, L.K., and A.D. Robson. 1984. The effect of VA mycorrhizae on plant growth. Pp. 113-130. C. Ll. Powell and D. J. Bagyaraj (Eds.), In: VA Mycorrhiza. CRC, Boca Raton, Florida.

Anderson, D.L., and L.J. Henderson. 1986. Sealed chamber digestion for plant nutrient analyses. Agronomy Journal 78:937-939.

Anderson, R.C., B.A.D. Hetrick, and G.W.T. Wilson. 1994. Mycorrhizal dependence of Andropogon gerardii and Schizachyrium scoparium in two prairie soils. The American Midland Naturalist 132:366-376.

Bethlenfalvay, G.J., R.L. Franson, M.S. Brown, and K.L. Mihara. 1989. The Glycine-GlomusBradyrhizobium symbiosis. IX. Nutritional, morphological and physiological responses of nodulated soybean to geographic isolates of the mycorrhizal fungus Glomus mosseae.

Physiolpgia Plantarum 76:226-232.

Brundrett, M.C. 1991. Mycorrhizas in natural ecosystems. Advances in Ecological Research 21:171-213.

Daft, M.J. 1983. The influence of mixed inocula on endomycorrhizal development. Plant and Soil 71:331-337.

Daft, M.J., and B.G. Hogarth. 1983. Competitive interactions amongst four species of Glomus on maize and onion. Transaction of British Mycological Society 80:339-345.

Gavito, M.E., and L. Varela. 1995. Response of "criollo" maize to single and mixed species inocula of arbuscular mycorrhizal fungi. Plant and Soil 176:101-105.

Giovannetti, M., and B. Mosse. 1980. An evaluation of techniques for measuring vesicular arbuscular mycorrhizal infection in roots. New Phytologist 84:489-500.

Graham, J.H., R.G. Linderman, and J.A. Menge. 1982. Development of external hyphae by different isolates of mycorrhizal Glomus spp. in relation to root colonization and growth of troyer citrange. New Phytologist 91:183-189.

Haas, J.H., and J. Krikun. 1985. Efficacy of endomycorrhizal-fungus isolates and inoculum quantities required for growth response. New Phytologist 100:613-621.

Johnson, N.C. 1993. Can fertilization of soil select less mutualistic mycorrhizae? Ecological Applications 3:749-757.

Koske, R.E., and J.N. Gemma. 1989. A modified procedure for staining roots to detect VA mycorrhizas. Mycoogical Research 92:486-505.

Lowther, J.R. 1980. Use of a single sulfuric acid hydrogen peroxide digest for the analysis of Pinus radiata needles. Communication Soil Science Plant Anals 11:175-188.

Moorman, T., and F.B. Reeves. 1979. The role of endomycorrhizae in revegetation practices in the semi-arid West. II. A bioassay to determine the effect of land disturbance on endomycorrhizal populations. American Journal of Botany 66:14-18.

Morton, J.B. 1997. Evolution of fungi in Glomales. J. White (Ed.). In: Evolution of Endophytism in Plants. (in press)

Morton, J.B., S.P. Bentivenga, and J.D. Bever. 1995. Discovery, measurement, and interpretation of diversity in arbuscular endomycorrhizal fungi (Glomales, Zygomycetes). Canadian Journal of Botany 73(suppl. 1):S25-S32.

SAS. 1995. JMP® Statistics and Graphics Guide. SAS Institute Inc., Cary, NC.

Schenck, N.C., and G.S. Smith. 1982. Responses of six species of vesicular-arbuscular mycorrhizal fungi and their effects on soybean at four soil temperatures. New Phytologist 92:193-201. 
Schubert, A., and D.S. Hayman. 1986. Plant growth responses to vesicular-arbuscular mycorrhiza. XVI. Effectiveness of different endophytes at different levels of soil phosphate. New Phytologist 103:79-90.

Skipper, H.D., and G.W. Smith. 1979. Influence of soil pH on the soybean-endomycorrhiza symbiosis. Plant and Soil 53:559-563.

Smith, S.E., and V. Gianinazzi-Pearson. 1988. Physiological interactions between symbionts in vesicular-arbuscular mycorrhizal plants. Annual Review Plant Physiology and Plant Molecular Biology 39:221-244.

Smith, S.E., and D.J. Read. 1997. Mycorrhizal Symbiosis. Academic Press, London, 605 pp.

Stahl, P.D., and W.K. Smith. 1984. Effects of different geographic isolates of Glomus on the water relations of Agropyron smithii. Mycologia 76:261-267.

Streitwolf-Engel, R., T. Boller, A. Wiemken, and I. Sanders. 1997. Clonal growth traits of two Prunella species are determined by co-occurring arbuscular mycorrhizal fungi from calcareous grasslands. Journal of Ecology 85:181-191.

Sylvia, D.M. 1988. Activity of external hyphae of vesicular-arbuscular mycorrhizal fungi. Soil Biology and Biochemistry 20:39-43.

Sylvia, D.M., D.O. Wilson, J.H. Graham, J.J. Maddox, P.P. Millner, J.B. Morton, H.D. Skipper, S.F. Wright, and A.G. Jarstfer. 1993. Evaluation of vesicular-arbuscular mycorrhizal fungi in diverse plants and soils. Soil Biology and Biochemistry 25:705-713.

Trappe, J.M. 1987. Phylogenetic and ecological aspects of mycotrophy in the angiosperms from an evolutionary standpoint. Pp. 5-25. G.R. Safir (Ed.), In: Ecophysiology of VA Mycorrhizal Plants. CRC Press, Boca Raton, Florida.

Wilson, J.M. 1984. Competition for infection between vesicular-arbuscular mycorrhizal fungi. New Phytologist 97:427-435.

Wilson, J.M., and M.J. Trinick. 1983. Infection, development and interaction between vesicular-arbuscular mycorrhizal fungi. New Phytologist 93:543-554. 
Table 1 Fungal species recovered from bait cultures of rhizosphere soil from three plant communities.

\begin{tabular}{|c|c|c|}
\hline Plant Community/Site & Fungal Species & INVAM No. \\
\hline \multirow{6}{*}{$\begin{array}{l}\text { Ammophila and Solidago species } \\
\text { on a sand dune of Assateague } \\
\text { Island, VA, U.S.A. } \\
\text { pH } 6.2-6.8,<10 \text { ppm P }\end{array}$} & Scutellospora fulgida Koske \& Walker & VA105A \\
\hline & S. verrucosa Koske \& Walker & VA105B \\
\hline & Gigaspora gigantea & VA105C \\
\hline & (Nicol \& Gerd.) Gerd. \& Trappe & \\
\hline & Glomus clarum Nicolson \& Schenck & VA105D \\
\hline & Entrophospora sp. & VA105E \\
\hline \multirow{3}{*}{$\begin{array}{l}\text { Triticum aestivum at an } \\
\text { experiment station in Hokkaido, } \\
\text { Japan. pH 6.1, } 24 \text { ppm P }\end{array}$} & Acaulospora trappei Ames \& Linderman & JA205B \\
\hline & G. mosseae (Nicol \& Gerd.) Gerd. \& Trappe & JA205C \\
\hline & Glomus sp. & JA205E \\
\hline \multirow{7}{*}{$\begin{array}{l}\text { Andropogon sp. on a } 60 \text { years old } \\
\text { field at Cedar Creek, MN, U.S.A. } \\
\text { pH } 5.1,<15 \text { ppm P }\end{array}$} & Acaulospora mellea & MN414A \\
\hline & Schenck, Spain, Sieverding \& Howeler & \\
\hline & Glomus sp. & MN414B \\
\hline & S. calospora Koske \& Walker & MN414C \\
\hline & Gigaspora gigantea & MN414D \\
\hline & (Nicol \& Gerd.) Gerd. \& Trappe & \\
\hline & Glomus sp. & MN414E \\
\hline
\end{tabular}


Table 2 Mycorrhizal root length of 7-week old soybean plants. Numbers represent mean \pm standard error.

\begin{tabular}{lc}
\hline \multicolumn{1}{c}{ Treatments } & Mycorrhizal Root Length (cm) \\
\hline A. trappei JA205B & $99.7 \pm 33.2$ \\
G. mosseae JA205C & $378.6 \pm 49.8$ \\
Glomus sp. JA205E & $356.9 \pm 40.76$ \\
A. mellea MN414A & $214.5 \pm 55.18$ \\
Glomus sp. MN414B & $591.6 \pm 58.8$ \\
S. calospora MN414C & $71.1 \pm 10.0$ \\
Gi. gigantea MN414D & $786.9 \pm 86.7$ \\
Glomus sp. MN414E & $304.0 \pm 83.6$ \\
S. verrucosa VA105B & $26.6 \pm 12.1$ \\
G. clarum VA105D & $2663.0 \pm 103.3$ \\
Entrophospora sp. VA105E & $1164.2 \pm 166.6$ \\
Artificial Community & $568.8 \pm 42.8$ \\
\hline
\end{tabular}


Table 3 Mycorrhizal root length of 8-week old red clover plants. Numbers represent mean \pm standard error.

\begin{tabular}{lc}
\hline \multicolumn{1}{c}{ Treatments } & Mycorrhizal Root Length (cm) \\
\hline S. verrucosa VA105B & $79.5 \pm 22.1$ \\
G. clarum VA105D & $250.2 \pm 34.7$ \\
S. verrucosa + G. clarum & $154.7 \pm 25.2$ \\
VA105 community & $425.5 \pm 187.8$ \\
Glomus sp. MN414B & $50.8 \pm 6.7$ \\
S. calospora MN414C & $60.3 \pm 1.5$ \\
Gi. gigantea MN414D & $232.7 \pm 43.8$ \\
Glomus sp. + S. calospora & $36.0 \pm 4.2$ \\
Glomus sp. + Gi. gigantea & $57.2 \pm 5.4$ \\
S. calospora + Gi. gigantea & $66.9 \pm 27.2$ \\
MN414 community & $68.8 \pm 14.4$ \\
\hline
\end{tabular}




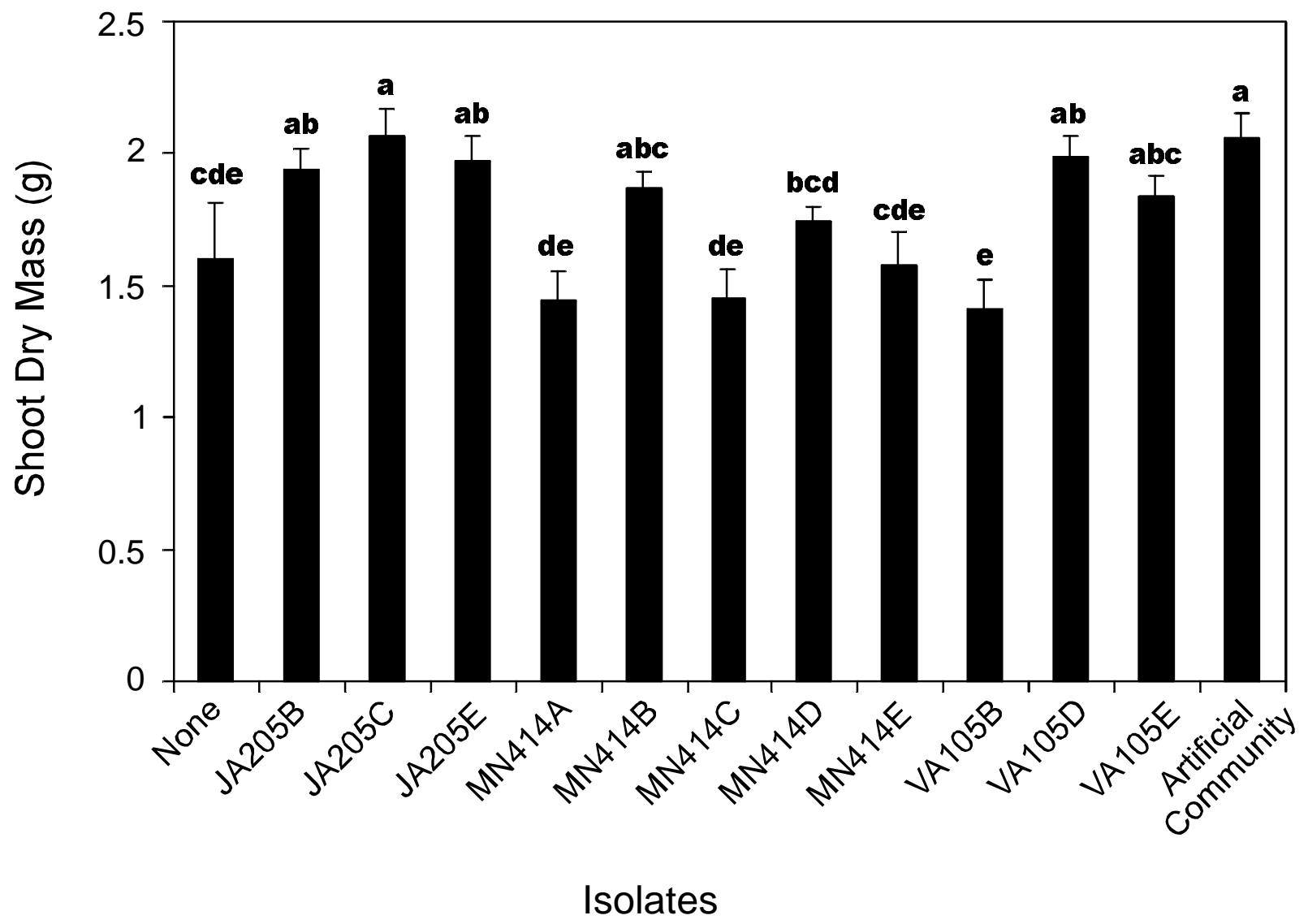

Fig. 1 Shoot dry weight of soybean plants inoculated with AMF isolates from three different communities. Columns represent the means of 5 replicates and bars represent standard errors. 


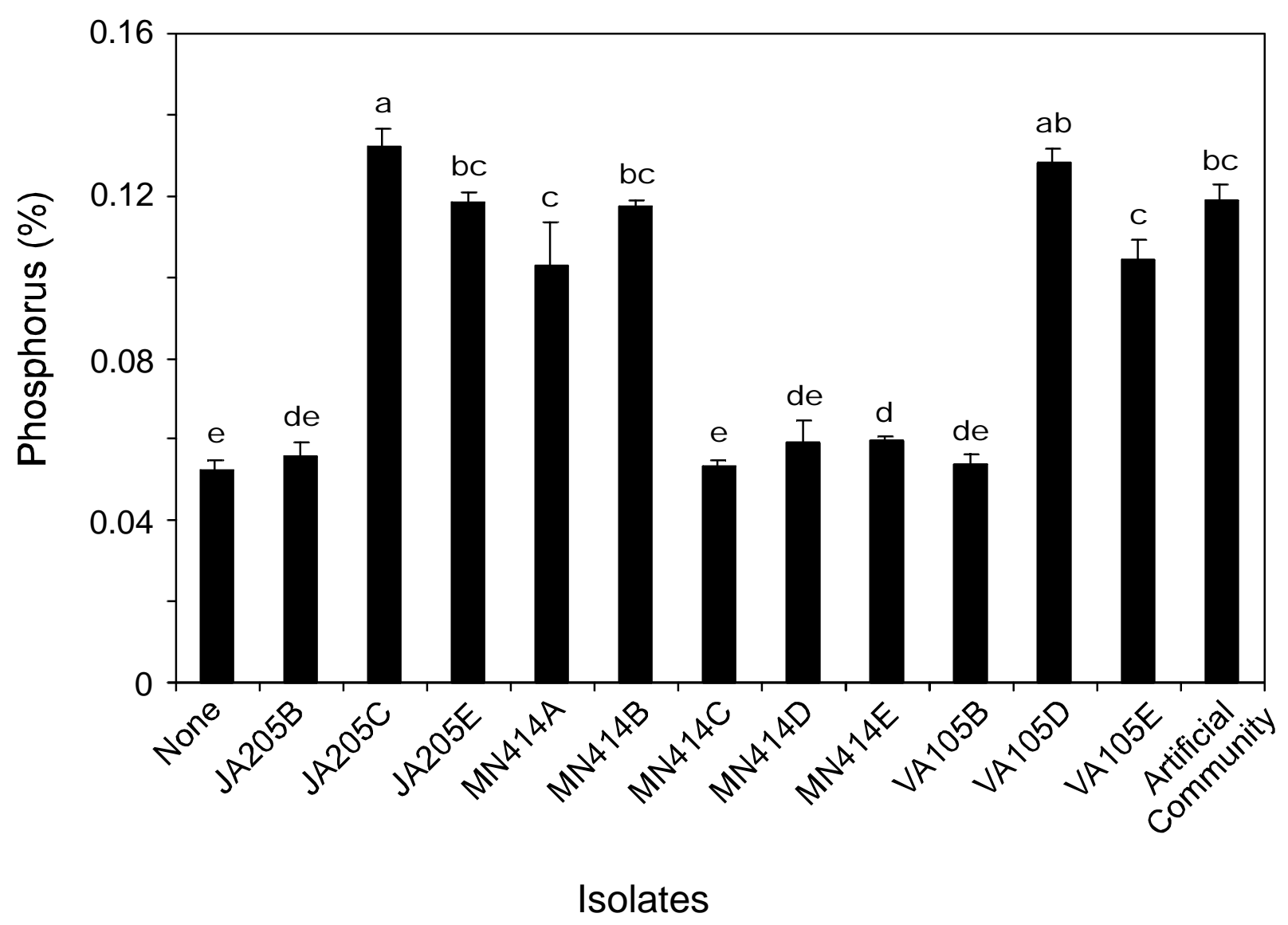

Fig. 2 Phosphorus content of soybean shoots inoculated with AMF isolates from three different communities. Columns represent the means of 5 replicates and bars represent standard errors. 


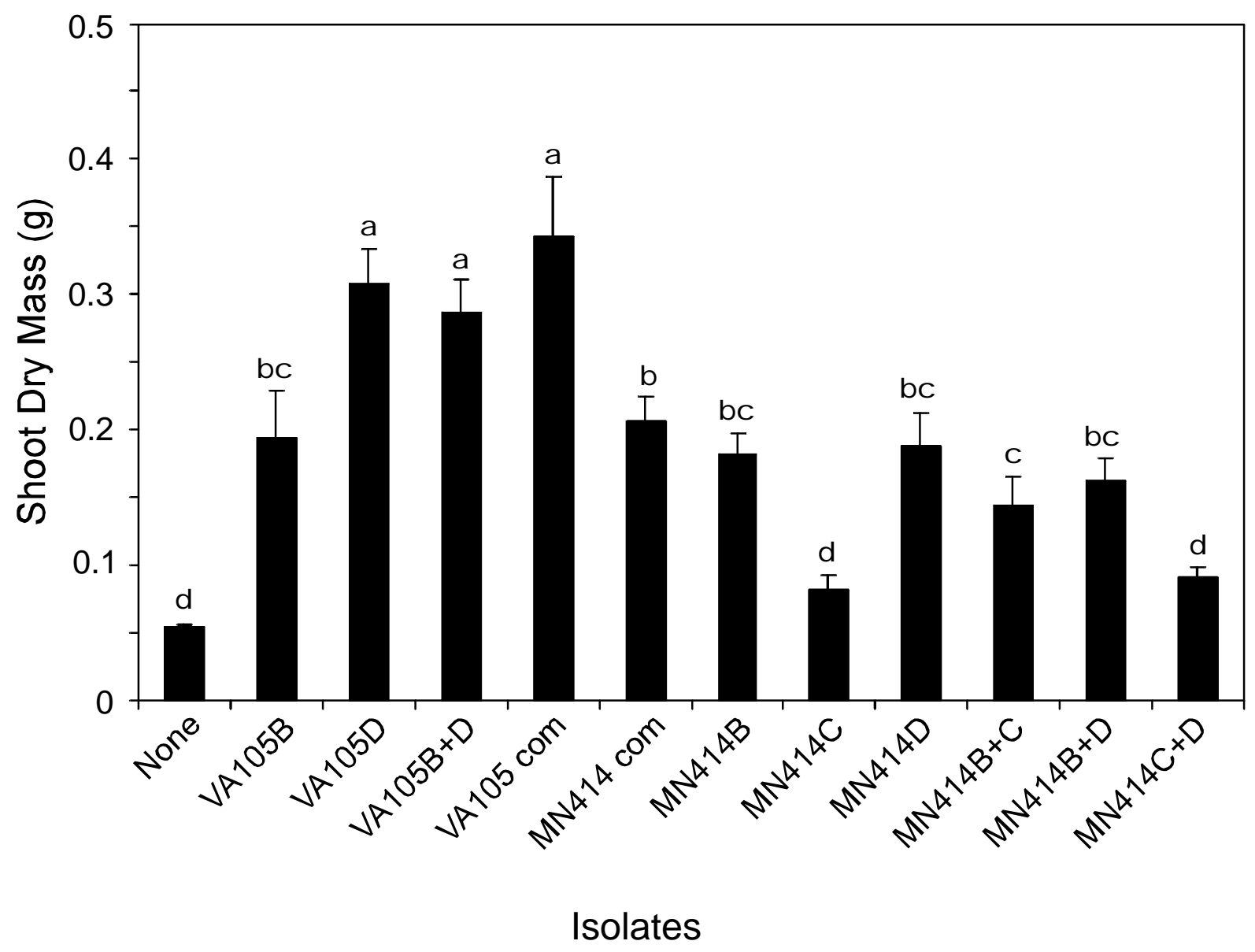

Fig. 3 Shoot dry weight of red clover plants inoculated with AMF isolates alone or in combination. Columns represent the means of 5 replicates and bars represent standard errors. 


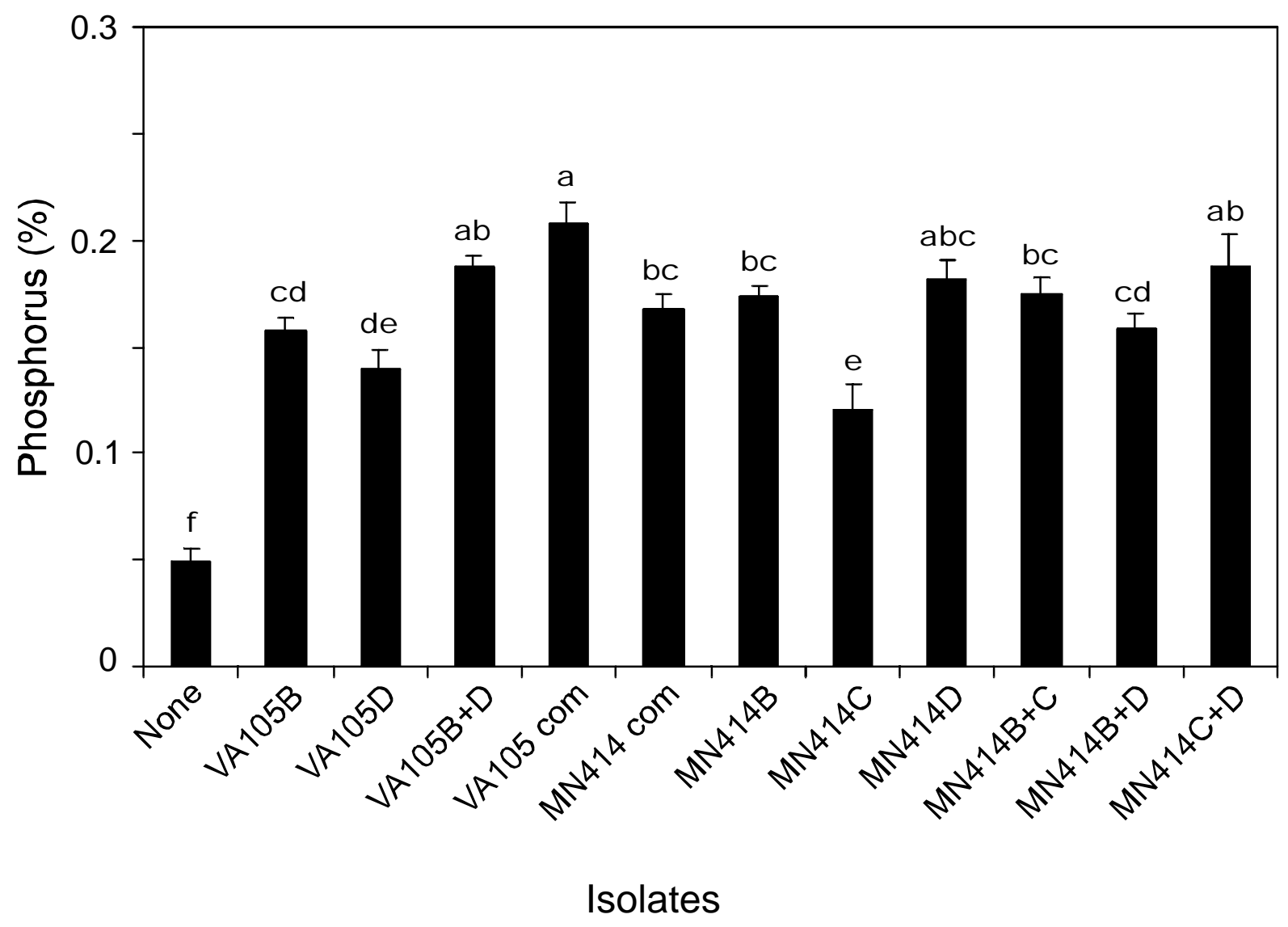

Fig. 4 Phosphorus content of red clover shoots inoculated with AMF isolates alone or in combination. Columns represent the means of 5 replicates and bars represent standard errors. 


\section{CONCLUSIONS}

Research was conducted to measure diversity of arbuscular mycorrhizal fungi taxonomically and physiologically at the levels of individual isolates, species and communities. I - Comparative Taxonomy

Morphology of subcellular structure in asexual spores was interpreted from ontogenetic comparisons among species of Glomus in the family Glomaceae and Acaulospora and Entrophospora in the family Acaulosporaceae to better define species and to interpret ranking of higher taxa. Conclusions:

1) Comparative spore developmental studies have important implications for the systematic of the order Glomales.

a) Spore development in families Glomaceae and Acaulosporaceae diverges considerably from that in family Gigasporaceae and suggests that the order Glomales is polyphyletic. Results of the present study together with biochemical properties and life history traits provide convincing evidence for maintaining Glomaceae and Acaulosporaceae in order Glomales and placing Gigasporaceae in a new order Gigasporales.

b) Properties of flexible inner walls are shared by two or more species, providing grouping criteria for a new taxonomic rank not yet recognized in Glomales. This rank is positioned between genus and species in the taxonomic hierarchy and therefore is likely to be designated as subgenus.

c) Spore wall properties are the criteria which group different populations into the same morphospecies.

2) Patterns of spore ontogenesis shared by all fungal species in Glomaceae and Acaulosporaceae were:

a) Spore formation and differentiation could be separated into three phases, in which spore expansion and spore wall differentiation occurred concurrently (phase I), flexible inner walls were differentiated with no further spore expansion (phase II), and a pre-germination structure was formed (phase III).

b) Subcellular parts of a spore differentiated in a linear sequence of separate and discrete stages within each phase, as defined by addition and transformation of a structure. Stages were causally linked in that each new stage required completion of differentiation in the previous stage. Each stage developed consistently among geographically disjunct fungal isolates of a species, thus providing reliable and consistent grouping criteria to circumscribe species.

c) Within each stage, structures were differentiated hierarchically. Layers were synthesized sequentially, followed by differentiation of phenotypic properties of each layer.

3) Ontogenetic patterns of spores unique to species of Glomus (Glomaceae) were:

a) The spore wall was the only major character complex formed in each spore, with each layer formed consecutively and concurrently with layers of the sporogenous hyphal wall. The number of layers in the spore wall and the phenotypes of each layer varied 
considerably among species. One or two outer layers of the spore wall usually degraded and sloughed from mature spores, so that some taxonomically informative structures were present only on juvenile spores.

b) Divergence in number of layers (1-2) in spore and hyphal walls of the most juvenile spores suggested distinct taxonomic lineages currently not recognized by current classification of Glomales. Divergence in number of phenotypes of spore wall layers defined species.

c) There is no pregermination structure formed. Instead, the germ tube arises from regrowth of the inner layer of the subtending hyphal wall after it (and the spore) have completed differentiation.

4) Ontogenetic patterns unique to species of Acaulospora and Entrophospora (Acaulosporaceae) were:

a) The spore wall consistently is made up of three layers in Acaulospora and two layers in Entrophospora, with the outer layer sloughing with maturation. Properties of these layers define species.

b) Two hyaline bilayered flexible inner walls were always formed sequentially after the spore wall has completed differentiation. Properties of these layers are more conserved and group species into supra-specific taxa currently not recognized in the present classification of Glomales.

II - Measurement of Community Structure

With improved interpretations of morphology to define species, the next goal was to assess taxonomic structure of fungal communities in five disparate habitats within the United States and in four sand dunes from around the world. Current assessment relies on sporulation by fungi colonizing a root system, so that successive propagation of trap cultures was examined to test recovery and detection of nonsporulating fungal species. Conclusions:

1) Successive trap pot cultures established with native soils from disparate habitats detected AMF species not sporulating in the field. Recovery efficiency ranged from $15-100 \%$ of these fungi, appearing to vary most when temperature of the original habitat and that in the greenhouse differed the greatest.

2) Species of Glomus were the predominant sporulators in trap cultures both in number of species and in abundance of sporulation which supports other data indicating that this genus is most widespread in nature.

3) AMF community structure approached a log series model after two cycles of trapping suggesting that trap cultures cycles select for more aggressive fungi that sporulate prolifically and dominate the mycorrhizal community.

4) Total number of spores and mycorrhizal infectivity of inocula from the five sites in the U.S.A. increased in the first propagation cycle and declined thereafter, whereas both variables increased through the second propagation cycle in the four sand dune sites. Differences are attributed mostly to the amount of disturbance to pot contents between propagation cycles greater disturbance caused a loss of infectivity. 
5) Taxonomic diversity had no influence on activity of the mycorrhizal community as evidenced by the absence of a relationship between AMF species richness and levels of mycorrhizal colonization in infectivity assays. Total spore numbers, as propagules of AMF, explain about $50 \%$ of the infectivity detected in the field and trap cultures and indicate that other fungal structures are important infective propagules.

6) Spore numbers of the most abundant sporulators explained a large portion of the mycorrhizal colonization observed in infectivity levels of some soils, suggesting that, in some cases, the most prolific spore producers are responsible for initial infection and secondary colonization of assay hosts.

7) Index of similarity was relatively high between habitats differing in abiotic properties, suggesting that historical processes partly explain distribution of AMF species.

III - Physiological Diversity on Fungal Communities

Assays of effectiveness of component members of a mycorrhizal community in promoting plant growth or plant phosphorus status complement taxonomic diversity by assessing functional relationships. Members of three fungal communities were screened to assess effectiveness on two mycotrophic assay hosts, soybean and red clover. Conclusions:

1) At least one isolate from each AMF community was effective in increasing plant shoot biomass or foliar P content. Some isolates differentially promoted shoot dry mass while other isolates differentially enhanced shoot $\mathrm{P}$ content.

2) Responses of highly effective or non-effective isolates were consistent in both soybean and red clover. Conservativeness in effectiveness responses suggests that this phenotype may be heritable.

3) Co-occurrence of paired effective and ineffective fungal isolates originating from the same mycorrhizal community resulted in either an additive or neutral effect on shoot biomass and $\mathrm{P}$ content relative to either isolate alone. Plants colonized by each pair of isolates always showed enhanced shoot biomass and foliar $\mathrm{P}$ contents relative to nonmycorrhizal controls.

4) In comparing a total fungal community relative to single isolates in each community, both communities tested (VA105 and MN414) performed equal to or better than their most effective isolate using either or both shoot biomass or foliar P content as criteria of effectiveness.

5) A net benefit was observed in red clover assay plants colonized by two of the fungal communities relative to nonmycorrhizal controls. This result suggests that management of native fungi may be a better strategy to increase plant productivity in natural or managed ecosystems than introduction of exotic fungi produced commercially. 


\section{Sidney L. Stürmer}

\section{EDUCATION}

1994-1998 - Ph.D. in Developmental Biology in the Division of Plant and Soil Sciences at West Virginia University in Morgantown, WV

Dissertation Title: Characterization of Diversity of Fungi Forming Arbuscular Endomycorrhizae in Selected Plant Communities.

1987-1991 - B.S. in Biological Sciences in the Biology Department at Universidade Federal de Santa Catarina in Florianópolis, SC, Brazil

\section{RESEARCH INTERESTS}

Biology, ecology and systematic of symbiotic fungi forming arbuscular endomycorrhizae with plants.

\section{EXPERIENCE}

> Research Assistant, Division of Plant and Soil Sciences, West Virginia University. Jan. 1994 - Dec. 1995.

> Research Assistant, CNPq Scholarship. Project: "Biology and Ecology of vesiculararbuscular endomycorrhizal fungi in dune regions in the Island of Santa Catarina (SC)". Jan. - Aug. 1993.

> Research Assistant, CNPq/UFSC Scholarship. Project: "Selection and inoculation of mycorrhizal fungi in fruit seedlings in nurseries of Santa Catarina". Aug. 1990 - Dec. 1992.

> Teaching Assistant 'Applied Microbiology'. Dept. de Microbiologia e Parasitologia, Universidade Federal de Santa Catarina, Brazil. March - Aug. 1989.

\section{PROFESSIONAL SERVICES}

> Instructor, Workshop Taxonomy of Endomycorrhizal Fungi. 5th REBRAM (Brazilian Meeting about Mycorrhiza), Florianópolis, Brazil. October 1994.

> Reviewer, Mycologia, 1996

$>$ Reviewer, Plant and Soil, 1997, 1998

> Instructor, Workshop Taxonomy of Endomycorrhizal Fungi. $1^{\text {st }}$ ICOM (International Conference on Mycorrhizal), Berkeley, CA - USA. August 1996.

\section{RESEARCH PUBLICATIONS}

\section{Book Chapters}

Morton, J. B.; R. E. Koske; S. L. Stürmer, and S. P. Bentivenga. 1999. Protocols for measurement of diversity among arbuscular fungi. In: Biological Diversity Handbook Series: Standard Methods for Fungi. Mueller, G., A. Rossman, and G. Bills, Eds. Smithsonian Institute Press, Washington, DC. (in press). 


\section{Journal Articles}

Stürmer, S.L. and M.M. Bellei. 1994. Composition and seasonal variation of spore populations of arbuscular mycorrhizal fungi in dune soils on the island of Santa Catarina, Brazil. Canadian Journal of Botany, 72:359-363.

Stürmer, S.L. and J.B. Morton. 1997. Developmental patterns defining morphological characters in spores of four species in Glomus. Mycologia 89:72-81.

Stürmer, S.L. and J.B. Morton. 1999. Scutellospora rubra, a new arbuscular mycorrhizal species from Brazil. Mycological Research (in press).

Stürmer, S.L. and J.B. Morton. Taxonomic reinterpretation of morphological characters in Acaulosporaceae based on developmental patterns in two Acaulospora and one Entrophospora species. Mycologia (submitted).

\section{Published Abstracts}

Stürmer, S.L. and M.M. Bellei. 1991. Ecology of vesicular-arbuscular mycorrhizal fungi in dunes in the Island of Santa Catarina. 4th REBRAM, Mendes, Brazil.

Stürmer, S.L. and M.M. Bellei. 1992. Seasonal variation of arbuscular mycorrhizal fungi populations on dune soils in the Island of Santa Catarina (South Brazil). The International Symposium on Management of Mycorrhizas in Agriculture, Horticulture and Forestry. Perth, Western Australia.

Klauberg F., O.; M.M. Bellei and S.L. Stürmer. 1993. Ecology of endomycorrhizal (AM) fungi in South Brazil. 9th NACOM, Guelph, Canada.

Stürmer, S.L.; M.M. Bellei and O. Klauberg F. 1993. Occurrence of endomycorrhizal fungi in soils and on roots of 3 successional stages in the development of Atlantic Forest in Brazil. 9th NACOM, Guelph, Canada.

Stürmer, S.L. and J.B. Morton. 1994. Spore differentiation sequences among isolates of Glomus etunicatum and Glomus intraradices. 5th REBRAM, Florianópolis, Brazil.

Stürmer, S.L. and J.B. Morton. 1998. Developmental patterns in three species of Acaulosporaceae redefining interpretation of morphological character sets. II International Conference on Mycorrhiza (ICOM), Uppsala, Sweden.

Stürmer, S.L. and J.B. Morton. 1998. Patterns of sporulation of AMF in sand dunes systems after successive cycles of trap cultures. II International Conference on Mycorrhiza (ICOM), Uppsala, Sweden.

\section{INVITED SPEAKER}

Stürmer, S.L. 1998. Analyses of arbuscular mycorrhizal fungi communities - Structure and function. II Brazilian Conference of Mycology, Rio de Janeiro, Brazil, April 17-21, 1998.

Stürmer, S.L. 1998. The role of morphology to reinterpret evolutionary patterns and process in AMF. FERTBIO98, Caxambu, Brazil, October 11-16, 1998. 